Aparecido Junior de Menezes

Preparação e Caracterização de Sistema Bifásico Monocomponente (SBM) a partir da Reação de Oxipropilação de Fibras Celulósicas e Amido.

Tese apresentada ao Instituto de Química de São Carlos, da Universidade de São Paulo - USP, para obtenção do Título de Doutor em Ciências (Físico-Química).

Orientador: Prof. Dr. Antonio Aprigio da Silva Curvelo

São Carlos 
Aos meus Pais: Aparecida e Joaquim, por estarem sempre presentes incentivando e encorajando. Aos meus irmãos. Antonio e Regina e aos meus sobrinhos Igor e Lucas. 
$\mathcal{A}$ Deus, que sempre proporciona oportunidades de amadurecer e melhorar, diminuindo o espectro de nossa ignorância.

A Nossa Senhora de Aparecida, a qual sou devoto.

Ao Professor e orientador Antonio Aprigio da Silva Curvelo, pela confiança depositada, em momentos que a mesma não me acompanhava.

Ao professor Alessandro Gandini, que em sua 6reve passagem por São Carlos, demonstrou que além de um grande pesquisador é um grande ser humano.

Ao companheiro de trabalho e amigo Daniel Pasquini pelo enorme incentivo e contribuição direta no trabalho.

A Professora Elisabete Frollini por disponibilizar o uso do aparelho de DMA para a realização dos ensaios de tração.

A todos os colegas do grupo de Físico-Química Orgânica, em especial à Eliangela, Roberta, Maria Teresa (obrigado Dinha), Alessandra, Ricardo, Luizão e Márcia que estiveram presentes em todos os momentos.

A Família Magaton, em especial ao Seu Genésio, Dona Maria e Marina, que me acolheram em uma grande parte da realização deste. MMVITO OBRIGADO!

Aos meus amigos Kinglston, Janildo, Fábio (chumbinho), Hilton (gaúcho), Messias (poeta), Luiz (tchuca) pelo companherismo e incentivo e aos meus amigos de longa data Miguel, Vinícius, Robson e Gilberto (gibóia) que os tenho como irmãos. Obrigado por estarem presentes nos momentos de instabilidade. 
A Julieta Bramorski pela compreensão, amor, carinho e principalmente por me ajudar a enxergar a vida de uma forma diferente. Minha Eterna Gratidão.

Aos Funcionários da Central de Análises Químicas Instrumentais - CAQI, Edson (in memoriam), Mauro, Silvana, Paulo e Bento, sempre muito prestativos e dispostos a ajudar, do Instituto de Química de São Carlos - USP.

École Française de Papétérie et dês Industries Graphiques (EFPG).

Faber Castell, pela utilização do equipamento de ângulo de contato.

Em Especial gostaria de agradecer a todos os tra6alhadores deste país, que com parte dos impostos pagos com o suor de seu trabalho, contribuíram com o financiamento deste trabalho e de tanto outros através de um dos órgãos Federais de fomento à pesquisa e a pósgraduação, conhecidos como CAPES e CNPq.

Não poderia deixar de citar os trabalhadores residentes no Estado de São Paulo, que com seus impostos mantém uma excelente agência de fomento à pesquisa (FAPESP) $e$ excelentes Universidades como a Universidade de São Paulo, campus de São Carlos.

Enfim, a todos que de certa forma contribuíram para a realização deste trabalho, seja com críticas construtivas ou não. 
"Todo mundo" sabe compadecer o sofrimento de um amigo, mas é preciso ter uma alma realmente 6onita para se apreciar o sucesso de um amigo.

\section{Oscar Wilde}

O egoísmo não consiste em vivermos conforme nossos desejos, mas exigirmos que os outros vivam da forma que gostaríamos. O altruísmo consiste em deixarmos todo mundo viver do jeito que bem quiser. 


\section{SUMÁRIO}

ÍNDICE DE FIGURAS

ÍNDICE DE TABELA

LISTA DE ABREVIATURAS

RESUMO

ABSTRACT

I - INTRODUÇÃO

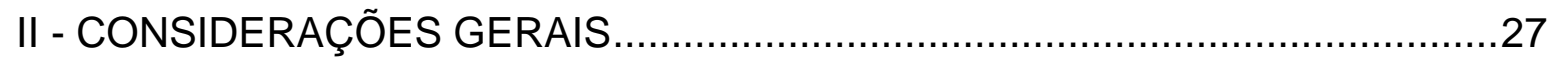

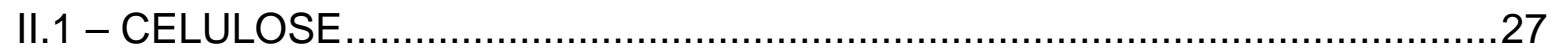

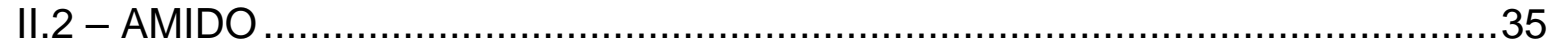

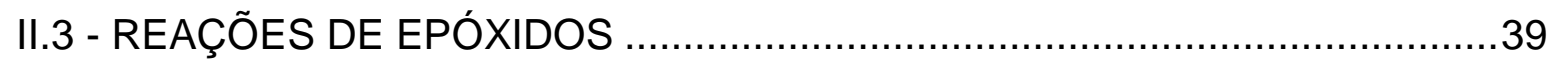

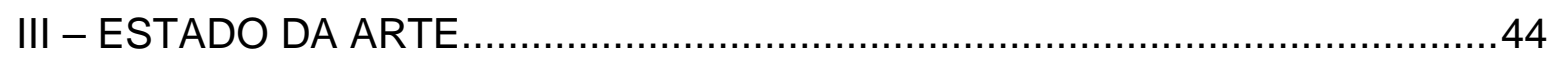

III.1 - COMPÓSITOS MONO-COMPONENTES …............................................4

III.2 - OXIPROPILAÇÃO DE MACROMOLÉCULAS NATURAIS .........................49

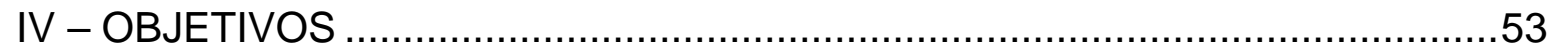

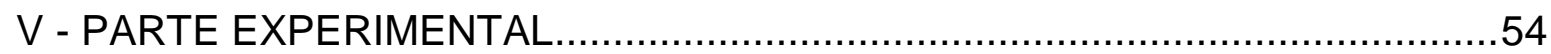

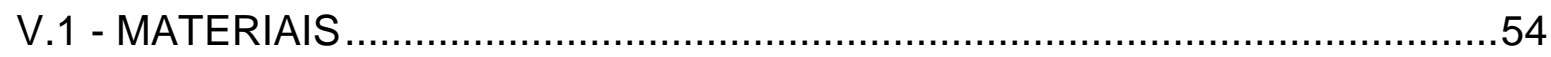

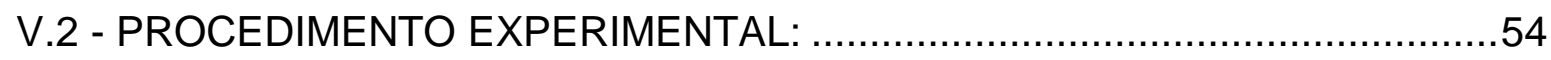

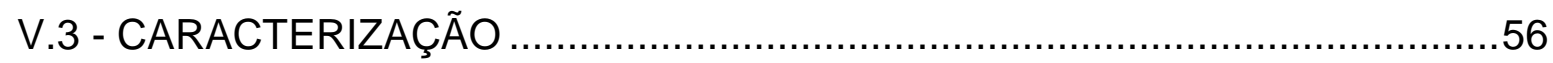

V.3.1 - ESPECTROSCOPIA NA REGIÃO DO INFRAVERMELHO (FTIR) ...........56

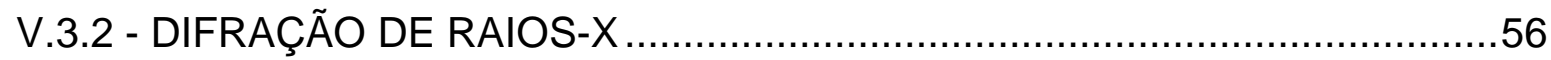

V.3.3 - MICROSCOPIA ELETRÔNICA DE VARREDURA (MEV) ….....................57

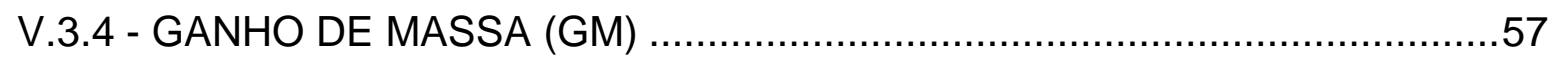




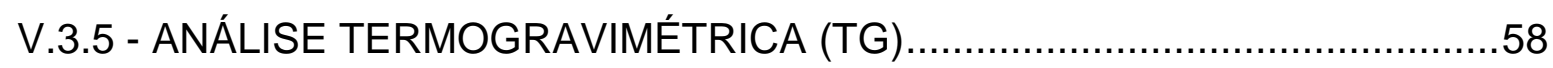

V.3.6 - CALORIMETRIA EXPLORATÓRIA DIFERENCIAL (DSC) ......................58

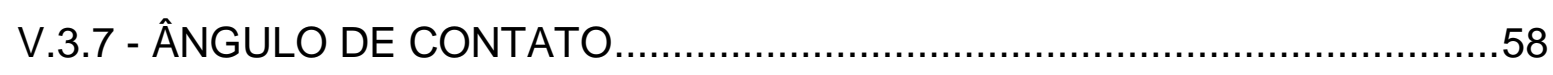

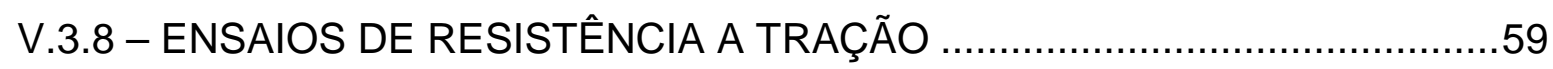

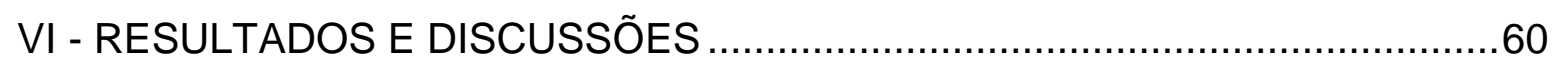

VI.1 - CARACTERIZAÇÃO DO HOMOPOLÍMERO DE POLI (ÓXIDO

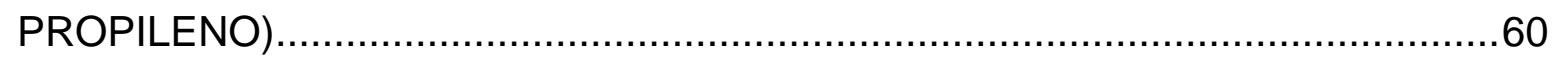

VI.2 - ANÁLISE POR ESPECTROSCOPIA NA REGIÃO DO INFRAVERMELHO 66

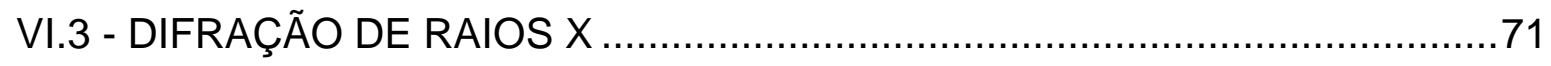

VI.4 - MICROSCOPIA ELETRÔNICA DE VARREDURA (MEV) ........................82

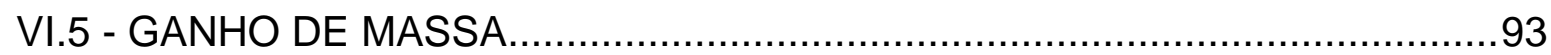

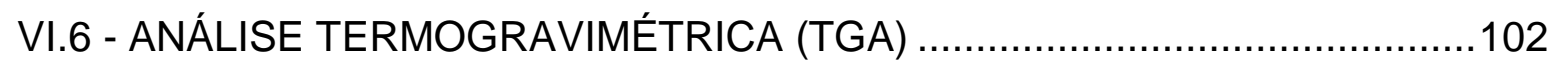

VI.7 - CALORIMETRIA EXPLORATÓRIA DIFERENCIAL (DSC) ....................111

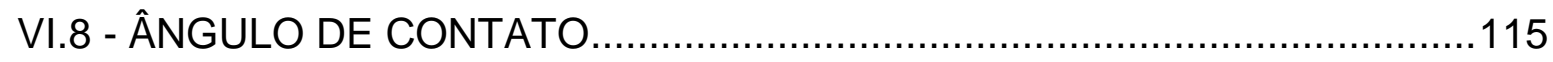

VI.9 - ENSAIOS DE TRAÇÃO VERSUS DEFORMAÇÃO ..............................125

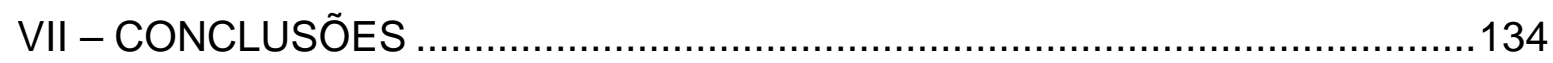

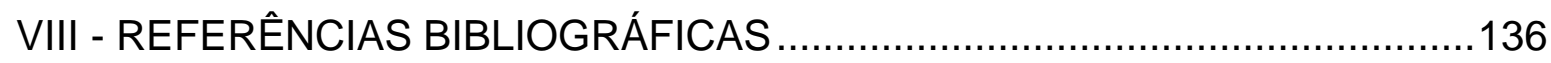




\section{ÍNDICE DE FIGURAS}

Figura 01: Visão idealizada de sistema Compósito formado por fibra celulósica in natura e matriz de baixa polaridade.

Figura 02: Visão idealizada de sistemas compósitos obtidos a partir de fibras celulósicas hidrofobizadas ou enxertadas.

Figura 03: Visão simplificada da produção de sistema mono-componente bifásico..25

Figura 04: Representação da estrutura da celulose.

Figura 05: Unidade repetitiva da celulose (celobiose).

Figura 06: Interações (pontes de hidrogênio) intra e intermoleculares na celulose...29

Figura 07: Esquema da célula vegetal (A); corte transversal da fibra celulósica, destacando as paredes celulares (B); fibrila ou macrocfibrila (C); microfibrila (D); micelas ou microfibrila elementar $(E)$; retículo cristalino $(F)$ e celobiose $(G) \ldots . .30$

Figura 08: Estrutura cristalina da celulose do tipo I (nativa), determinada por espalhamento de raios-X. 32

Figura 09: A esquerda está representada a estrutura química da amilose e a representação esquemática desta em forma de hélice (a) e a direita à amilopectina e representação esquemática das regiões cristalinas desta (clusters) (b).

Figura 10: Micrografias de amidos provenientes de espécies diferentes. 36

Figura 11: Difratogramas de Raios - X do amido de milho (a); arroz (b); mandioca (c) e batata $(d)$ .37

Figura 12: Estrutura geral dos epóxidos (a) e a estrutura do óxido de etileno (b).....39

Figura 13: Reação de formação do epóxido 40 
Figura 14: Reação entre o epóxido protonado e a água para formação do glicol (a) e com um álcool para formação de um hidroxiéter (b).

Figura 15: Reação geral do epóxido em meio básico.

Figura 16: Reação em meio básico entre um íon alcóxido (nucleófilo forte) e um epóxido assimétrico.

Figura 17: Reação em meio ácido entre o metanol (nucleófilo fraco) e um epóxido assimétrico.

Figura 18: Epóxido assimétrico protonado com carbono semelhante a um carbocátion terciário.

Figura 19: Reação de formação do homopolímero de óxido de propileno. 60

Figura 20 Espectro de FTIR (pastilha de KBr) do homopolímero de poli (óxido propileno) extraído com $n$-hexano em soxhlet, da reação do óxido propileno com celulose.

Figura 21 Espectro de FTIR (pastilha de $\mathrm{KBr}$ ) do homopolímero de poli (óxido propileno) Comercial.

Figura 22: Figura 22 Espectro de $\mathrm{RMN} \mathrm{H}^{1}$ do homopolímero de poli (óxido propileno) extraído com n-hexano em soxhlet, da reação do óxido propileno e da celulose.

Figura 23: Fórmula geral do homopolímero de poli (óxido) propileno. .64

Figura 24: Curva DSC do homopolímero de poli (óxido propileno) extraído com nhexano em soxhlet, da reação do óxido propileno com a celulose: primeira corrida (a) e segunda corrida (b). 65

Figura 25: Esquema da reação de oxipropilação da celulose. 66 
Figura 26: Espectro de FTIR (pastilha de KBr) da celulose Avicel antes (a) e após a reação de oxipropilação com razões molares de [OP]/OHcel] de 1 (b), 3 (c) e 5 (d), e após extração do homopolímero de OP com n-hexano em soxhlet.

Figura 27: Espectro de FTIR (pastilha de KBr) da celulose Papel Filtro/KOH (a) e após reação de oxipropilação com razões molares de [OP]/[ OH celulose] de 1 (b), 3 (c) e 5 (d), e após extração do homopolímero de OP com n-hexano em soxhlet.

Figura 28: Espectro de FTIR (pastilha de KBr) da celulose Polpa Kraft VCP (a) e após reação de oxipropilação com razões molares de [OP]/[ OH celulose] de 1 (b), 3 (c) e 5 (d), e após extração do homopolímero de OP com n-hexano em soxhlet.

Figura 29: Espectro de FTIR (pastilha de $\mathrm{KBr}$ ) da Regenerada Rayon (a) e após reação de oxipropilação com razões molares de [OP]/[ OH celulose] de 1 (b), 3 (c) e 5 (d), e após extração do homopolímero de OP com n-hexano em soxhlet.

Figura 30: Espectro de FTIR (pastilha de $\mathrm{KBr}$ ) da celulose Papel Filtro/DABCO (a) e após reação de oxipropilação com razões molares de [OP]/[OH celulose] de 1 (b), 3 (c) e 5 (d), e após extração do homopolímero de OP com n-hexano em soxhlet.

Figura 31: Espectro de FTIR (pastilha de $\mathrm{KBr}$ ) do Amido de Milho (a) e após reação de oxipropilação com razões molares de [OP]/[OH amido] de 1 (b), 3 (c) prétratados com $\mathrm{KOH}$ e (d) pré-tratado com DABCO, e após extração do homopolímero de OP com n-hexano em soxhlet. 
Figura 32: Representação dos difratogramas de raios x para diferentes espécies de celulose.

Figura 33: Difratograma de raios - X da celulose avicel microcristalina antes e após as reações de oxipropilação.

Figura 34: Difratogramas de raios - X sobrepostos da celulose Papel Filtro antes e após reações de oxipropilação pré-tratadas com KOH 76

Figura 35: Difratogramas de raios - X sobrepostos da celulose Polpa Kraft VCP antes e após reações de oxipropilação pré-tratadas com $\mathrm{KOH}$. .77

Figura 36: Difratogramas de raios - X sobrepostos da celulose Regenerada Rayon antes e após reações de oxipropilação pré-tratadas com $\mathrm{KOH}$. 78

Figura 37: Difratogramas de raios - X sobrepostos da celulose Papel Filtro antes e após reações de oxipropilação pré-tratadas com DABCO. 79

Figura 38: Estrutura química do DABCO no plano (a) e no espaço (b). 80

Figura 39: Gráfico de índice de cristalinidade (IC) em função da razão molar (RM). 80 Figura 40: Difratogramas de raios - X sobrepostos do Amido de Milho antes e após reações de oxipropilação. 81

Figura 41: Micrografias da celulose Avicel não modificada (a), modificada com razão molar igual a 1 (b), 3 (c) e 5 (d), com ampliação de 1000 X 82

Figura 42: Micrografias da celulose Avicel não modificada (a), modificada com razão molar igual a 1 (b), 3 (c) e 5 (d), com ampliação de 3000 X 83

Figura 43: Micrografias da celulose Avicel com razão molar de [OP]/[OHcel] igual a 5 e com aumento $200 \times(a)$ e $500 \times(b)$. 84

Figura 44: Micrografias da celulose Avicel com razão molar de [OP]/[ OHcel] igual a 5 em forma de filme e com aumento $200 \times$ (a) e $3000 \times$ (b). .84 
Figura 45: Micrografias da celulose Papel Filtro/KOH não modificada (a), modificada com razão molar igual a 1 (b), 3 (c) e 5 (d), com ampliação de 1000 X. 85

Figura 46: Micrografias da celulose Papel Filtro/KOH não modificada (a), modificada com razão molar igual a 1 (b), 3 (c) e 5 (d), com ampliação de 3000 X. 86

Figura 47: Micrografias da celulose Polpa Kraft VCP não modificada (a), modificada com razão molar igual a 1 (b), 3 (c) e 5 (d), com ampliação de 500 X. 87

Figura 48: Micrografias da celulose Polpa Kraft VCP não modificada (a), modificada com razão molar igual a 1 (b), 3 (c) e 5 (d), com ampliação de 3000 X. 88

Figura 49: Micrografias da celulose Regenerada Rayon não modificada (a), modificada com razão molar igual a 1 (b), 3 (c) e 5 (d), com ampliação de 1000 $X$. 89

Figura 50: Micrografias da celulose Celulose Regenerada Rayon não modificada (a), modificada com razão molar igual a 1 (b), 3 (c) e 5 (d), com ampliação de 3000 $X$. 90

Figura 51: Micrografias da celulose Celulose Regenerada Rayon modificada com razão molar igual a 3 (c) e 5 (d) em forma de filme, com ampliação de 3000 X. .90

Figura 52: Micrografias da celulose Papel Filtro/DABCO modificada com razão molar igual a 1 (a) e (b); 3 (c) e (d) e 5 (e) e (f), com ampliação de 1000 X e 3000, respectivamente.

Figura 53: Micrografia do amido de milho não modificado (a), pré-tratado com $\mathrm{KOH}$ e modificado com razão molar [OP]/[OH amido] igual a 1 (b), pré-tratado com KOH e modificado com razão molar [OP]/[OH amido] igual a 3 (c) e pré-tratado com DABCO e modificado com razão molar [OP]/[OH amido] igual a 3 (d). .92 
Figura 54: Gráfico de Ganho de Massa (\%) em função da razão molar [OP]/OH celulose] para a celulose Avicel pré-tratado com $\mathrm{KOH}$.

Figura 55: Gráfico de Ganho de Massa (\%) em função da razão molar [OP]/OH celulose] para celulose Papel Filtro pré-tratada com $\mathrm{KOH}$.

Figura 56: Gráfico de Ganho de Massa (\%) em função da razão molar [OP]/OH celulose] para celulose Polpa Kraft VCP pré-tratada com $\mathrm{KOH}$. 94

Figura 57: Gráfico de Ganho de Massa (\%) em função da razão molar [OP]/OH celulose] para celulose Regenerada Rayon pré-tratada com $\mathrm{KOH}$. 95

Figura 58: Gráfico de Ganho de Massa (\%) em função da razão molar [OP]/OH celulose] para celulose papel filtro pré-tratado com DABCO. 95

Figura 59: Ganho de Massa (\%) versus Razão molar [OP]/[OH celulose]. 98

Figura 60: Gráfico dos valores de ganho de massa experimental ( $\left.\mathrm{GM}_{\exp }\right)$ em função do ganho de massa teórico $\left(\mathrm{GM}_{\mathrm{teo}}\right)$. 100

Figura 61: Ganho de massa versus razão molar para o amido de milho oxipropilado com razão molar igual a 1 e pré-tratado com $\mathrm{KOH}(\mathrm{a})$, razão molar igual a 3 prétratado com $\mathrm{KOH}$ (b) e razão molar igual a 3 pré-tratado com DABCO (C)....101 Figura 62: Curvas TG da celulose Avicel antes e após as reações de oxipropilação.

Figura 63: Curvas TG da celulose Papel Filtro/KOH antes e após as reações de oxipropilação. 103

Figura 64: Curvas TG da celulose Polpa Kraft VCP antes e após as reações de oxipropilação. 103

Figura 65: Curvas TG da celulose Regenerada Rayon antes e após as reações de oxipropilação. 
Figura 66: Curvas TG da celulose Papel Filtro/DABCO antes e após as reações de oxipropilação. 104

Figura 67: Perda de massa no segundo estágio (degradação) versus da razão molar $[\mathrm{OP}] /[\mathrm{OH}$ celulose].

Figura 68: Temperatura em $2 \%$ de perda de massa versus da razão molar [OP]/[OH celulose]. 108

Figura 69: Curvas TG do amido de milho não modificado (a), oxipropilado com razão molar igual a 1 e pré-tratado com $\mathrm{KOH}(\mathrm{b})$, razão molar igual a 3 pré-tratado com $\mathrm{KOH}(\mathrm{c})$ e razão molar igual a 3 pré-tratado com DABCO (d) 109

Figura 70: Curvas DSC da celulose Papel Filtro/KOH antes da modificação (a), modificado com razão molar [OP]/[OH celulose] igual a 1 (b), 3 (c) e 5 (d)....111

Figura 71: Curvas DSC da celulose Papel Filtro/DABCO modificado com razão molar $[\mathrm{OP}] /[\mathrm{OH}$ celulose] igual a 1 (a), 3 (b) e 5 (c). 112

Figura 72: Curvas DSC do amido de Milho não modificado (a) e modificado com razão molar [OP]/[OH celulose] igual a 1 e pré-tratado com $\mathrm{KOH}$ (b), igual a 3 e pré-tratado com $\mathrm{KOH}$ (c) e igual a 3 e pré-tratado com DABCO (d). 114

Figura 73: Representação do ângulo de contato entre uma gota de um líquido qualquer e uma superfície sólida e horizontal.

Figura 74: Gráfico componente polar de superfície versus razão molar

[OP]/[OHcelulose] para celulose Avicel (a), Papel Filtro/KOH (b), Polpa Kraft

VCP (c), Regenerada Rayon (d) e Papel Filtro/DABCO (e). 122

Figura 75: Gráfico componente dispersiva de superfície versus razão molar [OP]/[OHcelulose] para celulose Avicel (a), Papel Filtro/KOH (b), Polpa Kraft VCP (c), Regenerada Rayon (d) e Papel Filtro/DABCO (e). 123 
Figura 76: Gráfico energia total de superfície versus razão molar [OP]/[OHcelulose] para celulose Avicel (a), Papel Filtro/KOH (b), Polpa Kraft VCP (c), Regenerada Rayon (d) e Papel Filtro/DABCO (e). 123

Figura 77: Curvas de tensão sob tração versus deformação para amostra de celulose de Papel Filtro Original. 126

Figura 78: Curva de tensão sob tração versus deformação pra celulose de Papel Filtro/KOH oxipropilada com razão molar de $[\mathrm{OP}] /[$ OHcel] igual a 1

Figura 79: Curva de tensão sob tração versus deformação pra celulose de Papel

Filtro/KOH oxipropilada com razão molar de [OP]/[ OHcel] igual a 3.

Figura 80: Curva de tensão sob tração versus deformação pra celulose de Papel

Filtro/KOH oxipropilada com razão molar de $[\mathrm{OP}] /[$ OHcel] igual a 5. 128

Figura 81: Curva de tensão sob tração versus deformação pra celulose de Papel

Filtro/DABCO oxipropilada com razão molar de [OP]/[ OHcel] igual a 1 . 129

Figura 82: Curva de tensão sob tração versus deformação pra celulose de Papel

Filtro/DABCO oxipropilada com razão molar de [OP]/[ OHcel] igual a 3. 130

Figura 83: Curva de tensão sob tração versus deformação pra celulose de Papel Filtro/DABCO oxipropilada com razão molar de [OP]/[ OH cel] igual a 5......130

Figura 84: Gráfico de tensão sob tração na ruptura versus razão molar [OP]/[OH celulose] para celulose Papel Filtro. 132

Figura 85: Gráfico de elongação versus razão molar [OP]/[OH celulose] para celulose Papel Filtro. 132

Figura 86: Gráfico do Módulo Elástico versus razão molar [OP]/[OH celulose] para celulose Papel Filtro. 133 


\section{ÍNDICE DE TABELAS}

Tabela 1: Parâmetros das celas cristalinas da celulose tipo I, II, III e IV. 32

Tabela 2: Deslocamentos químicos e hidrogênios correspondentes do espectro de $\mathrm{RMN} \mathrm{H}^{1}$ do homopolímero de poli(óxido) propileno. 63

Tabela 3: Valores de ângulo de difração e índice de cristalinidade das amostras de celulose. 75

Tabela 4: Valores de ganho de massa (GM) em função da razão molar (RM) 96

Tabela 5: Valores de massa de homopolímero de POP formado em função da razão molar (RM) 98

Tabela 6: Valores de ganho de massa experimental $\left(G^{\exp }\right)$ em função do ganho de massa teórico $\left(\mathrm{GM}_{\text {teor }}\right)$. 100

Tabela 7: Valores de temperatura onset e endset de temperatura e perda de massa. 105

Tabela 8: Valores dos ângulos de contato e energia de superfície das fibras de celulose Avicel antes e após modificação química por oxipropilação. 118

Tabela 9: Valores dos ângulos de contato e energia de superfície das fibras de celulose de Papel Filtro/KOH antes e após modificação química por oxipropilação.

Tabela 10: Valores dos ângulos de contato e energia de superfície das fibras de celulose Polpa Kraft VCP antes e após modificação química por oxipropilação 
Tabela 11: Valores dos ângulos de contato e energia de superfície das fibras de celulose Regenerada Rayon antes e após modificação química por oxipropilação.

Tabela 12: Valores dos ângulos de contato e energia de superfície das fibras de celulose de Papel Filtro/DABCO antes e após modificação química por oxipropilação. 121

Tabela 13: Valores dos ângulos de contato e energia de superfície das fibras de Amido de Milho antes e após modificação química por oxipropilação. 121

Tabela 14: Dados de ensaio de tensão sob tração versus deformação para celulose Papel Filtro/KOH antes e após modificação. 128

Tabela 15: Dados de ensaio de tensão sob tração versus deformação para celulose Papel Filtro/DABCO antes e após modificação. 131 


\section{LISTA DE ABREVIATURAS}

AVI: Celulose Avicel antes da reação de oxipropilção.

AVIOP1: Celulose Avicel oxipropilada com razão molar [OP]/[OHcel] igual a 1.

AVIOP3: Celulose Avicel oxipropilada com razão molar [OP]/[OHcel] igual a 3.

AVIOP5: Celulose Avicel oxipropilada com razão molar [OP]/[OHcel] igual a 5.

CEL: Celulose.

CRR: Celulose Regenerada Rayon antes da reação de oxipropilção.

CRROP1: Celulose Regenerada Rayon oxipropilada com razão molar [OP]/[OHcel] igual a 1.

CRROP3: Celulose Regenerada Rayon oxipropilada com razão molar [OP]/[OHcel] igual a 3.

CRROP5: Celulose Regenerada Rayon oxipropilada com razão molar [OP]/[OHcel] igual a 5 .

DMAc: Dimetil-Acetamida.

DSC: Calorimetria Exploratória Diferencial.

FTIR: Infravermelho com Transformada de Fourier.

MEV: Microscopia Eletrônica de Varredura.

PF: Celulose de Papel Filtro antes da reação de oxipropilção.

PFOP1: Celulose de Papel Filtro oxipropilada com razão molar [OP]/[OHcel] igual a 1.

PFOP3: Celulose de Papel Filtro oxipropilada com razão molar [OP]/[OHcel] igual a 3. 
PFOP5: Celulose de Papel Filtro oxipropilada com razão molar [OP]/[OHcel] igual a 5.

PKVCP: Celulose de Polpa Kraft VCP antes da reação de oxipropilção.

PKVOP1: Celulose de Polpa Kraft VCP oxipropilada com razão molar [OP]/[OHcel] igual a 1 .

PKVOP3: Celulose de Polpa Kraft VCP oxipropilada com razão molar [OP]/[OHcel] igual a 3.

PKVOP5: Celulose de Polpa Kraft VCP oxipropilada com razão molar [OP]/[OHcel] igual a 5 .

PO: Óxido de Propileno.

TG: Termogravimetria.

Tg: Temperatura de Transição Vítrea.

SMB: Sistema Bifásico Mono-componente.

DS: Grau de substituição.

MS: Grau de substituição molar. 


\section{RESUMO}

Modificações químicas foram aplicadas às fibras celulósicas e ao amido com o objetivo de obter produtos com uma camada termoplástica externa, preservando a parte interna desses substratos (não modificada). $O$ produto final deveria se comportar como um material compósito onde a parte interna não modificada é o agente de reforço e a camada termoplástica a matriz. As modificações foram realizadas através da inserção de pequenas cadeias de óxido propileno a cadeia carbônica do polissacarídeo (celulose e amido). As cadeias de poli(oxido propileno) enxertadas proporcionará uma camada termoplástica em torno da porção de polissacarídeo não modificada. A obtenção destes materiais pode dispensar as etapas de mistura e permitir o processamento térmico sem a necessidade de utilização de um segundo componente (matriz), uma vez que a própria capa polimérica desempenharia este papel. A construção da capa polimérica envolvente foi conduzida através da reação da celulose ou amido pré-ativados com o óxido de propileno. A etapa de ativação foi realizada com o tratamento dos substratos com $\mathrm{KOH}$ ou $\mathrm{DABCO}$ e a reação de enxertia foi realizada em sistema heterogêneo. Os materiais obtidos utilizando esses tratamentos foram caracterizados por diferentes técnicas (FTIR, Raios-X, MEV, TG, DSC, Ângulo de contato e ensaios de Resistência à Tração).

Os resultados obtidos demonstraram que é possível de produzir materiais com características termoplásticas reforçadas através da reação em uma única etapa, sem a necessidade de laboriosos procedimentos sintéticos. 


\begin{abstract}
Chemical modifications were applied to cellulosic materials and starch with the objective to obtain products with an external thermoplastic layer while preserving the inner part of these substrates. The final products should behave as composite materials where the unmodified inner part is the reinforcement agent and the thermoplastic layer the matrix. The modifications were performed by grafting polypropylene oxide short chains to the polysaccharide backbone (cellulose and starch). The grafted polypropylene oxide chains will render a thermoplastic layer around the unmodified polysaccharide portions. The attainment of these materials can excuse the stages of mixture and allow the thermal processing without the necessity of use the second component (matriz), a time that the proper polymeric layer would play this role. The construction of the involving polymeric layer was conducted by reacting pre-activated cellulose (or starch) and propylene oxide (PO). The activation step was performed with $\mathrm{KOH}$ (or DABCO) treatment and the grafting reaction was carried through in heterogeneous system. The materials obtained following these treatments were characterized by different techniques (FTIR, X-Ray, MEV, TG, DSC, Contact Angle and Mechanical Analyses).

The results had demonstrated that it is possible to produce materials with strengthened thermoplastic characteristics through the reaction in an only stage, without the necessity of laborious synthetic procedures.
\end{abstract}




\section{I - INTRODUÇÃO}

O interesse no uso de fibras celulósicas como agentes de reforço em materiais compósitos com matrizes poliméricas têm mostrado grande crescimento nos últimos anos (Gandini e Belgacem, 2002). Vários motivos justificam esta tendência na utilização de fibras celulósicas, podendo ser citados: seu caráter renovável; suas boas propriedades mecânicas, sua baixa densidade; a elevada disponibilidade, em diferentes morfologias; seu baixo custo e ainda, a destinação final após o uso em sistemas de compostagem ou reciclagem. Entretanto, existem algumas limitações ao uso intensivo e extensivo de fibras celulósicas em materiais compósitos, especialmente quando as matrizes poliméricas são muito pouco polares, como é o caso das poliolefinas em geral. Estas limitações estão associadas às características altamente polar e hidrofílica da superfície das fibras (devido à presença de grupos hidroxila) e resultam em baixas energias de adesão com materiais menos polares.

A solução normalmente empregada para a superação destas limitações é a modificação química da superfície das fibras, a qual pode ser realizada pela enxertia de moléculas de baixa massa molar, assim como substâncias oligoméricas e poliméricas.

Uma das estratégias utilizadas é a reação dos grupos hidroxilas presentes na superfície das fibras celulósicas com pequenas moléculas rígidas, contendo pelo menos duas funções ativas (ex. di-isociantos e anidrido piromelítico). Os produtos obtidos nestas reações apresentam grupos funcionais reativos ligados à superfície 
da fibra, os quais podem ser empregados para a construção de estruturas de poliuretanas, poliésteres, poliamidas, etc. (Gandini et al, 2001).

Uma outra abordagem já ensaiada para a inserção de grupos reativos polifuncionais na superfície da fibra celulósica é a reação dos grupos hidroxila com compostos organometálicos (ex. trietilalumínio e trietilboro), em sistema heterogêneo. Como exemplo desta estratégia de síntese, pode ser citada a reação de celulose modificada por trietilalumínio com oligoéteres perfluorados que resultaram no desaparecimento da contribuição polar e uma grande redução da componente dispersiva da superfície das fibras modificadas (Fabri, 2004). Um último exemplo é o emprego de trialcóxi-silanos na derivatização superficial de fibras celulósicas, tal como reportado por Valadez-Gonzalez et al.1999.

Resumidamente, as estratégias citadas acima para melhorar a adesão entre os componentes de um sistema compósito contendo fibras celulósicas e uma matriz pouco polar é conseguida pela hidrofobização da superfície das fibras e/ou pelo estabelecimento de ligações químicas entre as fibras modificadas e a matriz.

Em forma idealizada, os sistemas nos quais se emprega fibra celulósica in natura e uma matriz pouco polar pode ser visualizado como indicado na figura 1.

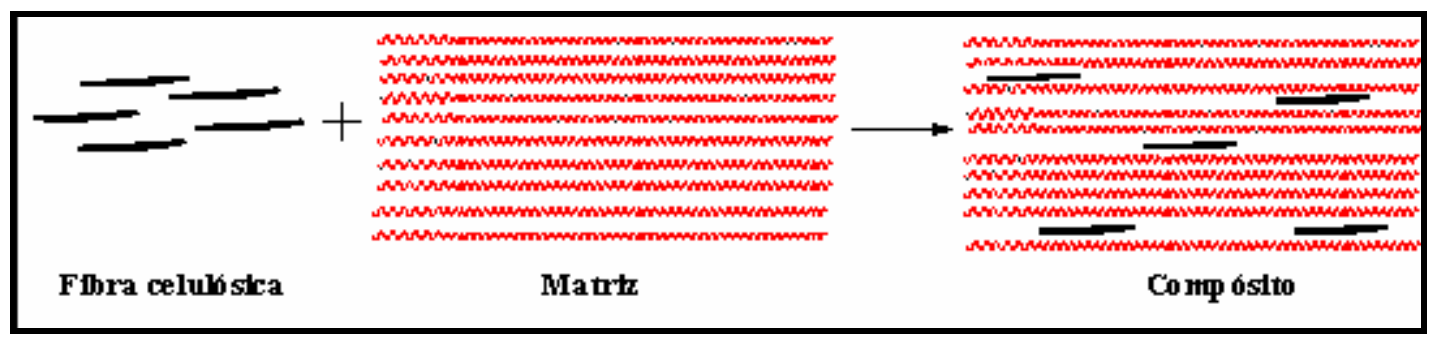

Figura 01: Visão idealizada de sistema Compósito formado por fibra celulósica in natura e matriz de baixa polaridade. 
Os sistemas produzidos pelo uso de fibras celulósicas modificadas para ter seu caráter polar reduzido e os sistemas contendo ligações químicas entre as fibras e a matriz estão representados, em forma idealizada, na figura 2.

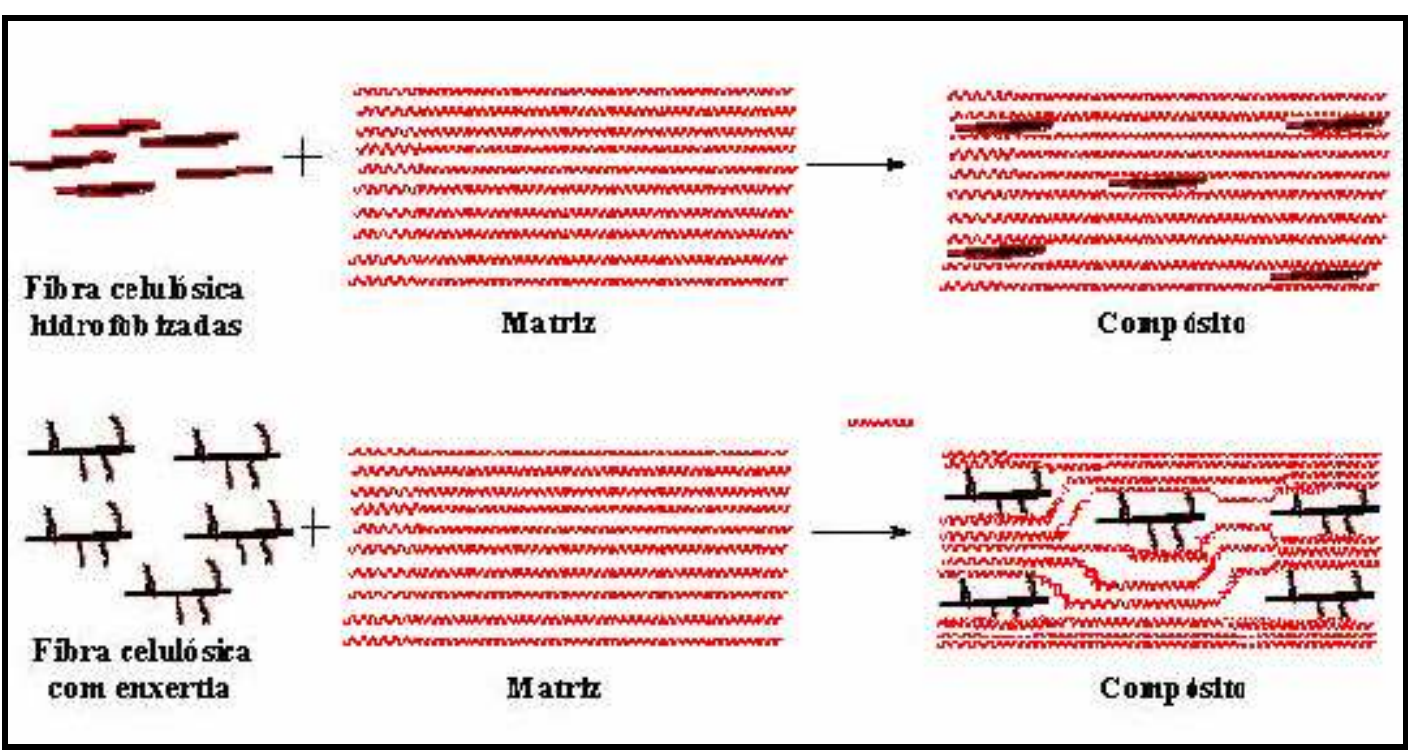

Figura 02: Visão idealizada de sistemas compósitos obtidos a partir de fibras celulósicas hidrofobizadas ou enxertadas.

Os produtos obtidos pelos tratamentos da fibra celulósica resultam em compósitos com melhores propriedades mecânicas e um bom desempenho em serviço, como conseqüência da melhor qualidade da adesão interfacial (Felix 1991, Jandura 2001). Entretanto, estes sistemas são ainda sistemas bi-componentes e apresentam limitações quanto à possibilidade de reciclagem de seus componentes ou do próprio compósito e requer operações de mistura mais elaboradas. 
Uma alternativa às limitações apresentadas por estes sistemas é a utilização de sistemas mono-componentes que dispensariam a necessidade das operações mais elaboradas de misturas e podem ser reciclados por simples operações de processamento térmico. Estes sistemas são extensões daqueles que utilizam fibras celulósicas enxertadas com cadeias oligoméricas e podem ser obtidos por processos similares. A construção de uma capa que envolva a fibra celulósica pode levar à não necessidade de uma fase contínua exógena para permitir a dispersão das mesmas. Estes devem ser preparados em fase heterogênea e na presença de solventes (para a dissolução dos monômeros) que não promovam o inchamento das fibras celulósicas. O grau de substituição e, principalmente, a grau de polimerização das cadeias enxertadas deve ser grande o suficiente para garantir um comportamento termoplástico para a capa envoltória da fibra celulósica. Uma visão esquemática destes sistemas pode ser observada na figura 3.

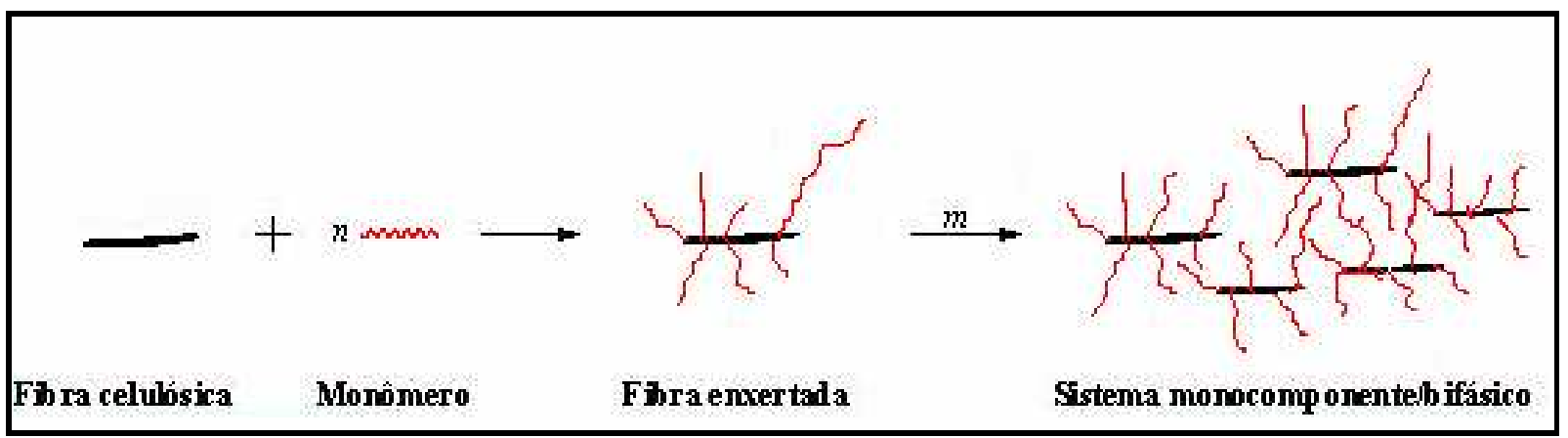

Figura 03: Visão simplificada da produção de sistema mono-componente bifásico.

A preservação da estrutura fibrosa com a existência de uma capa termoplástica deve permitir a obtenção de materiais mono-componentes com propriedades superiores às exibidas pelos compósitos reforçados tradicionais. 
Dentre as reações que podem ser empregadas para a geração dos sistemas indicados acima incluem-se as reações de polimerização clássicas, tais como as empregadas na preparação de poliéteres, poliésteres, poliuretanas, etc., desde que a fibra celulósica seja ativada ou derivatizada para fazer parte da cadeia polimérica produzida. Estes novos materiais poliméricos combinariam as propriedades de um sistema compósito com adesão entre a fibra celulósica e o enxerto polimérico, com as vantagens promovidas pela não necessidade de mistura entre componentes (sistema mono-componente).

Baseando-se nos relatos descritos acima, este trabalho de tese teve como objetivo reportar uma nova estratégia de obtenção de um compósito monocomponente, a qual envolve uma transformação direta da camada externa das fibras de celulose, gerando uma matriz termoplástica em torno da estrutura interna das fibras (não modificadas), as quais atuariam como reforço.

Conseqüentemente a isto, a tese está estruturada da seguinte forma: Neste capítulo, uma breve introdução dos sistemas conhecidos, a problemática e a motivação para a realização deste. No capítulo II são apresentadas algumas considerações gerais a respeito da fibra de celulose, do amido e das reações de epoxidação. No capítulo III consta o Estado da Arte, ou seja, uma revisão bibliográfica a respeito de compósitos mono-componentes e as reações de oxipropilação em polímeros naturais. Já no capítulo IV e V, são apresentados os objetivos do trabalho, bem como os procedimentos e os materiais utilizados para alcançá-los. Finalizando, no capítulo VI, são apresentados os resultados obtidos e a discussão elaborada sobre estes e, no capítulo VII, as conclusões dos mesmos. 


\section{II - CONSIDERAÇÕES GERAIS}

\section{II.1 - CELULOSE}

A celulose utilizada pelas plantas como material de construção abrange cerca de $40 \%$ do carbono disponível na biosfera e representa o mais abundante polissacarídeo estrutural da parede celular dos vegetais (Fengel e Wegener, 1989).

É um polissacarídeo linear (figura 04), formado por unidades $\beta$-Dglicopiranose unidas por ligações glicosídicas $\beta-1,4$ resultando em um polímero de alta massa molar de cerca de 300.000 a $500.000 \mathrm{~g} / \mathrm{mol}$, cujo valor depende da fonte e do tratamento que esta recebe (Assunção, 1995).

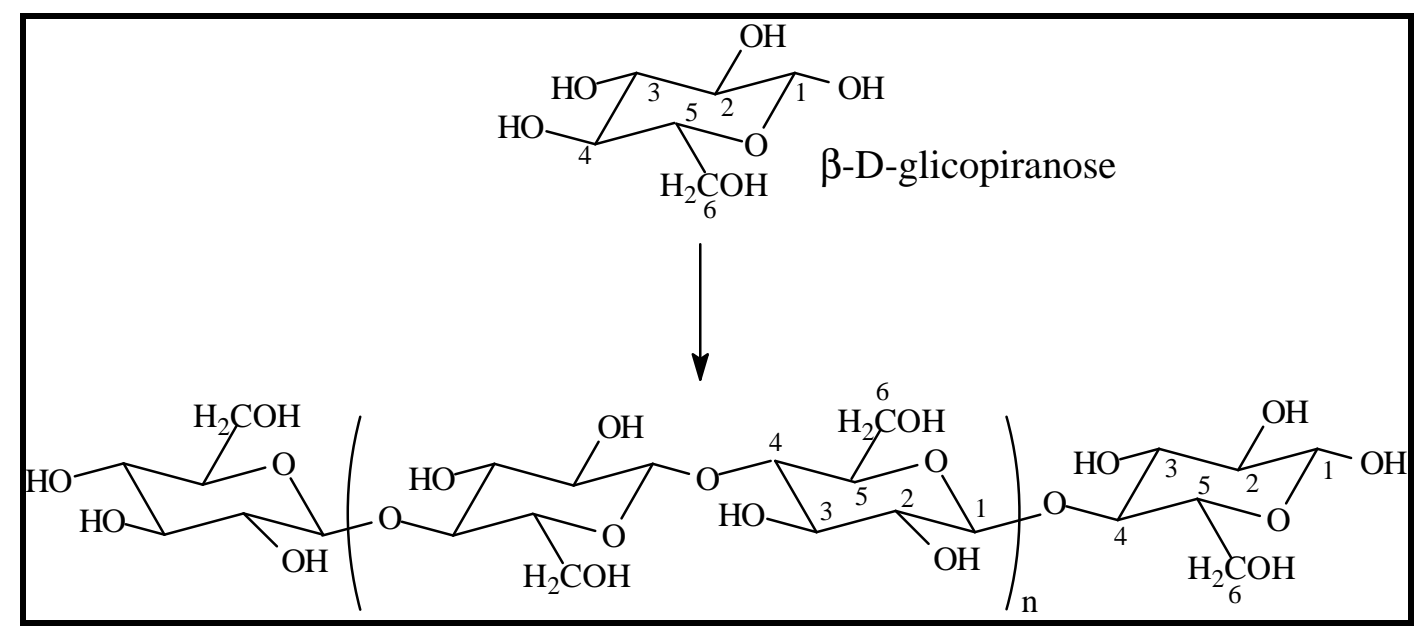

Figura 04: Representação da estrutura da celulose. 
Ocorre às vezes quase pura (algodão e paina) com cerca de 3 a $15 \%$ de material não celulósico e, com mais freqüência, associada à lignina e hemiceluloses. Apresenta elevadas propriedades mecânicas, em termos de resistência por massa de material quando comparadas com fibras sintéticas como a de vidro, e sua unidade repetitiva (figura 05) é chamada de celobiose (Eichhorn et al., 2001).

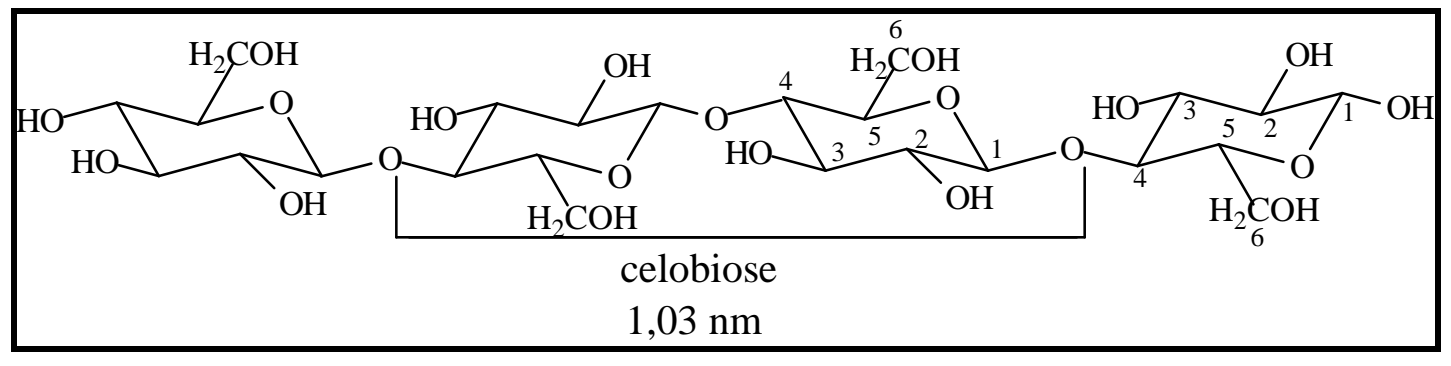

Figura 05: Unidade repetitiva da celulose (celobiose).

Devido à presença dos grupos hidroxilas, a celulose apresenta grande tendência a formar ligações de hidrogênio intra e inter moleculares (figura 06). As interações intramoleculares são responsáveis pela rigidez das cadeias unitárias e as interações intermoleculares pela formação da fibra vegetal (Fengel e Wegener, 1989). 


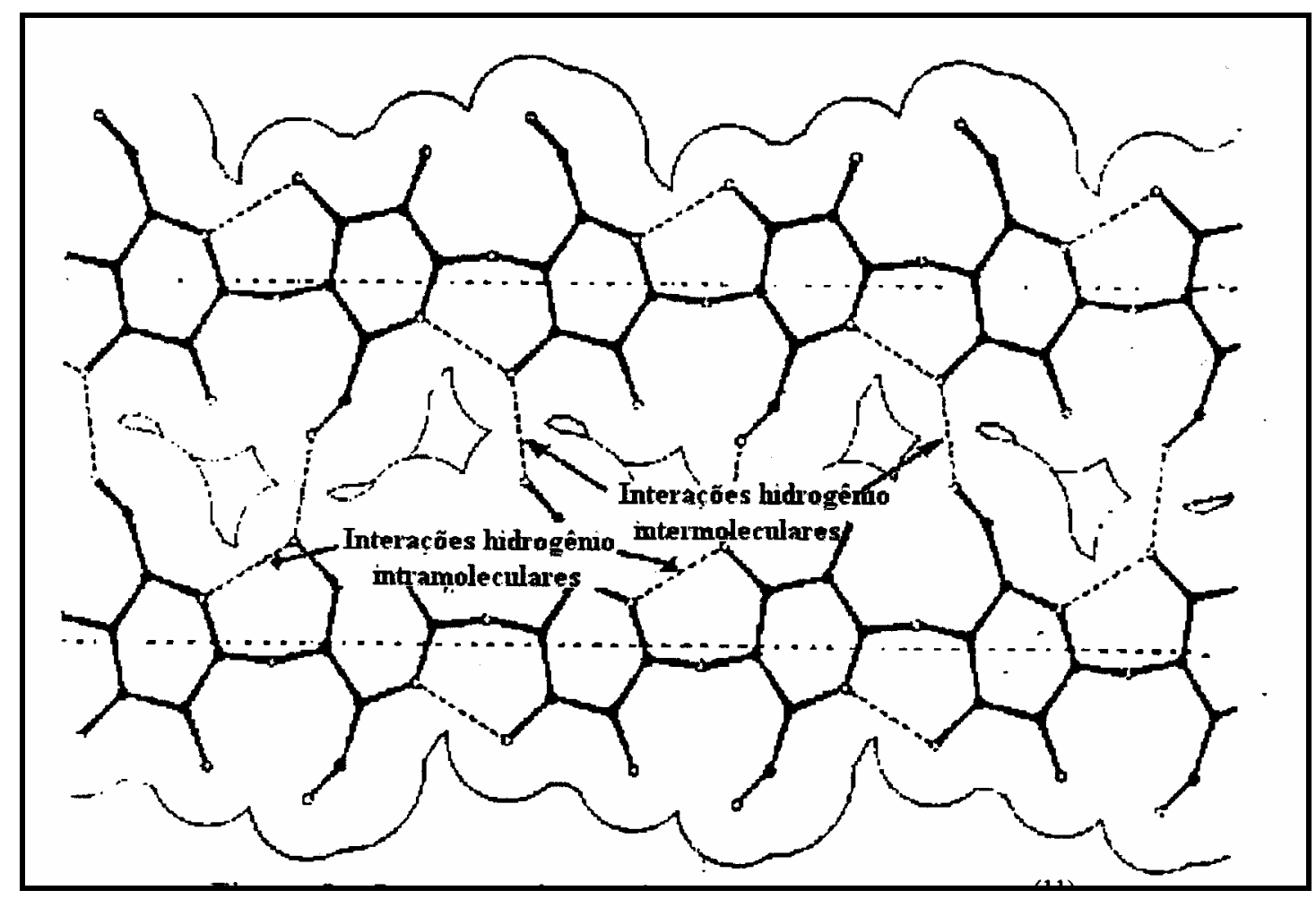

Figura 06: Interações (pontes de hidrogênio) intra e intermoleculares na celulose.

As fibras vegetais são compostas por vários feixes de moléculas de celulose agrupadas, formando os retículos cristalinos. A junção destes constituem as micelas ou microfibrilas elementares, enquanto que a união das microfibrilas elementares dá origem as microfibrilas e estas formam as fibrilas ou macrofibrilas que, por fim, dão origem à fibra de celulose, como demonstrado na figura 07 (D’almeida, 1988). 


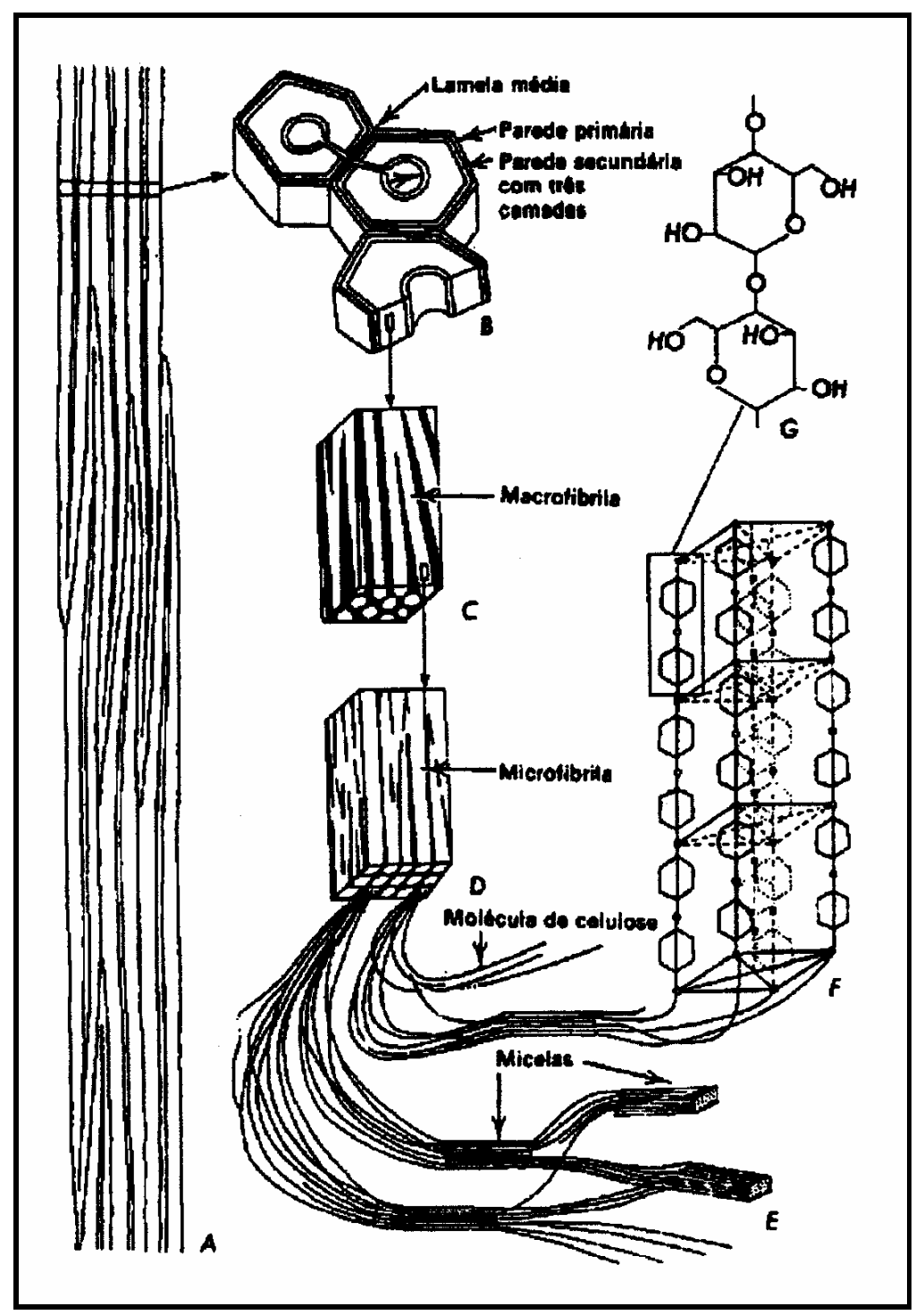

Figura 07: Esquema da célula vegetal $(\mathrm{A})$; corte transversal da fibra celulósica, destacando as paredes celulares (B); fibrila ou macrocfibrila (C); microfibrila (D); micelas ou microfibrila elementar $(E)$; retículo cristalino $(F)$ e celobiose $(G)$.

A cadeia principal é bastante hidrofóbica, mas os grupos hidroxilas livres dão ao material um caráter altamente hidrofílico. Mesmo contendo uma grande quantidade de grupos hidroxilas a celulose é um polímero insolúvel em água e esta observação mostra a importância das ligações de hidrogênio na manutenção da estrutura do polímero, uma vez que as ligações intermoleculares conferem a 
celulose uma significativa rigidez, enquanto as intramoleculares promovem a formação de regiões com ordem e regularidade, como citado anteriormente.

Estudos de difração de raios-x da organização da celulose revelam que este polímero natural é semi-cristalino, apresentando regiões altamente organizadas (cristalinas) que estão intercaladas com regiões menos organizadas (amorfas). Análises de raios- $x$ mostram que estrutura cristalina da cela unitária é do tipo monoclínica para celulose nativa denominada de celulose tipo I. Existem além da celulose tipo I, outras formas polimórficas, chamadas cellulose tipo II, celulose tipo III e celulose tipo IV.

A principal característica que as diferencia é o arranjo das cadeias moleculares na fase cristalina. Na tabela I, são apresentados os parâmetros de cela cristalina para as quatro formas polimóficas da celulose, onde pode ser observado que o ângulo $\beta$ é o parâmetro cristalográfico principal, uma vez que o arranjo diferenciado das cadeias de celulose na fase cristalina reflete na mudança desse valor (Sperling, 1992). Na figura 08, observa-se a cela unitária da celulose tipo I, apresentando os eixos cristalográficos e o ângulo $\beta$. 
Tabela 1: Parâmetros das celas cristalinas da celulose tipo I, II, III e IV.

$\begin{array}{ccccc}\text { Parâmetro } & \text { Celulose I } & \text { Celulose II } & \text { Celulose III } & \text { Celulose IV }^{\mathrm{a}} \\ \text { Eixo a }(\AA) & 8,35 & 8,02 & 7,74 & 8,12 \\ \text { Eixo b }(\AA) & 10,30 & 10,30 & 10,30 & 10,30 \\ \text { Eixo c }(\AA) & 7,90 & 9,03 & 9,96 & 7,99 \\ \beta\left({ }^{\circ}\right) & 83,3 & 62,8 & 58,0 & 90,0 \\ \text { Densidade } & 1,625 & 1,620 & 1,610 & 1,610 \\ \left(\mathrm{~g} . \mathrm{cm}^{-3}\right) & & & & \end{array}$

${ }^{a}$ O. Ellefsen, J. G. Ønnes and N. Norman, Acta Chem. Scand., 13, 853 (1959)

${ }^{\mathrm{b}}$ C. Legrand, J. Polym. Sci., 7, 333 (1951)

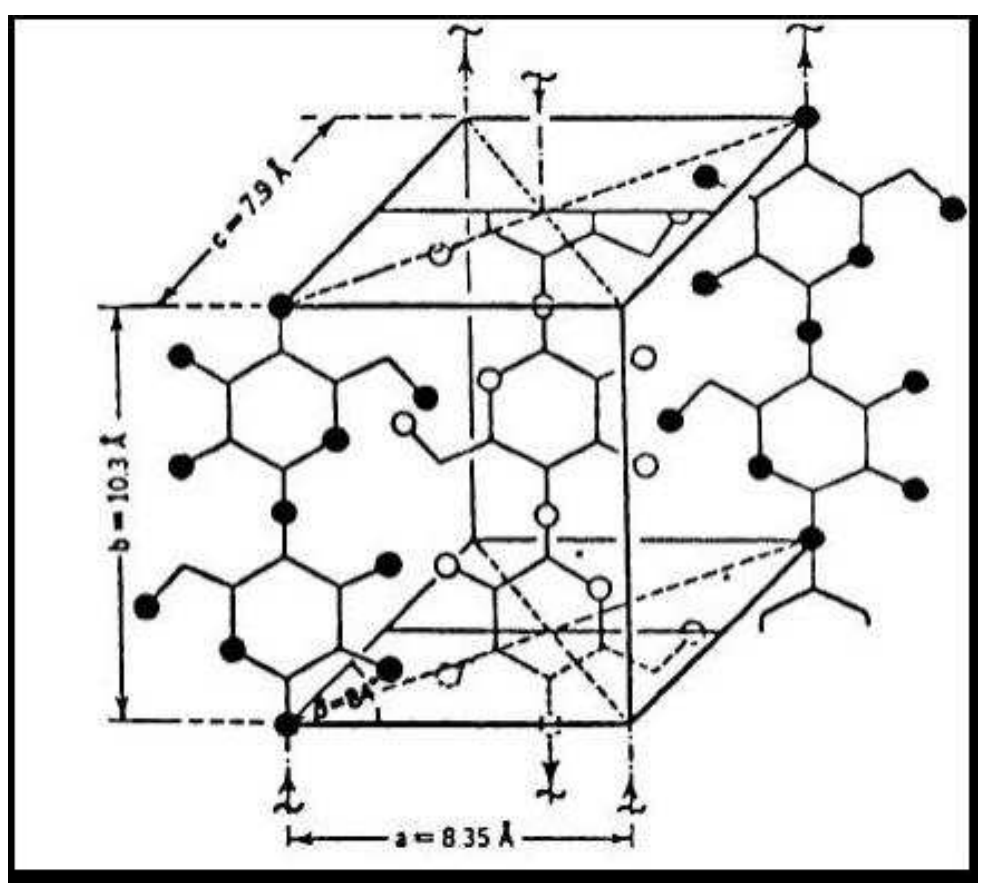

Figura 08: Estrutura cristalina da celulose do tipo I (nativa), determinada por espalhamento de raios- $X$. 
Através do tratamento com base forte, a estrutura da celulose tipo I pode ser rompida e convertida em celulose tipo II. A celulose tipo III pode ser produzida por tratamento da celulose tipo I ou II com aminas orgânicas (ex. etilenodiamina) ou amônia, enquanto a celulose tipo IV por tratamento com glicerol ou álcali a altas temperaturas ou apenas por tratamento térmico da celulose do tipo I ou II. Devido ao alto grau de organização e das ligações de hidrogênio nas regiões cristalinas, a celulose apresenta considerável resistência à tração, elongação e a solvatação, ou seja, a água não pode penetrar e nem rompê-las (Smole et al. 2003).

As ligações de hidrogênio não afetam apenas as propriedades físicas da celulose, mas também sua reatividade. Na reação de esterificação, a reatividade da hidroxila no carbono seis (C6) é cerca de seis vezes maior do que em outras posições disponíveis. Já durante a reação de eterificação a reatividade do carbono dois (C2) é duas vezes maior que no carbono seis (C6) e este por sua vez é duas vezes mais reativo que o carbono três (C3). A reatividade diferenciada na posição seis pode estar relacionada à existência de isômeros rotacionais relacionados à ligação C5-C6.

O fato que torna propício aos grupos hidroxilas serem alcançados por reagentes é um importante fator a ser considerado com relação à acessibilidade da celulose. Os grupos hidroxilas localizados em regiões amorfas são acessíveis e reativos, enquanto que em regiões cristalinas, devido a um eficiente empacotamento e fortes interações entre as cadeias, estes podem ser inacessíveis (Esau, 1974).

O processo de intumescimento da celulose é um meio de se alcançar os grupos hidroxilas menos acessíveis, entretanto, se levado ao extremo resulta na completa dissolução da celulose, desintegrando as regiões cristalinas das fibras 
(D’Almeida). Esta pode ser intumescida em diferentes solventes, tanto ácidos como básicos e a extensão de intumescimento depende do solvente, bem como da natureza da amostra de celulose (Esau, 1974). Quando ocorre o intumescimento da celulose, as forças intermoleculares são minimizadas devido a solvatação, tornando os grupos hidroxilas presentes nas moléculas de celulose mais reativos.

Esse processo é importante devido ao fato de que os processos de modificação química de polímeros ocorrem através da dissolução ou da fusão do material a ser utilizado. Entretanto, a celulose não sofre o processo de fusão, visto que esta se decompõe em temperaturas inferiores à temperatura de fusão $\left(T_{f}\right)$. $O$ preparo de soluções de celulose tem sido muitas vezes bem sucedido, mas requer condições extremas e solventes especiais. Normalmente, a produção comercial de derivados de celulose é realizada em meio heterogêneo, utilizando-se polpa celulósica e solventes que intumescem, mas não o dissolvem as fibras. 


\section{II.2 - AMIDO}

O amido é formado pela mistura de dois homopolissacarídeos (amilose e amilopectina) constituídos por anéis da $\alpha$-D-glicopiranose, unidos por meio das ligações glicosídicas $\alpha-1,4$. A amilose é um polímero não ramificado, com cerca de 250-300 unidades de glicose em ligações 1,4- $\alpha$-D-glicopiranose e a amilopectina, um polímero ramificado que contém 1000 unidades de glicose, sendo que a cada 25 unidades encontra-se ramificação em ligação 1,6- $\alpha$-D-glicopiranose (figura 09) (Van Soest e Vliegenthart, 1997).

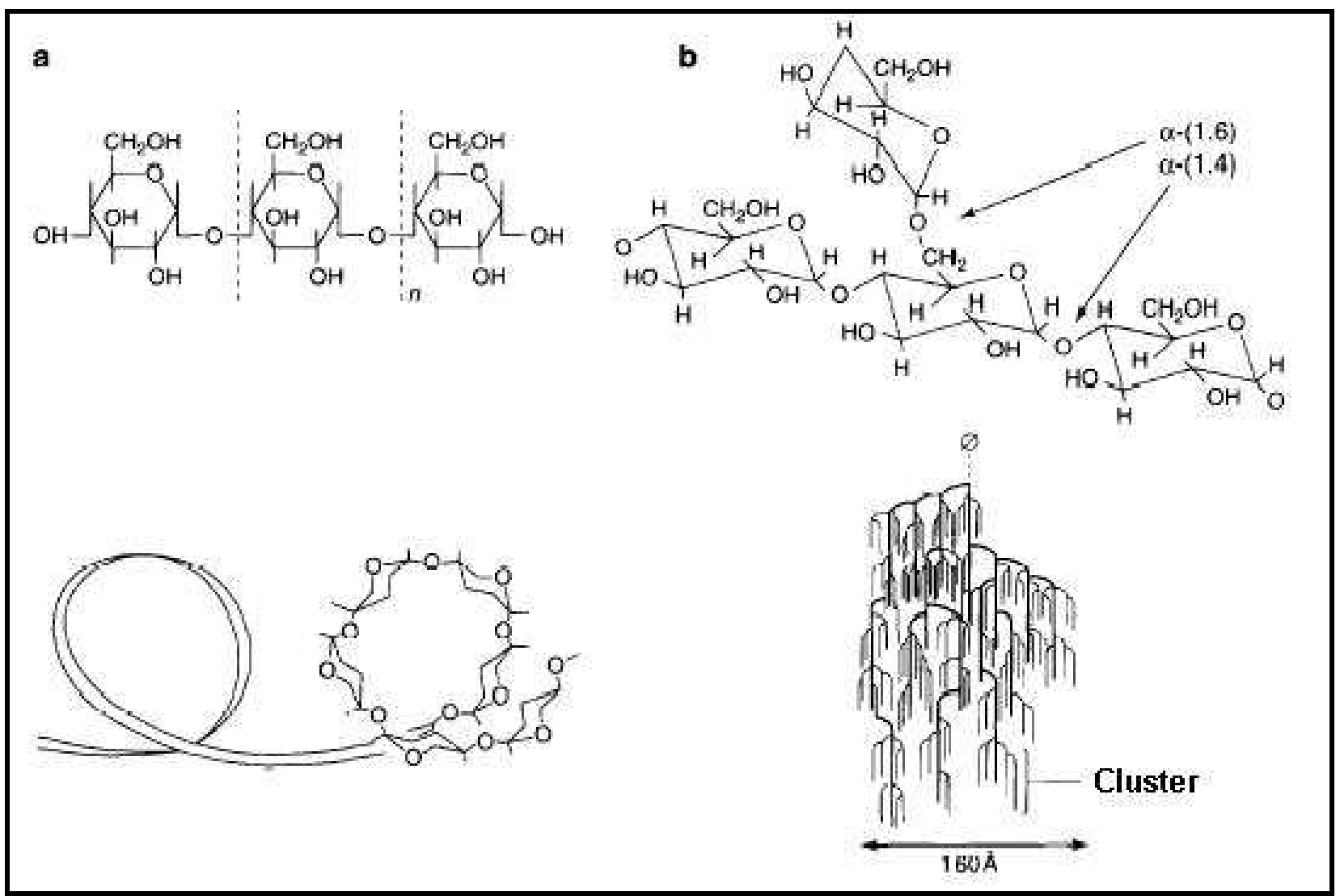

Figura 09: A esquerda está representada a estrutura química da amilose e a representação esquemática desta em forma de hélice (a) e a direita à amilopectina e representação esquemática das regiões cristalinas desta (clusters) (b). 
A obtenção do amido é relativamente simples. Primeiramente a fonte de amido é submetida ao processo de moagem com água, cujo produto, o amido na forma de pó na cor branca e insolúvel em água fria, é filtrado e centrifugado (Aspinall, 1985). O polímero obtido é composto por grânulos semi-cristalinos, cristalinidade proveniente devido a presença da amilopectina, cujo formato e tamanho dependem da matéria-prima utilizada para sua obtenção, figura 10, (Guinesi et al., 2006). A cristalinidade do amido é determinada por difração de Raios - X, sendo que a cristalinidade do amido proveniente de cereais e definida como tipo - A, proveniente de tubérculos do tipo - B e os que possuem estrutura intermediária a esses, são denominados do tipo - C. Na figura 11 são apresentados os difratogramas de raios $-X$ de amidos provenientes de espécies diferentes (Guinesi et al., 2006).
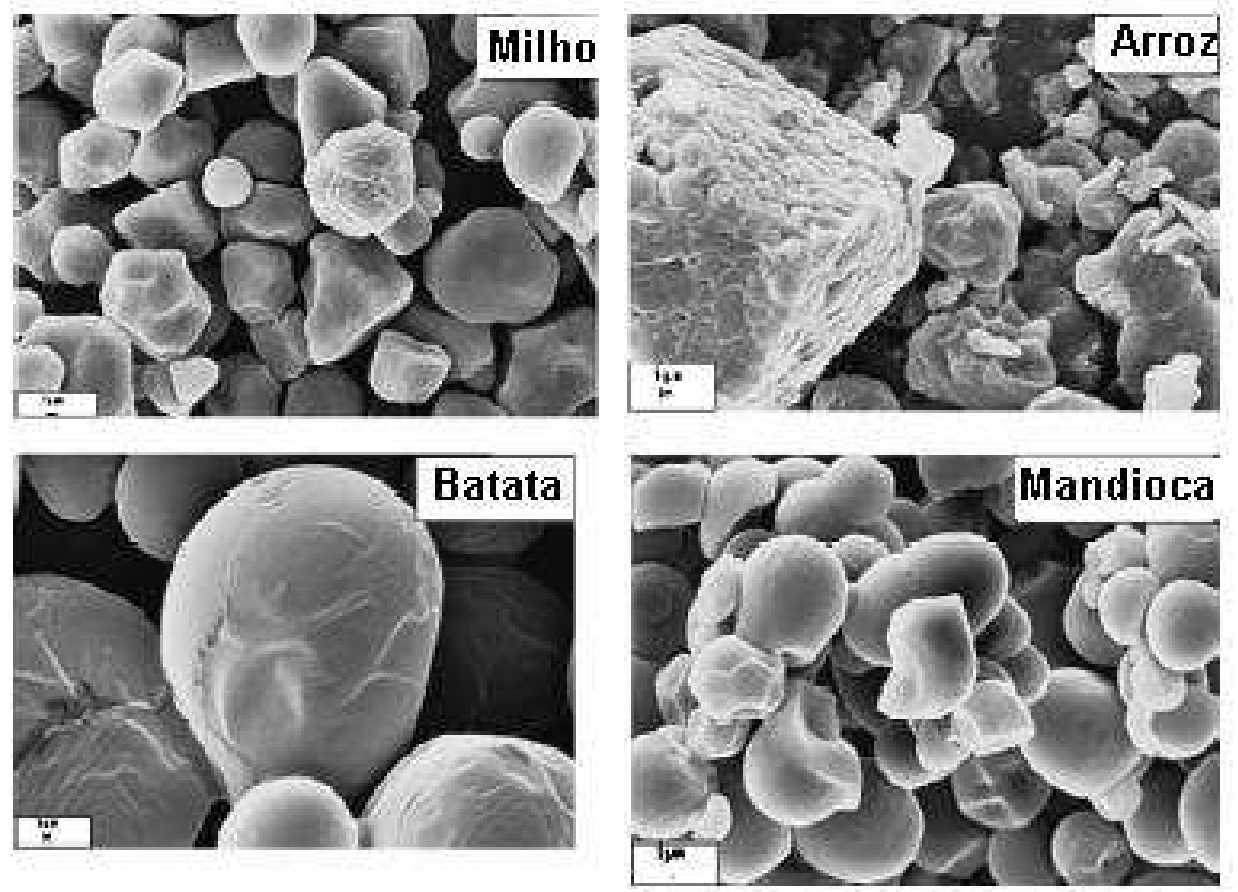

Figura 10: Micrografias de amidos provenientes de espécies diferentes. 


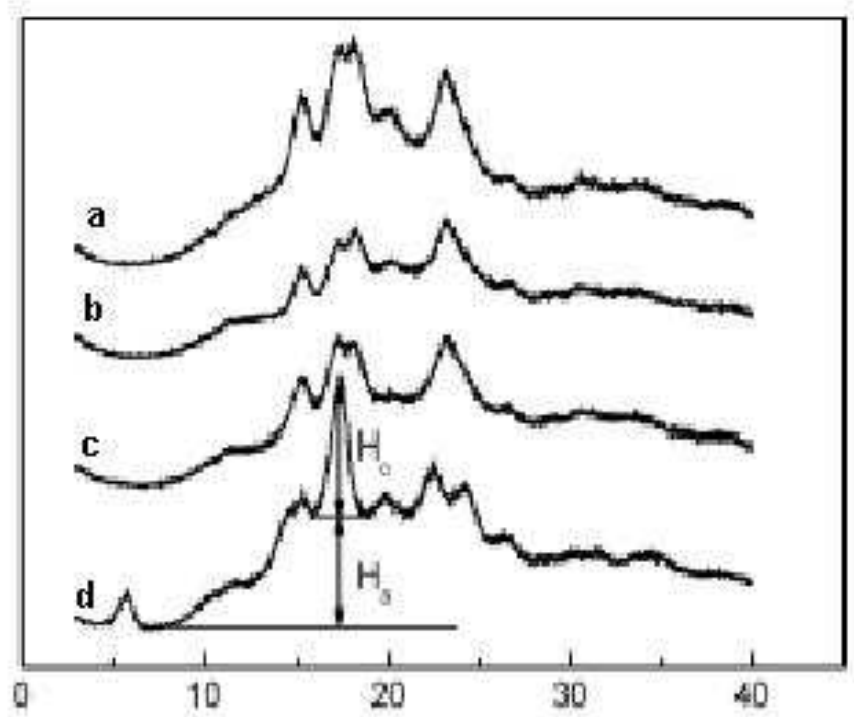

Figura 11: Difratogramas de Raios - X do amido de milho (a); arroz (b); mandioca (c) e batata $(d)$.

Com o avanço no desenvolvimento de materiais biodegradáveis baseados em amido plasticizado, aprofundou-se o estudo na formação de tipos de cristais e suas influências em algumas propriedades mecânicas. Objetivando tornar o amido processável, é necessário romper os grânulos e diminuir a sua cristalinidade. Uma das maneiras mais utilizadas é a obtenção do amido termoplástico (TPS), em que após a gelatinização em água e adição de plasticizante, obtêm-se um produto com a propriedade de formar filme.

O amido e seus derivados podem também ser modificados por reações de enxertia. A introdução de ramificações na cadeia do amido pode produzir diferenças marcantes em seu comportamento químico e físico-químico. Os produtos enxertados podem ser obtidos por diferentes processos químicos (radicalares ou iônicos), por meio de reações de substituição ou de adição. Nestes processos podem ser utilizados reagentes monofuncionais ou polifuncionais (monômeros ou oligômeros). 
Uma das modificações químicas do amido, bastante investigada, é a enxertia com monômeros. Este é um dos métodos mais efetivos para obter propriedades desejáveis no amido, sem sacrificar sua natureza biodegradável (Athawale e Lele, 2000). O estudo realizado por Mani e Tang, 1998, mostraram que policaprolactona (PCL) pré-funcionalizada com a função isocianato foi enxertada ao amido através de ligações de uretanas e os produtos gerados (amido enxertado com PCL) apresentou boas propriedades como compatibilizador da blenda amido/PCL.

Bagley et al., 1977, estudaram as propriedades de várias misturas de amido enxertado com poliestireno, tornando-o processável. Já Patil e Fanta, 1994, avaliaram as propriedades de formação de filmes de amido enxertado com poli(acrilato de metila). Desta forma, transformações químicas e físicas empregadas na produção de derivados de amido, descrita brevemente acima, podem alterar as propriedades do amido puro como exemplo a cristalinidade e a temperatura de transição vítrea $(\mathrm{Tg})$, possibilitando a formação de filmes. Estas modificações podem resultar em novos e interessantes materiais com diferentes potenciais de aplicação. 


\section{II.3 - REAÇÕES DE EPÓXIDOS}

Os epóxidos são éteres cíclicos com anéis de três membros. Segundo a nomenclatura da IUPAC, são chamados de oxiranos. O epóxido mais simples é comumente conhecido como óxido de etileno, demonstrado na figura 12.

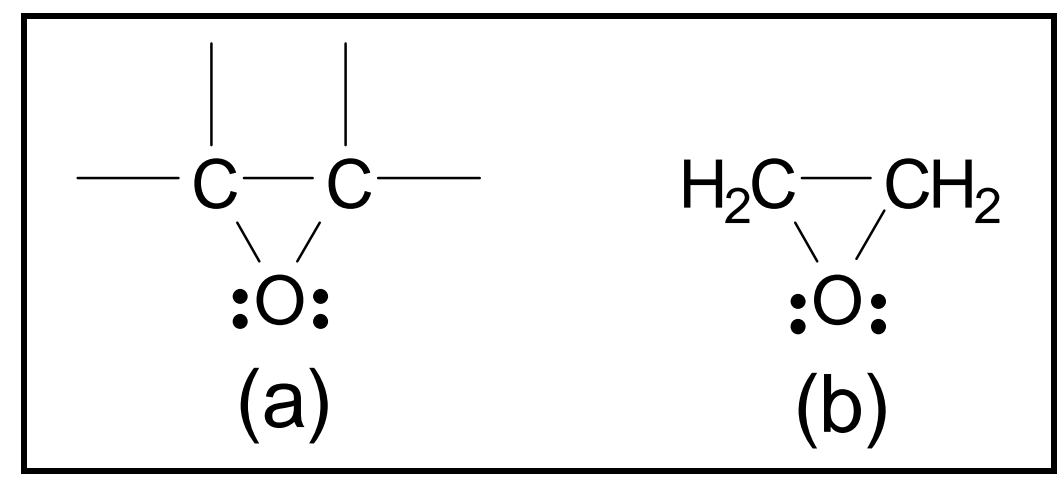

Figura 12: Estrutura geral dos epóxidos (a) e a estrutura do óxido de etileno (b).

Os ângulos das ligações no anel são de $60^{\circ} \mathrm{e}$, portanto, consideravelmente menores do que o usual ângulo tetraédrico de $109,5^{\circ}$ do carbono, ou ângulo de $110^{\circ}$ das ligações do oxigênio nos éteres de cadeia aberta. Visto que os átomos, nos epóxidos não estão dispostos de forma a permitir a máxima sobreposição de orbitais, as ligações são mais fracas do que nos éteres de cadeia aberta e, conseqüentemente, a molécula é menos estável.

O método mais largamente utilizado para a síntese de epóxidos é a reação entre um alceno e um perácido, conhecido como epoxidação (Figura 13). 


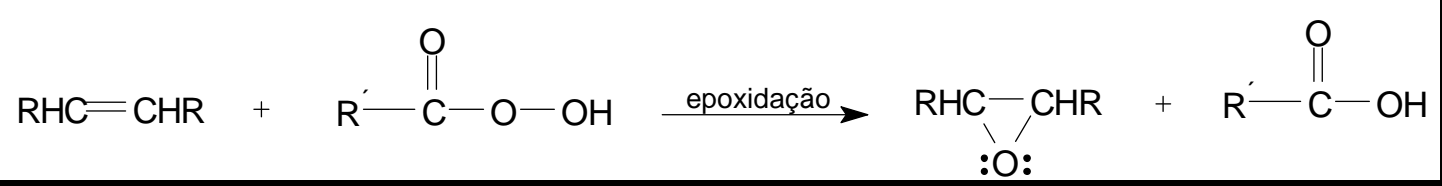

Figura 13: Reação de formação do epóxido.

Os epóxidos ou oxiranos são importantes por possuírem alta reatividade, a qual se deve à facilidade com que se abre o anel que se encontra sob grande tensão. Estes reagem tanto em meio ácido quanto em meio básico. Analogamente aos outros éteres, em meio ácido, os epóxidos são protonados e conseqüentemente tornam-se susceptíveis ao ataque de um agente nucleófilo, como demonstrado na figura 14.

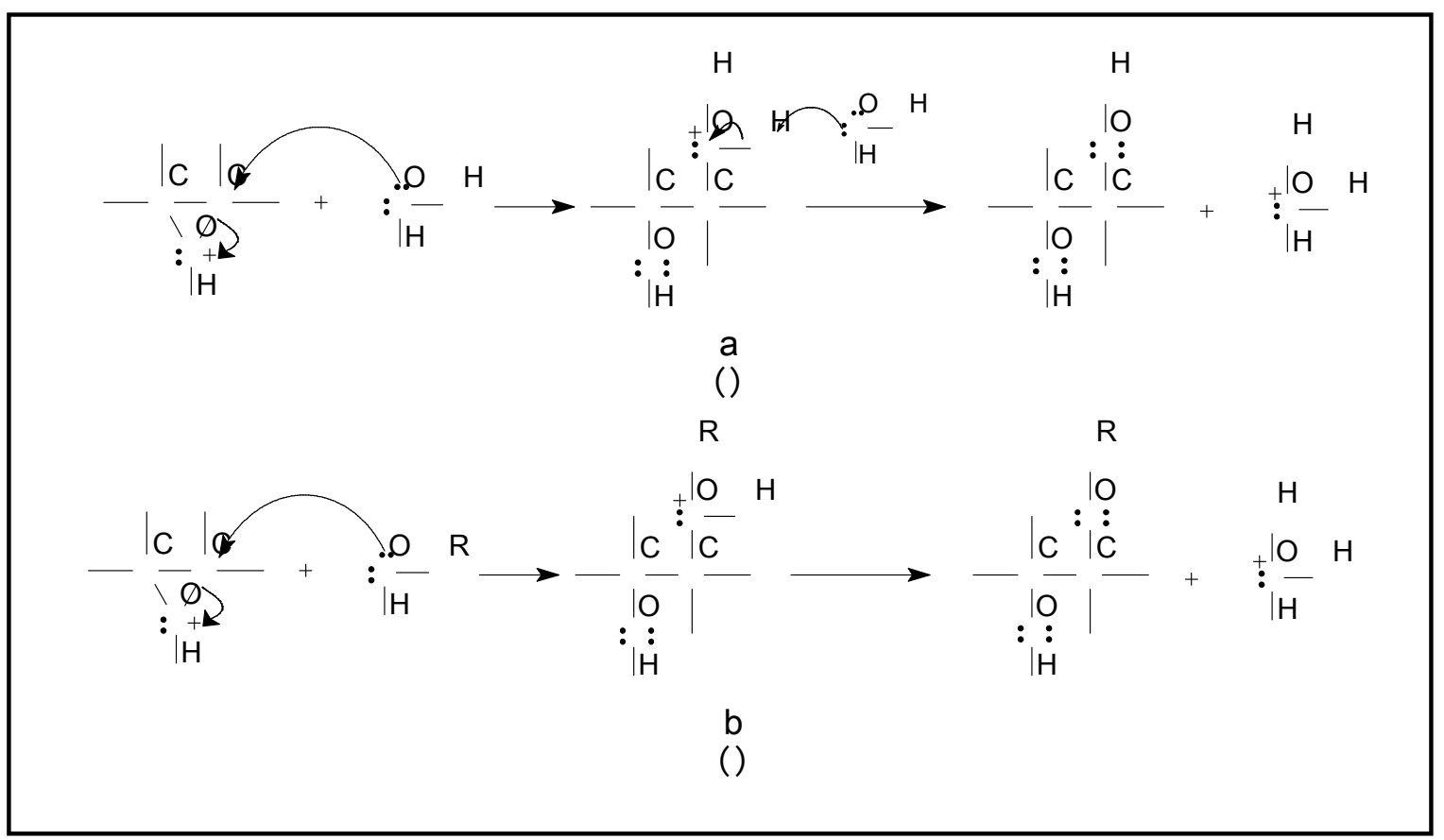

Figura 14: Reação entre o epóxido protonado e a água para formação do glicol (a) e com um álcool para formação de um hidroxiéter (b). 
Uma característica interessante neste tipo de reação é a formação de compostos com dois grupos funcionais diferentes. Assim, a reação com a água da origem a um diol - 1,2 e a reação com álcoois conduz a compostos que são simultaneamente éter e álcool.

Em meio básico, ao contrário de outros éteres, a reação é possível quando se utiliza um nucleófilo mais forte, o qual é também uma base mais forte, como o íon alcóxido ou íon hidróxido (figura 15).

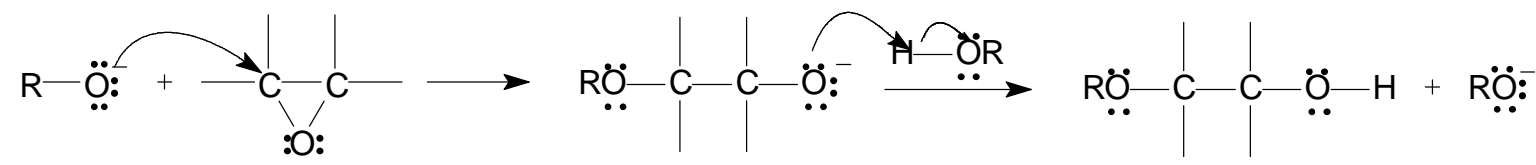

Figura 15: Reação geral do epóxido em meio básico.

Num epóxido simétrico, como o caso do óxido de etileno citado anteriormente, os dois carbonos são equivalentes e o ataque ocorre indiferentemente em ambos. Já em um epóxido não simétrico, carbonos não são equivalentes, o produto da reação que se obtém depende do carbono que for atacado.

O carbono que sofrerá o ataque nucleofílico depende do meio reacional, ou seja, se a reação é catalisada por ácido ou por base. Em meio básico o ataque do nucleófilo ocorre principalmente no átomo de carbono menos substituído. Por exemplo, o metiloxirano ou óxido de propileno reage com o íon alcóxido principalmente no átomo de carbono primário (Figura 16). 


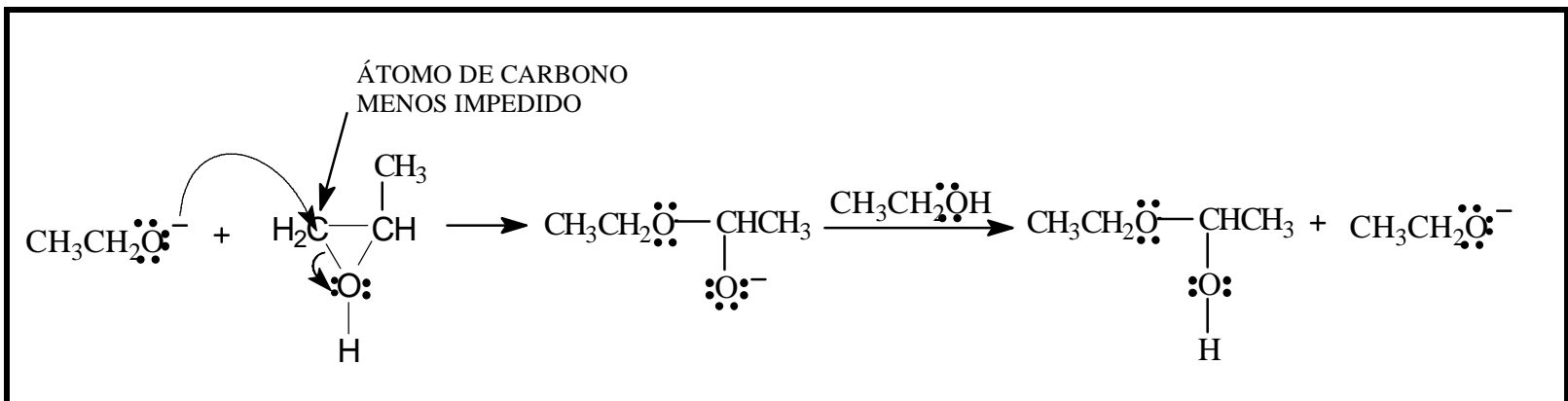

Figura 16: Reação em meio básico entre um íon alcóxido (nucleófilo forte) e um epóxido assimétrico.

A reação é do tipo $S_{N} 2$ e os substratos primários reagem mais rapidamente por esse mecanismo devido o substrato ser menos impedido estéricamente.

Em meio ácido, o ataque nucleofílico ocorre principalmente no átomo de carbono mais substituído. O exemplo abaixo (figura 17) ilustra bem esse tipo de comportamento.

$$
\mathrm{CH}_{3} \mathrm{OH}+\mathrm{H}_{3} \mathrm{C}-\underset{\mathrm{O}}{\stackrel{\mathrm{C}}{\mathrm{l}}-\mathrm{CH}_{2} \stackrel{\mathrm{H}_{3} \mathrm{O}^{+}}{\longrightarrow}} \mathrm{H}_{3} \mathrm{C}-\underset{\mathrm{OCH}_{3}}{\stackrel{\mathrm{C}}{\mathrm{CH}_{3}}-\mathrm{CH}_{2} \mathrm{OH}}
$$

Figura 17: Reação em meio ácido entre o metanol (nucleófilo fraco) e um epóxido assimétrico.

Esse comportamento pode ser justificado analisando o epóxido protonado (Figura 18). Observa-se que o átomo de carbono mais substituído carrega uma carga consideravelmente positiva, tornando-se semelhante a um carbocátion terciário. O nucleófilo, portanto, ataca este átomo de carbono mesmo este sendo o átomo mais substituído. Deve-se ressaltar que neste caso a reação é fortemente 
dependente dos fatores eletrônicos e não dos fatores estéricos, sendo esta considerada do tipo $S_{N} 1$ (Solomons, 2000; Pavier, 1998; Morrison, 1996).

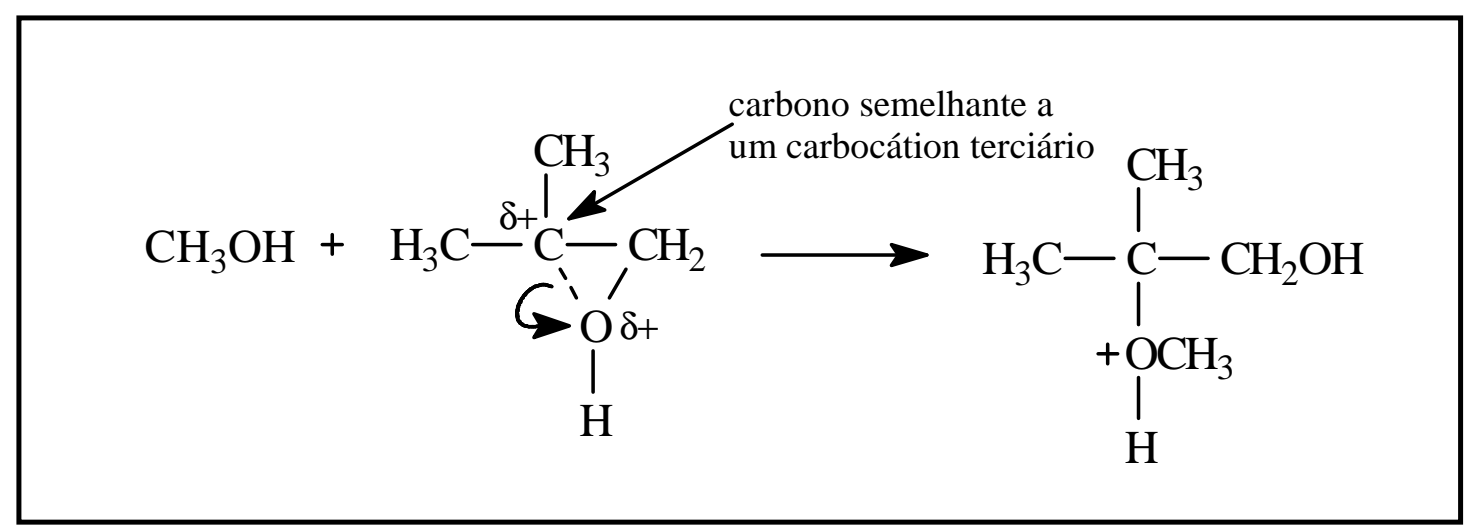

Figura 18: Epóxido assimétrico protonado com carbono semelhante a um carbocátion terciário. 


\section{III - ESTADO DA ARTE}

\section{III.1 - COMPÓSITOS MONO-COMPONENTES}

Materiais compósitos em que a celulose é a fonte de ambos, matriz e reforço, já são relatados na literatura. A combinação de ésteres de celulose e fibras foi explorada por duas linhas de pesquisa distintas:

1 - A incorporação de fibras lyocell em uma matriz de acetato de celulose. Nesta linha, compósitos termoplásticos foram preparados usando fibras de lyocell (celulose regenerada) com alto módulo como reforço para a matriz de acetato butirato de celulose - CAB. (Seavey et al. 2001). Os autores avaliaram as diferentes alternativas de manufatura, em particular a opção de se usar fibras na forma de tela (woven fabric) ou em forma de fios contínuos (continuous tow) e o tipo de deposição na matriz como pré-impregnação com pó (powder prepregging), empilhamento de filme (film stacking) e impregnação em solução (solution impregnation).

Os resultados obtidos demonstraram que a impregnação em solução das fibras em forma de fios contínuos (continuous tow) apresentaram os melhores resultados, com valores de resistência à tração, módulo elástico e deformação na ruptura de aproximadamente $250 \mathrm{MPa}, 20 \mathrm{GPa}$ e 3-4\%, respectivamente, utilizando uma quantidade de fibra em volume de cerca de $60 \%$.

Em outro trabalho, dando continuidade ao anterior, Seavey e Glasser (2001) preparam compósitos termoplásticos usando o método de impregnação em solução de fios contínuos de fibras de lyocell e, como matriz, o acetato butirato de celulose. Foi avaliada a adesão interfacial fibra-matriz, antes e após a modificação de 
superfície da fibra por acetilação, e a consolidação nas condições de fusão com o objetivo de produzir compósitos uniformes com quantidades de vazios menores e com alta resistência mecânica.

Embora tenha sido observado um ganho significante na resistência à tração dos compósitos reforçados com fibras de celulose descontínuas provenientes de madeira amarela (Liriodendron tulipifera), previamente acetiladas, a utilização do mesmo material como matriz (Glasser et al. 1999), não produziu o mesmo comportamento em relação ao ganho de resistência a tração para o sistema em questão, ou seja, para o compósito reforçado com fibras contínuas de lyocell.

Finalizando, Franko et al. 2001, prepararam compósitos termoplásticos variando o tipo de fibra, rayon e lyocell, com diferentes matrizes termoplásticas, acetato proprionato de celulose - CAP e diversos acetato butirato de celulose $\mathrm{CAB}$, com diferentes quantidades de grupos butil. Os resultados obtidos mostraram que os compósitos produzidos com fibras lyocell são significantemente mais resistentes e rígidos, cerca de $20 \%$ e $250 \%$, respectivamente, quando comparados com os compósitos produzidos com fibras rayon. O valor de módulo elástico para os compósitos reforçados com fibras de lyocell excederam $20 \mathrm{Gpa}$, enquanto que os compósitos reforçados com fibras rayon apresentaram módulo de elasticidade entre 6 e 8 Gpa.

2 - A esterificação parcial de fibras de polpa de madeira com anidrido hexanóico, em meio orgânico, gerou materiais que deformam termicamente quando submetidos a pressão. Nestes materiais a matriz termoplástica é o éster de celulose e as fibras não modificadas os elementos de reforço. Esses materiais foram preparados através da dissolução de fibras de celulose, provenientes de madeira 
dura (hardwood), na mistura p-tolueno sulfônico/anidrido hexanóico em um meio orgânico não intumescente, neste caso o cicloexano. Os materiais obtidos demonstraram ser resistentes ao intumescimento em água, deformáveis e mantiveram sua característica biodegradável (Matsumura e colaboradores, 2000 e Matsumura e Glasser, 2000).

Lu et al. 1999, prepararam um compósito consistindo de fibras vegetais como reforço e fibras vegetais plasticizadas como matriz. Através da reação de cianoetilação seguido da reação de cloração, serragem de pinus (pinus sawdust) e sisal (chopped sisal) foram convertidos em materiais termoplásticos e em seguida combinados com fibras de sisal e ramie. O compósito de fibra natural não só exibiu propriedades similares a dos compósitos de fibras convencionais, mas também caracterizou-se pelo fácil processamento, baixo impacto ambiental e baixo custo.

Na linha de eterificação (Lu et al. 2002, 2003), a reação de benzilação de serragem (pinus sawdust) em meio aquoso foi realizada. $O$ material obtido foi utilizado como matriz e fibras de sisal foram adicionadas como reforço. Laminados com orientação unidirecional foram produzidos por um método similar ao dos compósitos termoplásticos convencionais. Estes apresentaram características de fácil processamento, baixo impacto ambiental e baixo custo. Os produtos exibiram valores de propriedades mecânicas moderadas, 100 MPa para resistência à tração e 25 GPa para módulo elástico, quando comparados aos valores já obtidos pelo grupo em questão, pois as fibras de sisal não foram bem impregnadas pela matriz devido à relativa alta viscosidade desta.

Permanecendo na linha de eterificação, a reação de benzilação parcial de fibras de sisal em meio aquoso foi realizada. Compósitos auto-reforçados (Lu et al. 
2003) foram preparados através do processo de termoprensagem, no qual uma fração da superfície das fibras de sisal plasticizada atuou como matriz e as fibras não modificadas, bem como a parte interior da fibra que não foi modificada, atuaram como reforço. Os autores avaliaram a influência das várias condições de benzilação na estrutura, índice de fluidez e nas propriedades mecânicas desses materiais compósitos.

A compatibilidade interfacial do compósito é garantida devido à homogeneidade química de ambos matriz e reforço. Notou-se também que o grau de modificação é função da concentração e da dosagem da solução de $\mathrm{NaOH}$, dosagem de cloreto de benzila, tempo de reação, etc. Conseqüentemente, estrutura, índice de fluidez e propriedades mecânicas das fibras tratadas e dos compósitos podem ser alcançadas de acordo com estas variáveis e, como o material compósito auto-reforçado ainda consiste de celulose, hemicelulose e lignina, a biodegradabilidade associada ao material antes da modificação deve ser conservada.

Em um trabalho posterior, Lu et al. 2004, avaliaram o comportamento de degradação ambiental desses materiais, observando os efeitos de envelhecimento em água, solução enzimática e em solo, respectivamente. Estes confirmaram que a biodegradabilidade inerente ao material antes da modificação ainda está associada ao compósito.

Em uma outra linha, Nishino et al. 2004 em um trabalho recente descreveram a preparação de um compósito mono-componente de celulose (all-cellulose composite) através da dissolução em $\mathrm{DMAc/LiCl}$ de fibras ramie pré-tratadas e introduzindo fibras não tratadas dentro da subseqüente solução. Os compósitos 
foram em seguida isolados através da coagulação com metanol e secos. A estrutura e as propriedades mecânicas e térmicas destes materiais compósitos foram investigadas através das técnicas de difração de raios $X$, microscopia eletrônica de varredura e teste de tração versus deformação.

O valor de resistência a tração deste compósito foi de $480 \mathrm{MPa}$ a $25{ }^{\circ} \mathrm{C}$, resultados esses comparáveis aqueles dos compósitos convencionais reforçados com fibras de vidro.

Gindl e Keckes (2005) prepararam filmes, via casting, de nanocompósitos mono-componente de celulose (all-cellulose nanocomposite) com diferentes razões de celulose I e celulose II através da dissolução parcial de celulose microcristalina, em forma de pó, em DMAc/LiCl. As propriedades mecânicas e estruturais foram caracterizadas através das técnicas de difração de raios $\mathrm{X}$ e testes de tração versus deformação. Os filmes obtidos são isotrópicos, transparentes a luz visível, altamente cristalinos e contém diferentes quantidades de cristalitos de celulose I na matriz de celulose regenerada.

Os resultados demonstraram que, variando a razão entre celulose I e celulose II, as propriedades mecânicas dos nanocompósitos podem ser ajustadas. Dependendo da composição foram observados valores de resistência à tração, módulo de elasticidade e deformação de 240MPa, 13,1GPa e $8,6 \%$, respectivamente. 


\section{III.2 - OXIPROPILAÇÃO DE MACROMOLÉCULAS NATURAIS}

De forma geral, a oxipropilação de polissacarídeos (celulose, amido, quitina, etc.) é um processo bem documentado no contexto de sua conversão em polióis, que podem ser apropriadamente utilizados como macromonômeros na manufatura de poliuretanos (Gandini e Belgacem, 1998, 2002; Evtiouguina et al., 2000, 2001, 2002; Pavier e Gandini, 2000a, 2000b, 2000c). Este procedimento tem com objetivo aumentar o acesso aos grupos $\mathrm{OH}$ desses materiais sólidos, geralmente de difícil penetração. Outra aplicação desses materiais oxipropilados é no desenvolvimneto de eletrólitos sólidos poliméricos (Schoenenberger, Le Nest e Gandini, 1995; Velasquez-Morales, Le Nest e Gandini, 1998; Machado, Pawlicka e Yonashiro, 2004; Machado, Ferreira e Pawlicka, 2005; Lopes, Machado, Pawlicka e Donoso, 2005).

De forma específica, pode-se citar o trabalho de Lee e Perlin (1982), onde estes obtiveram informações sobre o grau de substituição individual nos átomos de oxigênio e sobre a substituição molar total do $O$-(2-hidroxipropril) cellulose através de medidas de $\mathrm{RMN}^{13}$ do polímero antes e após este sofrer hidrólise. Com base nos deslocamentos químicos do ${ }^{13} \mathrm{CH}_{3}$, pôde-se observar que os substituintes $\mathrm{O}$-2hidroxipropril (HOPr) que ocorreram individualmente ou como unidades terminais de substituintes de cadeia, foram prontamente diferenciados dos HOPr internos da cadeia. Distinção entre as unidades monoméricas de $\mathrm{HOPr}$ e as longas cadeias localizadas no átomo de oxigênio dois (O-2) dos resíduos de D-glicosil foi efetuada através da transformação por hidrólise de açúcares apropriadamente substituídos, com grupo 2-O-(2-hidroxipropil) incorporados, em 1,2-acetais cíclicos. 
Similarmente, substituição padrão no átomo de oxigênio seis (O-6) de resíduos glicosídicos foi determinada, através da degradação seletiva de etileno glicol derivatizado com HOPr, representando os átomos de carbono cinco (C-5) e seis (C-6) dos resíduos. De uma forma geral, foi encontrado que, embora O-2 e O-6 sejam mais seletivos que $0-3$, a velocidade na qual cada substituinte de $\mathrm{HOPr}$, inicialmente introduzida, é convertido em uma estrutura dimérica (dímero) não é afetada pela localização destes.

Já na linha de oxipropilação de amido, Seow e Themavalar (1993) avaliaram os efeitos dessa na transição de fase associada à gelatinização de grânulos de amido de arroz através da técnica de calorimetria exploratória diferencial. A uma razão amido/água igual a um (1), um deslocamento progressivo das endotermas de gelatinização para temperaturas menores, bem como um alargamento e encurtamento das mesmas com o aumento da substituição molar foram observados, indicando um aumento da plasticização interna e a desestabilização das regiões amorfas dos grânulos de amido. A entalpia de gelatinização também foi reduzida.

Grupos hidróxipropil, que são ligados primariamente às moléculas de amido nas regiões amorfas dos grânulos, comportam-se como cadeias laterais flexíveis e os movimentos dessas cadeias laterais geram uma grande quantidade de volume livre, diminuindo desse modo a temperatura de transição vítrea associada ao amido gelatinizado. Os grânulos de amido modificado podem então ser vistos como polímeros plasticizados internamente, que são mais facilmente gelatinizados do que o amido não modificado.

Ainda na linha de oxipropilação de amido, Morita e Hung (2005), estudaram as propriedades de grânulos grandes de amido de trigo (tipo A - 12-20 $\mu \mathrm{m}$ ) e 
pequenos (tipo $\mathrm{B}-2-8 \mu \mathrm{m}$ ) após esses serem submetidos à reação de hidroxipropilação e hidroxipropilação seguido de entrecruzamento. Os grânulos tipo A apresentaram inicialmente uma maior quantidade de amilose, menor temperatura de gelatinização e maior entalpia de transição quando comparados com os grânulos tipo B. Amido hidroxiprolilado $(\mathrm{AH})$ e amido hidroxiprolilado entrecruzado (AHE) provenientes dos grânulos tipo A foram mais hidroxipropilados do que os provenientes dos grânulos tipo B. Alem disso, AH e AHE provenientes dos grânulos tipo A apresentam maior poder de intumescimento e resultaram em materiais (pasta) mais consistentes e transparentes do que $\mathrm{AH}$ e $\mathrm{AHE}$ provenientes dos grânulos tipo B. De forma geral, a reação de hidroxipropilação dos amidos aumentou seu poder de intumescimento, consistência e transparência. Em contraste, a reação de entrecruzamento do $\mathrm{AH}$ inibiu o poder de intumescimento dos grânulos e reduziu a consistência e a transparência destes. Ambos, AH e AHE apresentaram menores temperaturas de gelatinização, mas apresentaram melhores comportamentos geldegel (freeze-thaw) quando comparados com os grânulos de amido nativo.

Além dos trabalhos cronologicamente citados acima, vários estudos foram e vem sendo realizados ao longo do tempo com intuito de um melhor entendimento a respeito das condições de reação e das propriedades físico-químicas dos materiais obtidos através da hidroxipropilação de vários tipos de amido, tais como os trabalhos realizados por Kavitha e Bemiller, 1998; Shi e Bemiller, 2000, 2002; Staplev e Bemiller, 2003; Ji, Ao, Han, Jane e Bemiller, 2004; Gray e Bemiller, 2005; Villwock e Bemiller, 2005; Han e Bemiller, 2005, 2006; Aziz et al., 2004; oxipropilação de lignina, de Oliveira e Glasser, 1989; Hofmann e Glasser, 1993; Jain e Glasser, 1993; xilana, Jain, Sjostedt e Glasser, 2000; e açúcar, Yadav, Bemiller e Wu, 1994. 
É importante salientar que os trabalhos citados anteriormente foram realizados em meio aquoso ou meio orgânico. No presente trabalho, um dos objetivos foi de realizar a reação de oxipropilação em meio heterogêneo, ausência de solvente e de procedimentos laboriosos de purificação. 


\section{IV - OBJETIVOS}

- Preparação/caracterização de sistema bifásico mono-componente (SBM) a partir de modificações químicas superficiais, em diferentes extensões, de fibras de celulose e amido de milho.

- Conservar as propriedades mecânicas da parte interna (não modificada) do polissacarídeo, ao mesmo tempo em que permita que a camada interna (não modificada) possa fundir com as camadas externas dos materiais modificados. 


\section{V - PARTE EXPERIMENTAL}

\section{V.1 - MATERIAIS}

- Celulose microcristalina Avicel em pó (50 microns tamanho médio de partículas) da FMC Europe N. V.

- Celulose Papel Filtro de porosidade média (Hexis).

- Celulose Regenerada Rayon (Cermav/Grenoble-França)

- Celulose Polpa Kraft (Votorantin Celulose e Papel - VCP)

- Amido de Milho (Amidex 3001 - 28\% amilose) da Corn Products Brasil.

- 1,4 - Diazabiciclo $[2,2,2]$ octano - DABCO

- $\mathrm{KOH}$ (Synth)

- Óxido de propileno 98\% (Acros).

\section{V.2 - PROCEDIMENTO EXPERIMENTAL:}

As reações de oxipropilação foram realizadas em quatro diferentes substratos de celulose. Inicialmente foi realizado pré-tratamento de aproximadamente $2,00 \mathrm{~g}$ do substrato com uma solução etanólica de $\mathrm{KOH}$ (razão molar [KOH]/[OH celulose] 0,1) por 12 horas. O pré-tratamento utilizando solução etanólica de DABCO, razão molar [DABCO]/[OH celulose] e [DABCO]/[OH amido] 0,1 por 12 horas, foi aplicado somente para a celulose papel filtro e para o amido de milho. Após remoção do etanol, a reação de oxipropilação foi realizada em um reator autoclave de $100 \mathrm{~mL}$, equipado com um manômetro e um sistema de aquecimento, monitorando a pressão 
até que o sistema atingisse a temperatura desejada, $135^{\circ} \mathrm{C}$ para as celuloses avicel, papel filtro e polpa Kraft e $150{ }^{\circ} \mathrm{C}$ para celulose regenerada.

Sendo o óxido de propileno um líquido volátil, $\mathrm{T}_{\mathrm{eb}}$ igual $37^{\circ} \mathrm{C}$, estabelece-se um equilíbrio líquido-vapor ao atingir a temperatura de reação, gerando uma pressão correspondente. O final da reação foi determinado pelo abaixamento da pressão, devido ao consumo do agente modificador durante a reação. Após o término da reação, o material obtido foi submetido à extração com n-hexano em equipamento soxhlet (24 horas) para remoção de homopolímero de óxido propileno, sendo em seguida seco em estufa a vácuo $\left(70^{\circ} \mathrm{C}\right)$ até massa constante.

A razão molar $[\mathrm{OP}] /[\mathrm{OH}$ celulose] e $[\mathrm{OP}] /[\mathrm{OH}$ amido] utilizada foi 1,3 e 5, considerando três (3) grupos hidroxilas por unidade de glicopiranose, para os substratos tratados previamente com solução etanólica de $\mathrm{KOH}$ e DABCO. O tempo de reação variou de 2-7 horas, dependendo do tipo de substrato. É importante ressaltar, com exceção da celulose de papel filtro, que todas as amostras foram alocadas no fundo do reator, ficando conseqüentemente em contato direto com o óxido de proprileno no estado líquido. No caso do Papel Filtro, o mesmo foi enrolado em forma de cone e apenas uma parte ficou imersa no líquido. A maior parte da folha ficou em contato com o vapor após se estabelecer o equilíbrio líquido-vapor na temperatura desejada. 


\section{V.3 - CARACTERIZAÇÃO}

As amostras, antes e após as reações de oxipropilação, foram caracterizadas através das seguintes técnicas: Espectroscopia na região do Infravermelho (FTIR), Difração de Raios-x, Microscopia Eletrônica de Varredura (MEV), Ganho de Massa (GM), Análise Termogravimétrica (TG), Calorimetria Exploratória Diferencial (DSC), medidas de Ângulo de Contato e ensaios de Resistência à Tração.

\section{V.3.1 - ESPECTROSCOPIA NA REGIÃO DO INFRAVERMELHO (FTIR)}

Utilizou um espectrofotômetro BOMEN - MB102 e as pastilhas de KBr foram preparadas por prensagem após as amostras terem sidos misturadas com $\mathrm{KBr}$ seco na proporção (amostra/KBr) de 1/100 (m/m).

\section{V.3.2 - DIFRAÇÃO DE RAIOS-X}

Para avaliar a cristalinidade das amostras utilizou-se um difratômetro CarlZeis-Jena - UDR6 a uma velocidade de $1,2^{\circ} / \mathrm{min}$, no intervalo de $5^{\circ}$ e $40^{\circ}$ para o ângulo $2 \theta$. 


\section{V.3.3 - MICROSCOPIA ELETRÔNICA DE VARREDURA (MEV)}

Com intuito de observar a morfologia das amostras e avaliar as possíveis mudanças ocorridas após a reação de modificação, utilizou-se microscópio eletrônico de varredura digital marca LEO-440. As amostras, após sofrerem fratura em nitrogênio líquido, foram alocadas sobre uma fita adesiva de carbono e esta foi fixada em um porta-amostra de alumínio. Os materiais foram secos em estufa a vácuo $\left(40^{\circ} \mathrm{C}\right)$ e em seguida recobertas com ouro.

\section{V.3.4 - GANHO DE MASSA (GM)}

Após a extração com n-hexano em equipamento soxhlet (24 horas) para remoção de homopolímero de óxido propileno, as amostras foram submetidas à secagem em estufa à vácuo $\left(70^{\circ} \mathrm{C}\right)$ até massa constante, calculando-se o ganho de massa (GM) através da seguinte expressão:

$$
\mathrm{GM}=\left[\left(\mathrm{M}_{\mathrm{f}}-\mathrm{M}_{\mathrm{i}}\right) / \mathrm{M}_{\mathrm{i}}\right] \times 100 \text { Equação (1) }
$$

Onde GM é o ganho de massa em porcentagem; $M_{f}$ é a massa da amostra oxipropilada e $\mathrm{M}_{\mathrm{i}}$ é a massa da amostra antes da reação de oxipropilação. 


\section{V.3.5 - ANÁLISE TERMOGRAVIMÉTRICA (TG)}

Equipamento da Shimadzu TA-50WSI com módulo TGA50, utilizou-se portaamostra de platina, razão de aquecimento de $10{ }^{\circ} \mathrm{C} / \mathrm{min}$ sob fluxo de $\mathrm{N}_{2}$ de 20 $\mathrm{mL} / \mathrm{min}$, num intervalo de temperatura ambiente à $1000{ }^{\circ} \mathrm{C}$.

\section{V.3.6 - CALORIMETRIA EXPLORATÓRIA DIFERENCIAL (DSC)}

Equipamento da Shimadzu TA-50WSI, com razão de aquecimento de $10^{\circ} \mathrm{C} / \mathrm{min}$ sob fluxo de $\mathrm{N}_{2}$ de $20 \mathrm{~mL} / \mathrm{min}$, porta-amostra de alumínio, em um intervalo de temperatura $-100^{\circ} \mathrm{C}$ à $180^{\circ} \mathrm{C}$.

\section{V.3.7 - ÂNGULO DE CONTATO}

Objetivando avaliar as propriedades de superfície dos materiais em questão, realizaram-se medidas de ângulo de contato, com quatro líquidos de diferentes polaridades; água, formamida, etileno glicol e diiodometano. As medidas foram realizadas utilizando o seguinte equipamento: Contact Angle System OCA Dataphysics/Faber Castell. 


\section{V.3.8 - ENSAIOS DE RESISTÊNCIA A TRAÇÃO}

Os ensaios de resistência a tração para a celulose de Papel Filtro em forma de filme, antes e após as modificações, foram realizadas em equipamento DMA, modelo 2980 - TA instruments, nas seguintes condições:

- Garra: Tensão para Filmes

- Comprimento da Amostra: $10 \mathrm{~mm}$

- Pré-carga: 0,5 N

- Método: $0,5 \mathrm{~N} \cdot \mathrm{min}^{-1}$ até $18 \mathrm{~N}$

As amostras foram previamente secas em estufa à vácuo por $24 \mathrm{~h}$ a $70{ }^{\circ} \mathrm{C}$. 


\section{VI - RESULTADOS E DISCUSSÕES}

\section{VI.1 - CARACTERIZAÇÃO DO HOMOPOLÍMERO DE POLI (ÓXIDO PROPILENO)}

Em princípio a reação esperada/desejada para o sistema em questão é a reação entre os grupos hidroxilas ativados com a base e o óxido de propileno. Entretanto, uma reação secundária que ocorre neste, é a formação de homopolímero de óxido de propileno (esquema abaixo). Na presença do hidróxido de potássio, o óxido de propileno polimeriza (St Pierre e Price, 1956; Steiner, Pelletier e Trucks, 1964; Wu e Glasser, 1984). O hidróxido de potássio se dissocia em $\mathrm{K}^{+}$e $\mathrm{HO}^{-}$e o íon $\mathrm{HO}^{-}$, iniciador da reação, provoca a abertura do anel oxirano gerando um íon alcóxido que irá acrescentando novas unidades de óxido de propileno.

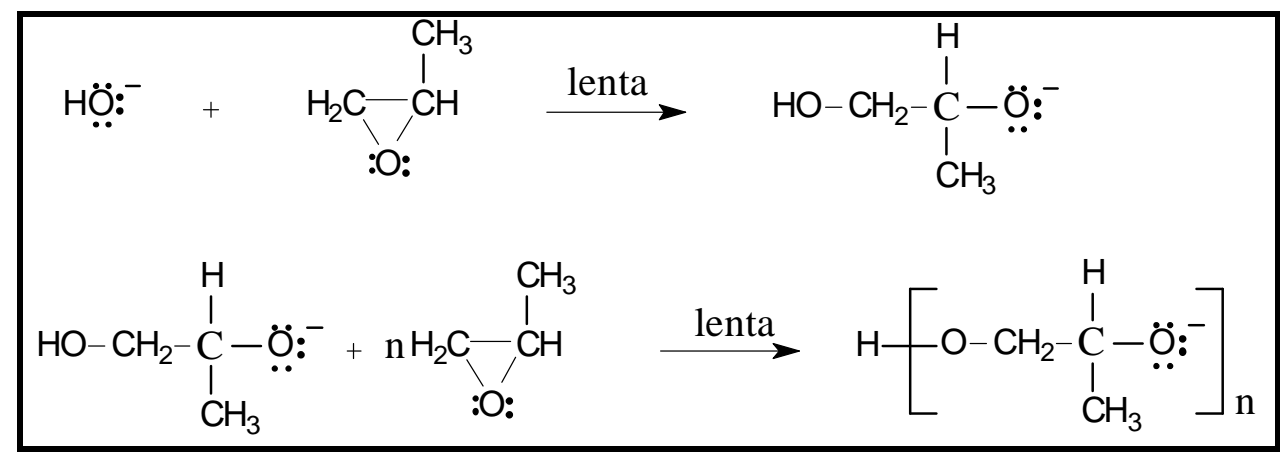

Figura 19: Reação de formação do homopolímero de óxido de propileno.

Conseqüentemente, é necessário realizar um processo de separação entre a celulose ou amido oxipropilado e o homopolímero. O procedimento utilizado foi o da 
extração com n-hexano em soxhlet, com base nos resultados obtidos por Pavier, 1998 e Pavier e Gandini, 2000.

Segundo Pierre e Price, 1956, para que ocorra a reação não é preciso, necessariamente, da presença de um iniciador, entretanto, Steiner, Pelletier e Trucks, 1964, observaram que a presença de um composto contendo um grupo hidroxila ou íon hidróxido aumenta a velocidade da reação.

Wu e Glasser, 1984, em seus estudos sobre a síntese de lignina oxipropilada, colocam em evidência a presença do homopolímero de óxido propileno. Eles mostraram que a reação é praticamente nula a temperaturas inferiores a $85^{\circ} \mathrm{C}$ e que a reação é demasiadamente rápida para ser medida a temperaturas superiores ou iguais a $150{ }^{\circ} \mathrm{C}$. É importante comentar que Pierre e Price já haviam mostrado em 1955, que a polimerização do óxido de propileno ocorria a temperatura ambiente na presença de hidróxido de potássio em pó (Pavier, 1998).

Após a extração fez-se algumas caracterizações para confirmar a presença destes. Nas figuras 20 e 21 são apresentados os espectros de infravermelho do homopolímero de óxido propileno e poli (óxido propileno) comercial de massa molar numérica média de 425 g/mol (Pavier, 1998 e Pavier e Gandini, 2000). 


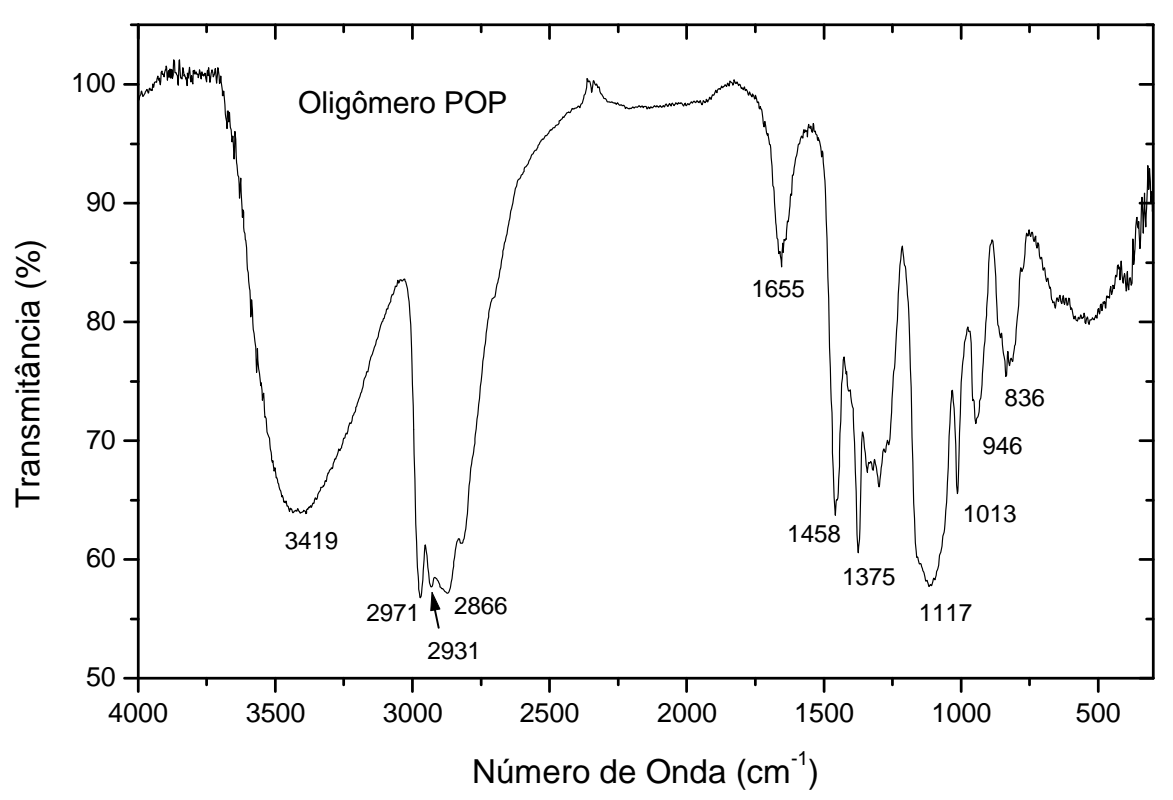

Figura 20 Espectro de FTIR (pastilha de $\mathrm{KBr}$ ) do homopolímero de poli (óxido propileno) extraído com $n$-hexano em soxhlet, da reação do óxido propileno com celulose.

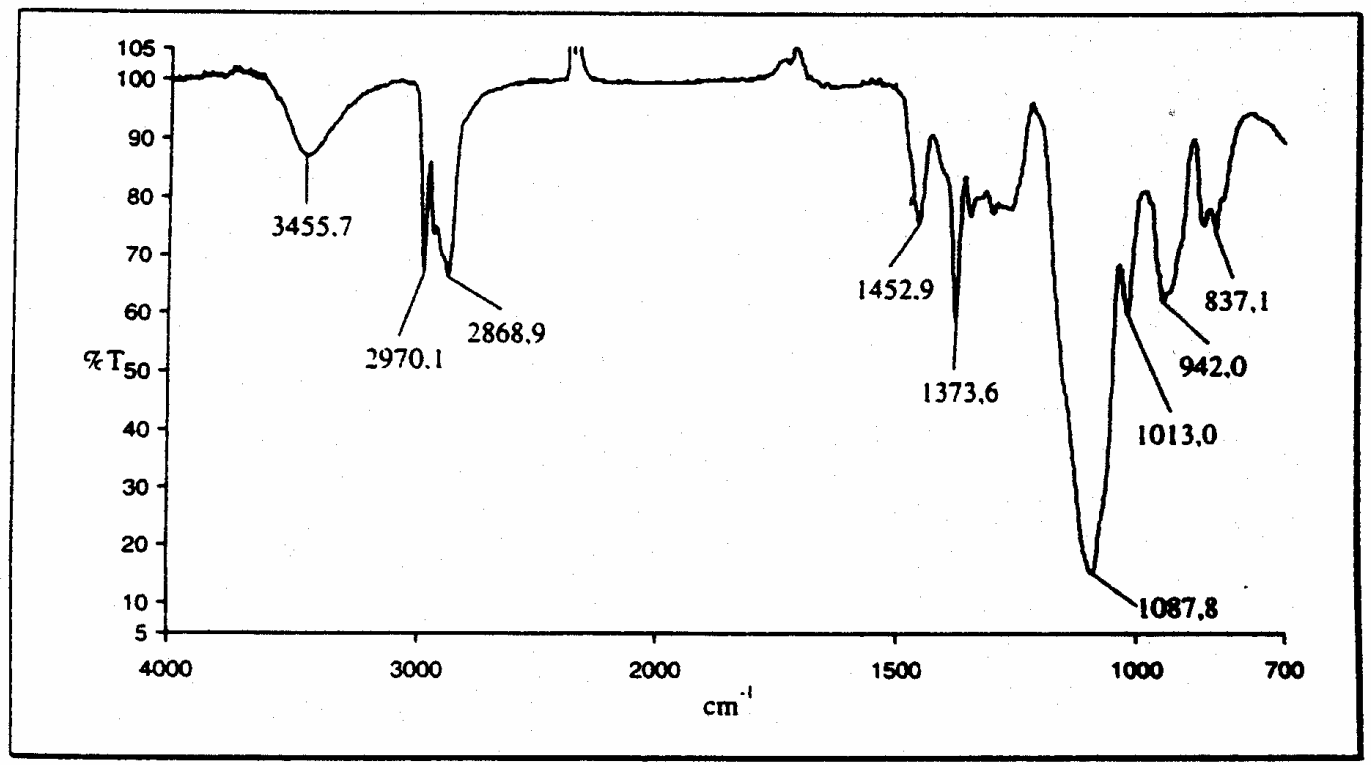

Figura 21 Espectro de FTIR (pastilha de $\mathrm{KBr}$ ) do homopolímero de poli (óxido propileno) Comercial. 
Observa-se a presença de um pico em $1655 \mathrm{~cm}^{-1}$, não observado no poli (óxido propileno) comercial, o qual pode ser atribuído a uma pequena fração de celulose presente no homopolímero. Os demais picos apresentam correspondência de absorção nos dois espectros.

Fez-se também a análise por $\mathrm{RMN} \mathrm{H}^{1}$. A figura 22 apresenta o espectro de RMN H${ }^{1}$ do homopolímero. Como descrito por Pavier e Pavier e Gandini, 1998, 2000b, respectivamente, os deslocamentos químicos atribuídos aos prótons referentes aos grupos $\mathrm{CH}$ e $\mathrm{CH}_{2}$ foi realizado após um criterioso estudo, onde fez-se análise dos espectros de $\mathrm{RMN} \mathrm{H}^{1}$ de várias amostras de poli(propileno) glicóis comerciais de massas molares médias diferentes. $\mathrm{Na}$ tabela abaixo são apresentados os valores de deslocamentos químicos e os prótons correspondentes a estes.

Tabela 2: Deslocamentos químicos e hidrogênios correspondentes do espectro de RMN H${ }^{1}$ do homopolímero de poli(óxido) propileno.

Deslocamento químico (ppm) Hidrogênios correspondentes

$\begin{array}{cc}1,1 & \mathrm{CH}_{3}-\mathrm{C} \\ 3-4 & \mathrm{CH}_{2}-\mathrm{O} \text { e } \mathrm{CH}-\mathrm{O} \\ 7,2 & \mathrm{CHCl}_{3}, \text { solvente }\end{array}$




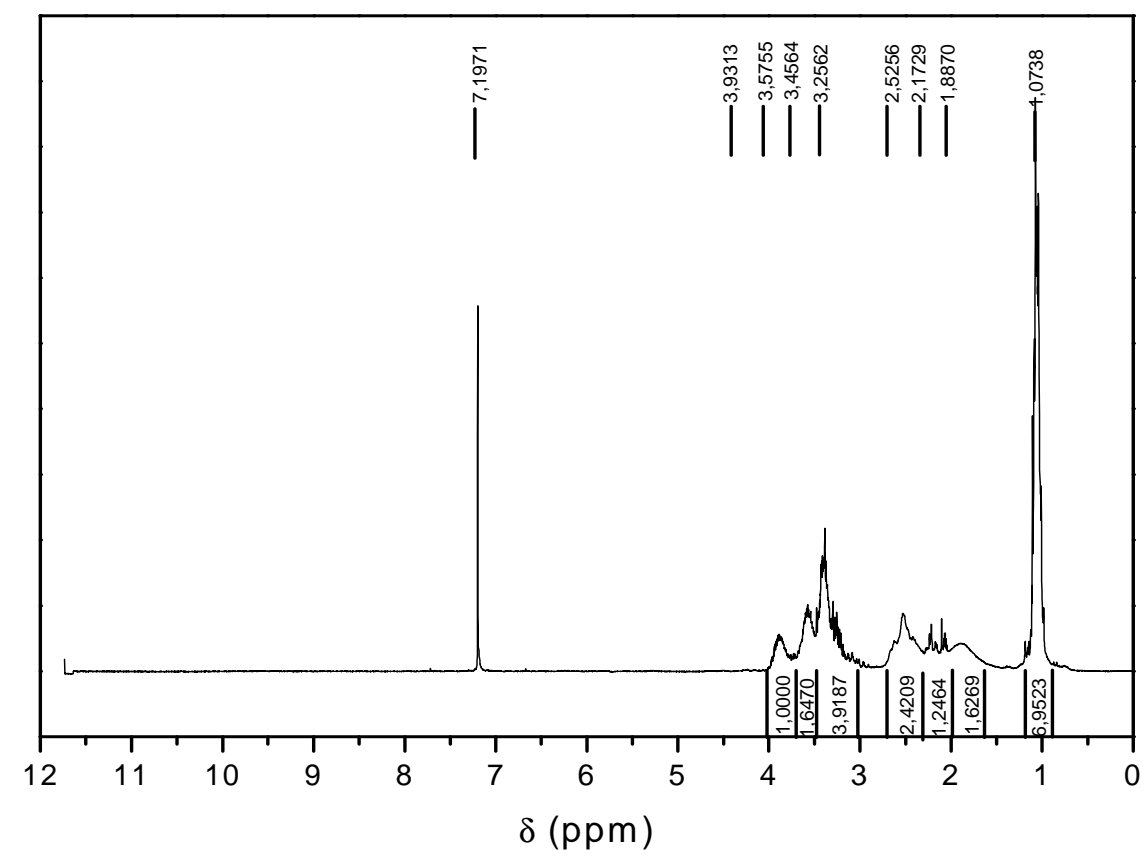

Figura 22: Figura 22 Espectro de $\mathrm{RMN} \mathrm{H}^{1}$ do homopolímero de poli (óxido propileno) extraído com $n$-hexano em soxhlet, da reação do óxido propileno e da celulose.

Através da fórmula geral do poli (óxido propileno) descrita abaixo, observa-se que a razão das integrais entre os prótons da função $\mathrm{CH}_{3}-\mathrm{C}$ e da função $\mathrm{CH}_{2}-\mathrm{O}$ e $\mathrm{CH}-\mathrm{O}$ deve ser unitária, que pode ser observado no espectro de RMN $\mathrm{H}^{1}$ mostrado na figura 22, valor esse obtido por Pavier, 1998 e Pavier e Gandini, 2000.

$$
\mathrm{HO}-\mathrm{CH}_{2}-\stackrel{\mathrm{CH}_{3}}{\mathrm{CH}}-\mathrm{O}-\mathrm{-}-\mathrm{H}
$$

Figura 23: Fórmula geral do homopolímero de poli (óxido) propileno. 
Realizou-se também a medida de uma propriedade física, temperatura de transição vítrea - $T_{g}$, do homopolímero através da técnica de calorimetria exploratória diferencial (DSC). Na figura 24, encontra-se a curva DSC do homopolímero e observa-se uma transição entre as temperaturas de -80 e $-70{ }^{0} \mathrm{C}$, a qual é atribuída a temperatura de transição vítrea, como relatado por Pavier e Gandini, 2000.

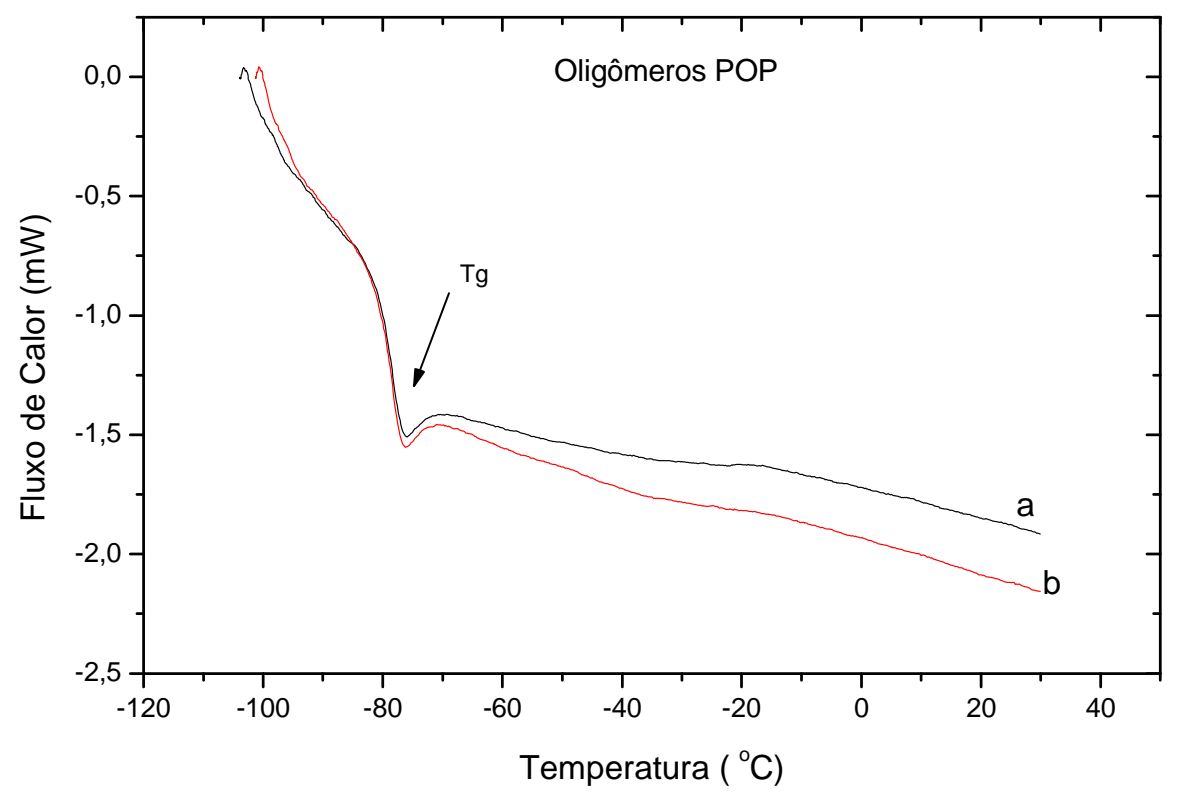

Figura 24: Curva DSC do homopolímero de poli (óxido propileno) extraído com nhexano em soxhlet, da reação do óxido propileno com a celulose: primeira corrida (a) e segunda corrida (b).

De acordo com os resultados demonstrados acima, pôde-se confirmar a presença do homopolímero gerado como produto secundário e que o processo de extração com n-hexano é válido e eficiente. 


\section{VI.2 - ANÁLISE POR ESPECTROSCOPIA NA REGIÃO DO INFRAVERMELHO}

As principais bandas observadas no espectro FTIR de fibras de celulose, em geral, são as bandas de absorção na região de 3400 a $3450 \mathrm{~cm}^{-1}$ atribuídas à presença de grupos hidroxilas $(\mathrm{OH})$, região de 2880 a $2900 \mathrm{~cm}^{-1}$ referente ao estiramento da ligação $(\mathrm{C}-\mathrm{H})$ e a banda correspondente à ligação éter localizada na região entre 1150 - $1085 \mathrm{~cm}^{-1}$ (Tasker et al.,1994).

Como a celulose foi submetida a reação com óxido de propileno (OP), demonstrado na figura 25, a análise por infravermelho fornece evidências de que a reação entre os grupos hidroxilas da celulose e o óxido de propileno ocorreu devido à presença, ausência ou aumento da intensidade dos picos referentes a alguns grupos funcionais provenientes do reagente modificador $(\mathrm{C}-\mathrm{H})$, como demonstrado para a celulose em questão, figuras 26 a 30 .

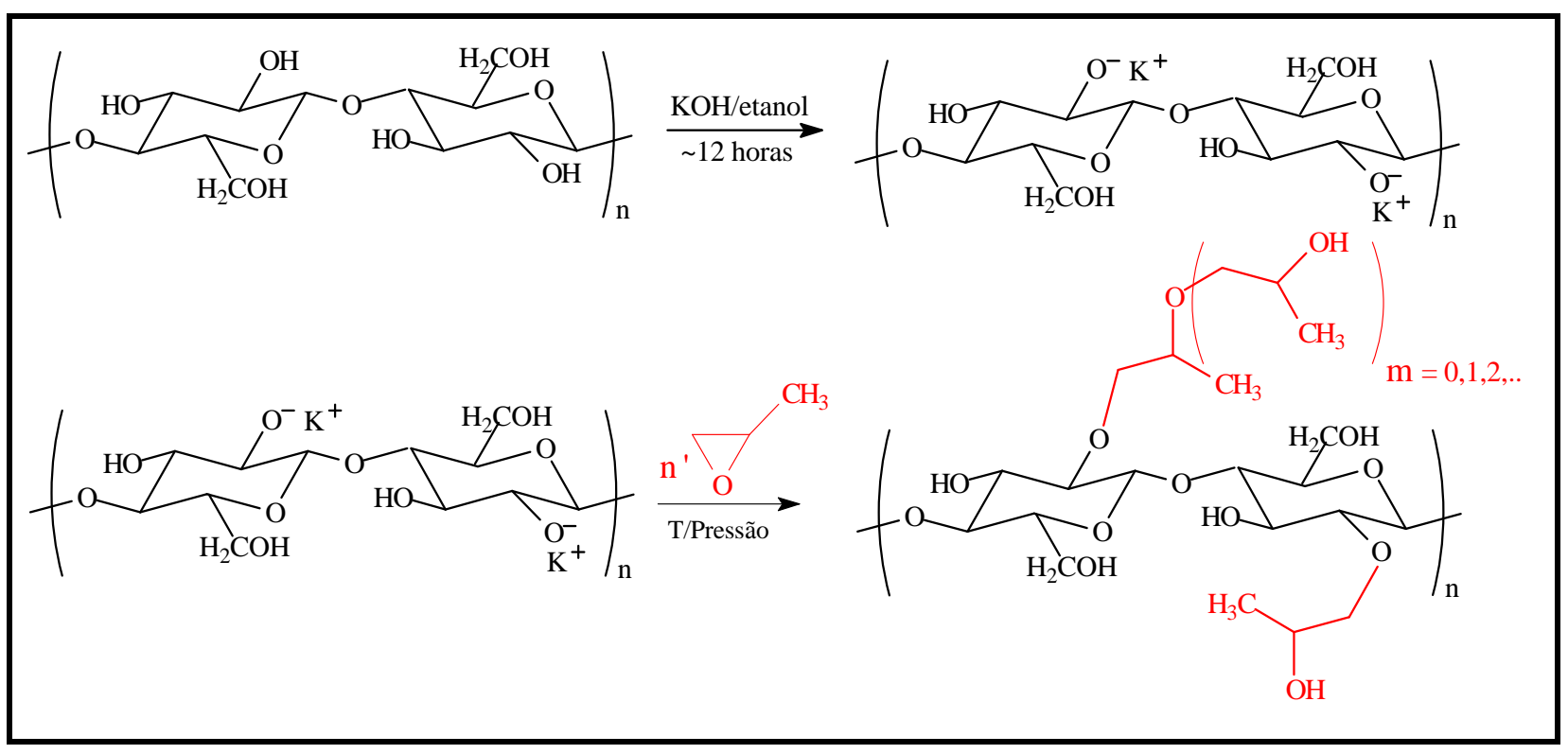

Figura 25: Esquema da reação de oxipropilação da celulose. 


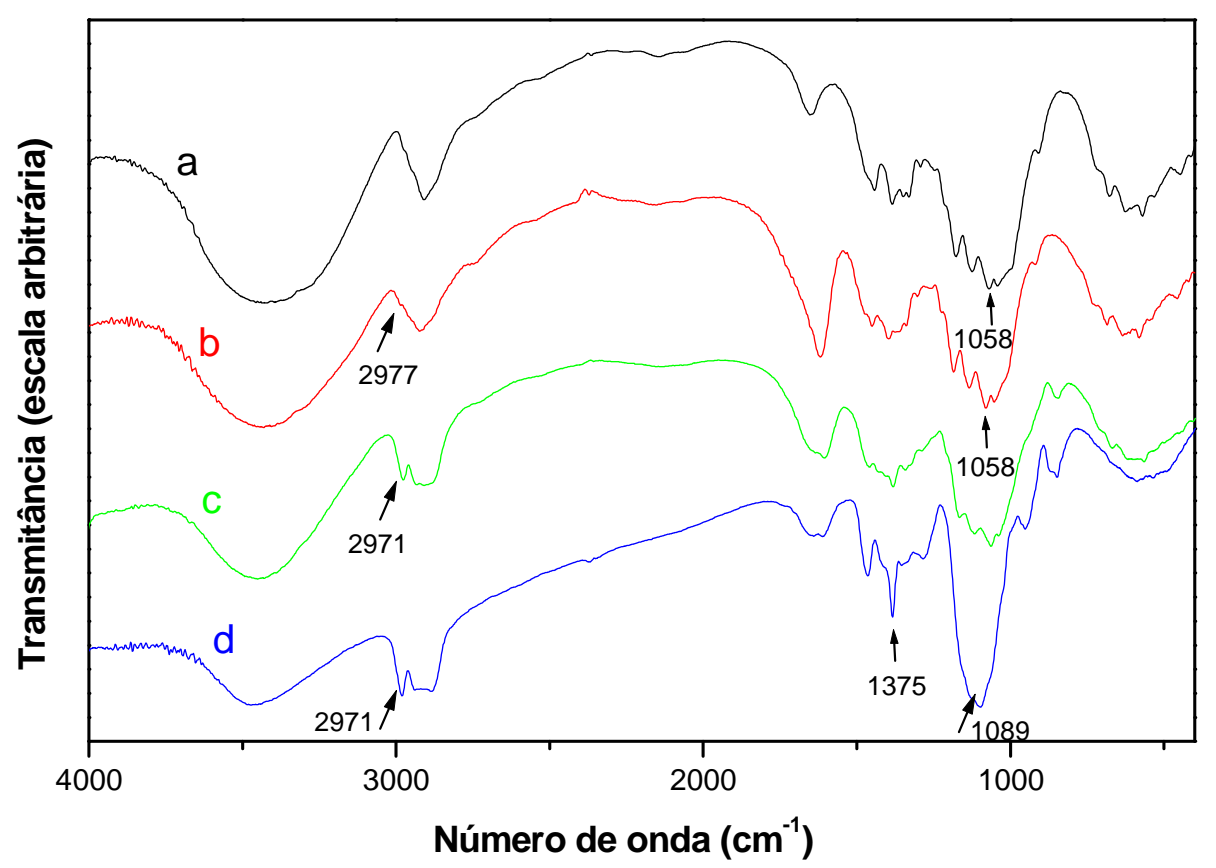

Figura 26: Espectro de FTIR (pastilha de $\mathrm{KBr}$ ) da celulose Avicel antes (a) e após a reação de oxipropilação com razões molares de [OP]/OHcel] de 1 (b), 3 (c) e 5 (d), e após extração do homopolímero de OP com $n$-hexano em soxhlet.

A análise comparativa dos espectros de infravermelho das amostras de celulose não modificada e após as reações de oxipropilação (figuras 26 e 30) revelam características relevantes do processo de modificação, tais como: aumento da absorção na região de estiramento do $\mathrm{CH}$ alifático $\left(2800-3000 \mathrm{~cm}^{-1}\right)$, com o aparecimento de um novo pico em torno de $2970 \mathrm{~cm}^{-1}$, atribuído ao grupo metila do óxido de propileno (OP) incorporado à cadeia da Celulose. Aumento e mudança na região de absorção do estiramento C-O (1000-1100 $\left.\mathrm{cm}^{-1}\right)$, associado com a função éter, proveniente da reação do óxido de propileno com as hidroxilas da celulose, e um novo pico a $1380 \mathrm{~cm}^{-1}$, confirmando a presença dos grupos $\mathrm{CH}_{3}$. A pequena alteração na absorção, devido ao estiramento $\mathrm{O}-\mathrm{H}$, justifica-se pelo esperado (e desejável) pequeno grau de substituição das celuloses oxipropiladas. 0 mesmo comportamento foi observado para o amido de milho, figura 31 . 


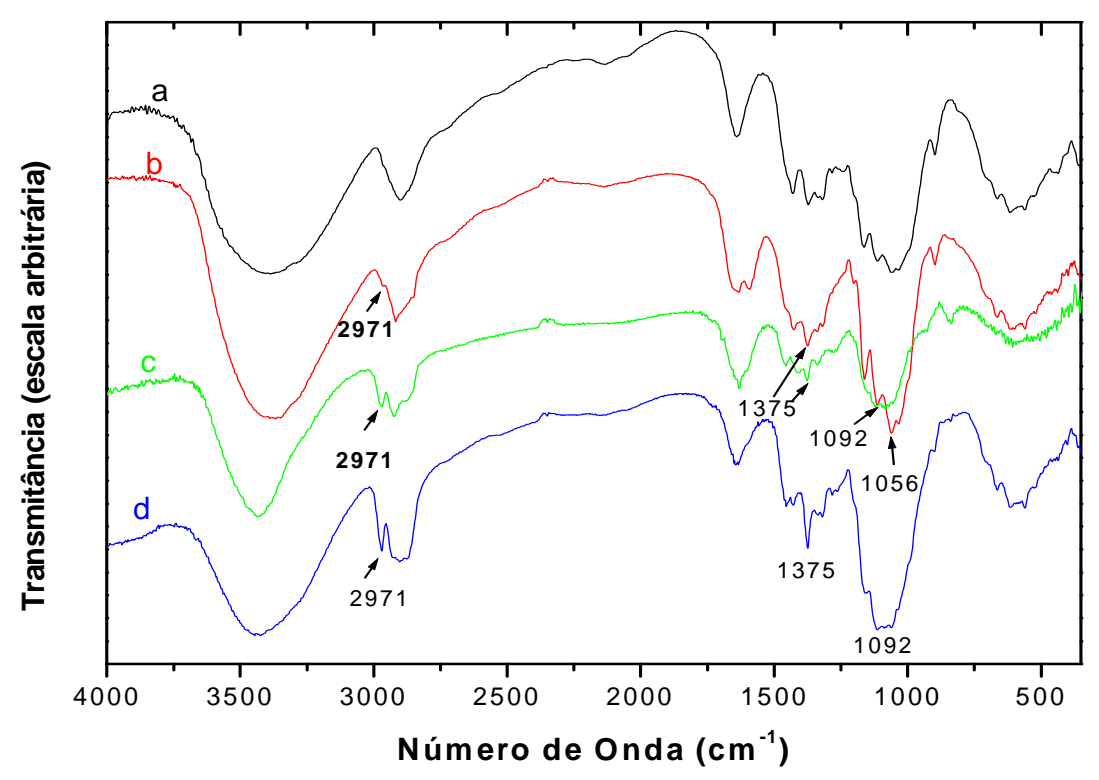

Figura 27: Espectro de FTIR (pastilha de $\mathrm{KBr}$ ) da celulose Papel Filtro/KOH (a) e após reação de oxipropilação com razões molares de [OP]/[ OH celulose] de 1 (b), 3 (c) e 5 (d), e após extração do homopolímero de OP com $n$-hexano em soxhlet.

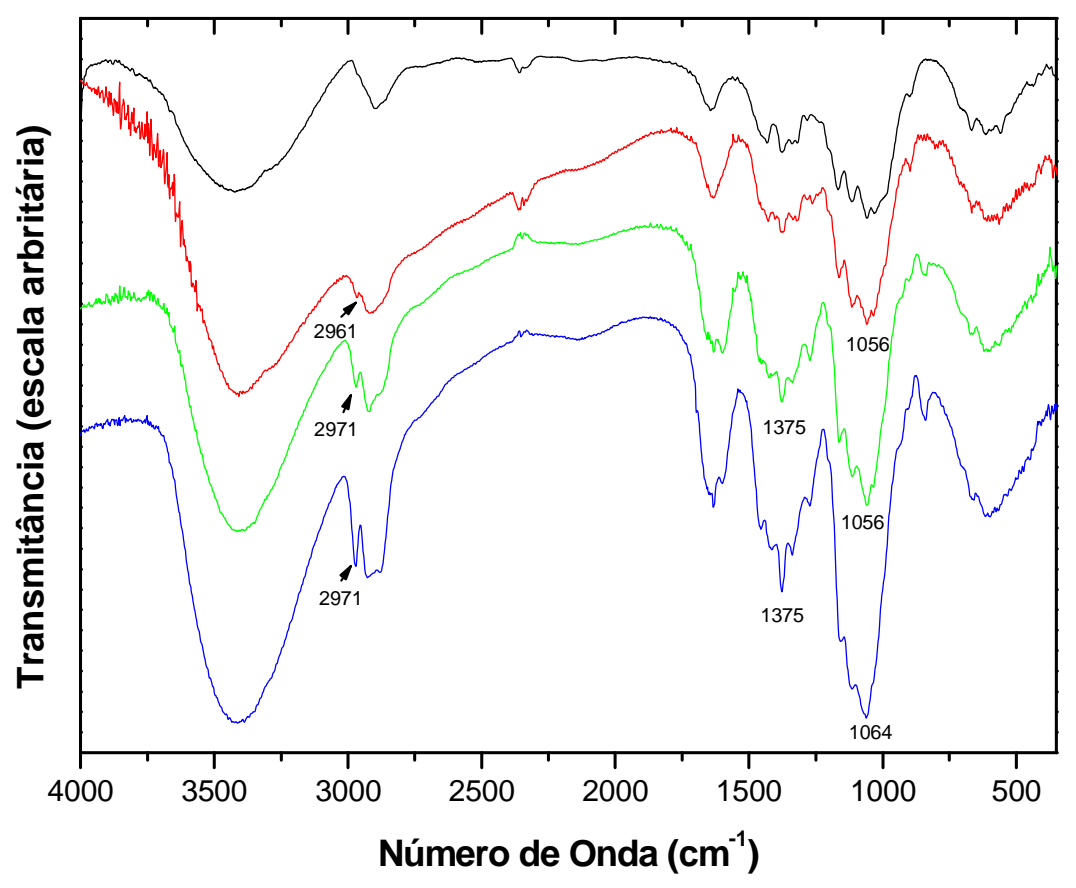

Figura 28: Espectro de FTIR (pastilha de $\mathrm{KBr}$ ) da celulose Polpa Kraft VCP (a) e após reação de oxipropilação com razões molares de [OP]/[ OH celulose] de 1 (b), 3 (c) e 5 (d), e após extração do homopolímero de OP com $n$-hexano em soxhlet. 


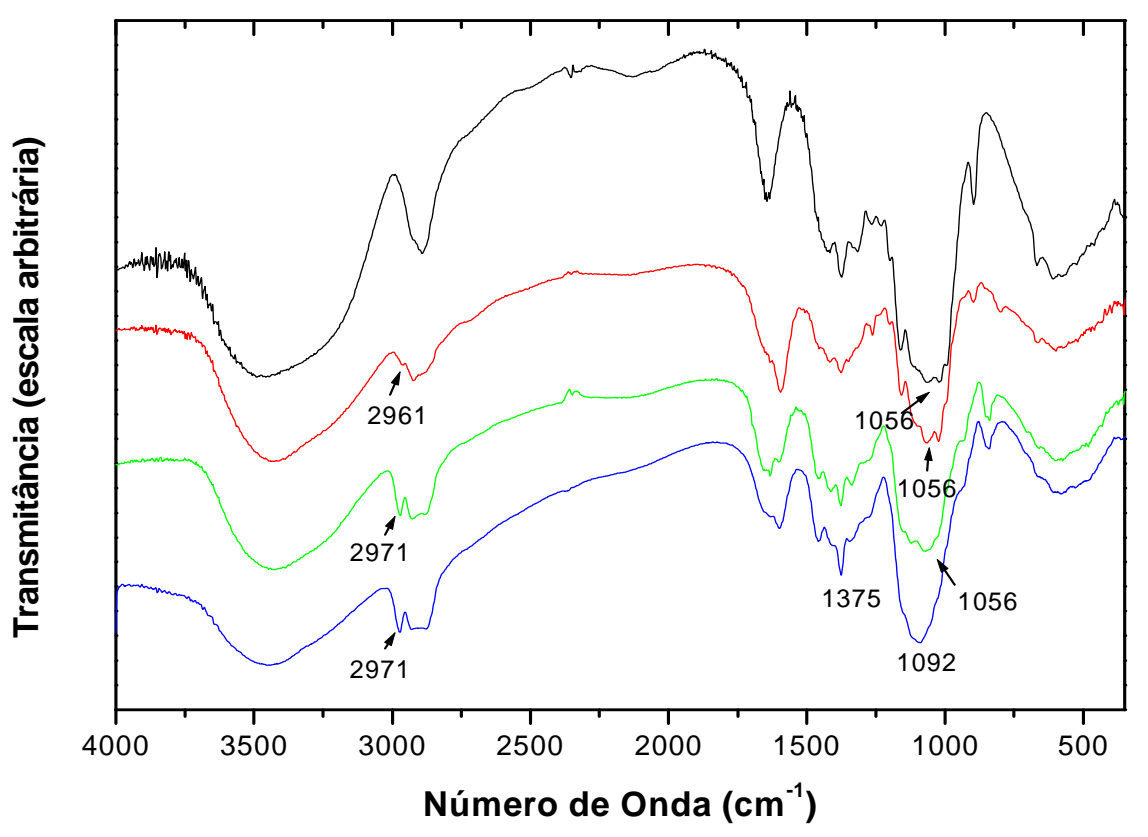

Figura 29: Espectro de FTIR (pastilha de $\mathrm{KBr}$ ) da Regenerada Rayon (a) e após reação de oxipropilação com razões molares de [OP]/[ OH celulose] de 1 (b), 3 (c) e 5 (d), e após extração do homopolímero de OP com $n$-hexano em soxhlet.

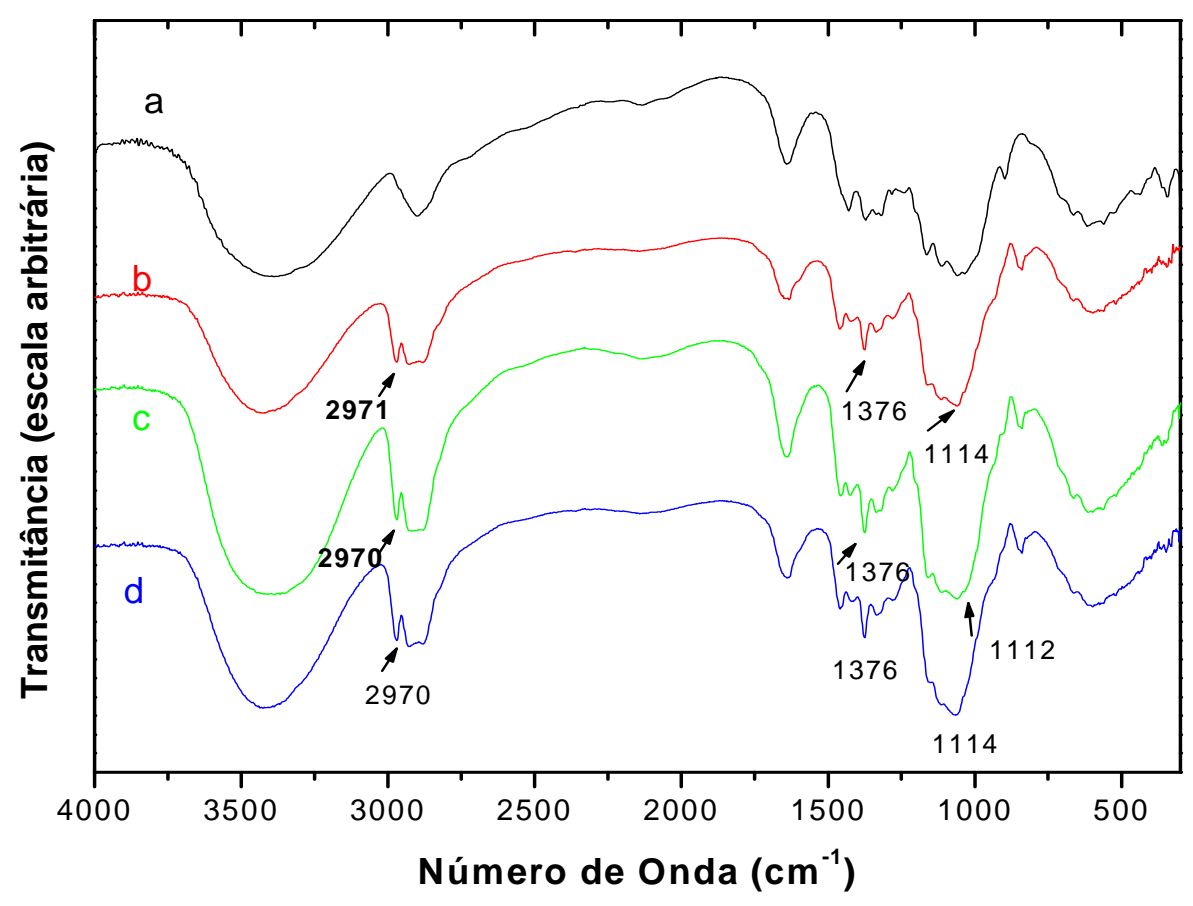

Figura 30: Espectro de FTIR (pastilha de $\mathrm{KBr}$ ) da celulose Papel Filtro/DABCO (a) e após reação de oxipropilação com razões molares de [OP]/[OH celulose] de 1 (b), 3 (c) e 5 (d), e após extração do homopolímero de OP com $n$-hexano em soxhlet. 


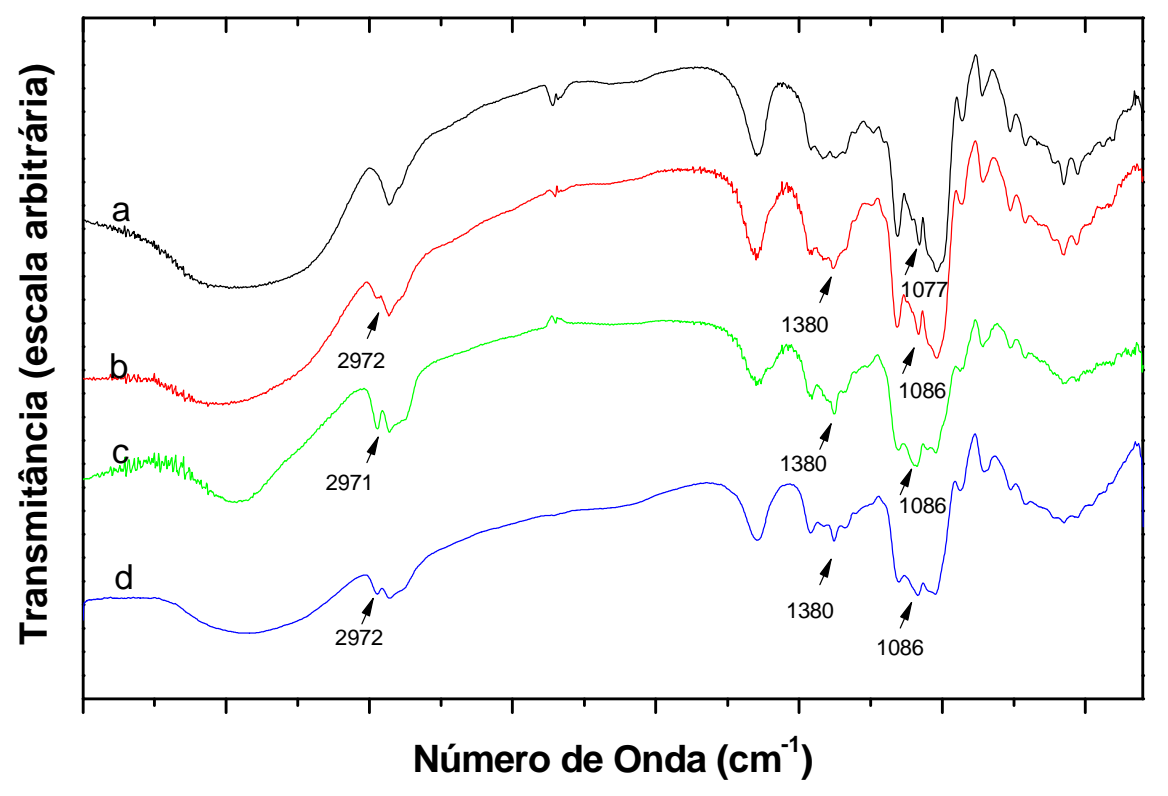

Figura 31: Espectro de FTIR (pastilha de KBr) do Amido de Milho (a) e após reação de oxipropilação com razões molares de [OP]/[OH amido] de 1 (b), 3 (c) pré-tratados com KOH e (d) pré-tratado com DABCO, e após extração do homopolímero de OP com $n$-hexano em soxhlet. 


\section{VI.3 - DIFRAÇÃO DE RAIOS X}

A análise de difração de raios -X permite avaliar as modificações ocorridas na estrutura do material quanto à cristalinidade. O fenômeno de difração de raios - X ocorre quando a matéria é irradiada com um feixe de elétrons de alta energia. Os raios difratados de diferentes planos cristalinos interagem sistematicamente entre si, fornecendo padrões que descrevem a estrutura cristalina da amostra.

De acordo com a lei de Bragg, equação 2, a posição de difração é dada pelo comprimento de onda $\lambda$ do feixe de raios-x incidente, da distância entre os planos paralelos e o ângulo $\theta$ entre o raio incidente e o plano de rede.

$$
\mathrm{n} \lambda=2 \mathrm{~d} \operatorname{sen} \theta \quad \text { equação (2) }
$$

onde $\mathrm{n}$ é a ordem de reflexão.

Para determinação do índice de cristalinidade a partir desta técnica, é necessário distinguir os sinais devido às regiões cristalinas e as porções amorfas das amostras. Na figura 32 são apresentados os difratogramas de algumas espécies de celulose (Fengel e Wegener, 1989). Pode-se observar que a principal característica que diferencia cada uma de suas formas polimórficas é a difração

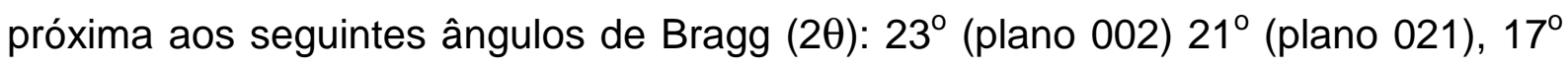
(plano 101'), $15^{\circ}$ (101), uma vez que o arranjo diferenciado das cadeias de celulose na fase cristalina reflete em mudanças acentuadas no valor de $2 \theta$. (Hermans e Weindinger, 1948, 1949 e 1951). 


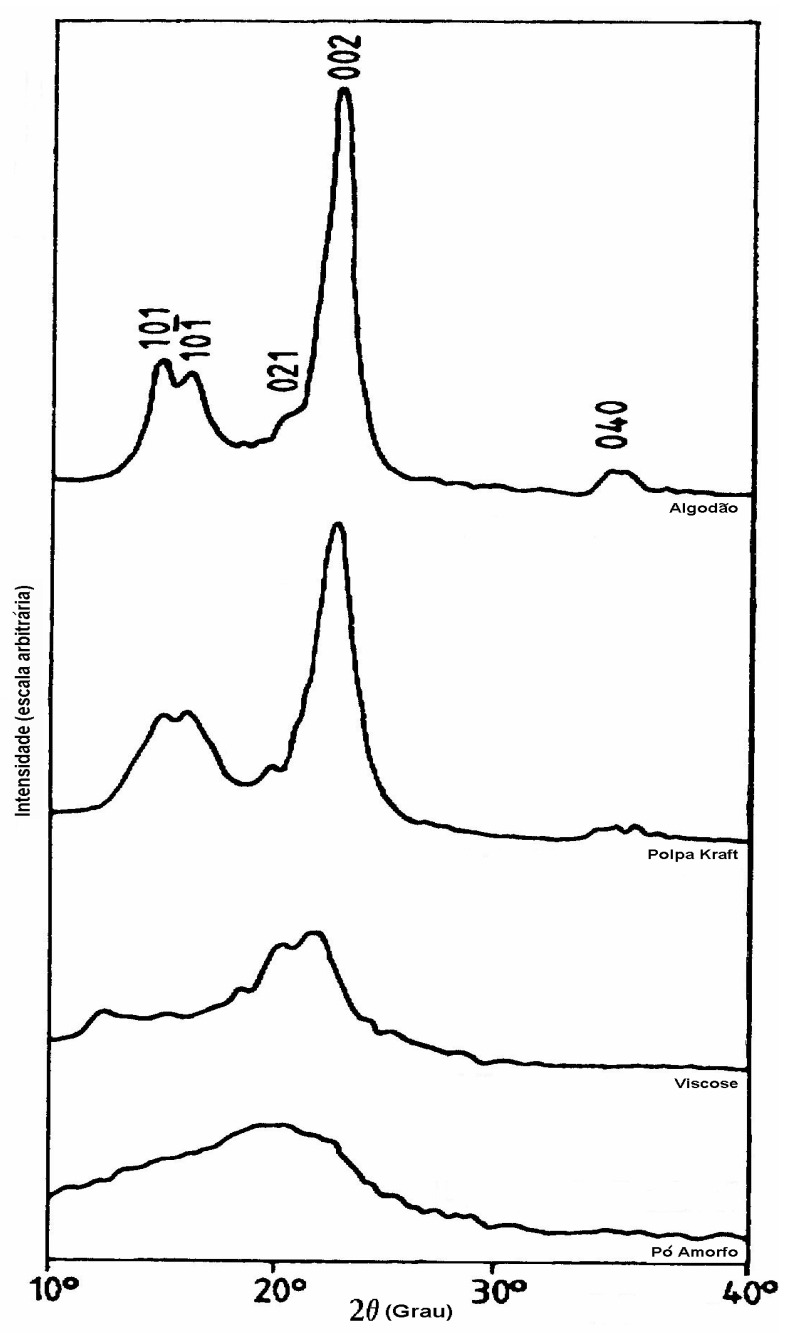

Figura 32: Representação dos difratogramas de raios x para diferentes espécies de celulose.

A partir destas definições e considerando o modelo de duas fases para o polímero (Sao et al. 1994), onde a estrutura supramolecular do polímero é considerada como um sistema de duas fases; uma fase cristalina (ordenada) e uma fase amorfa (desordenada), pôde-se estimar o índice cristalino de acordo com a equação (3), que é determinado através da relação entre os picos de intensidade máxima e mínima adjacente.

$$
I C=\left(I_{002}-I_{A M} / I_{002}\right) \times 100 \text { equação (3) }
$$


Onde; IC é o índice de cristalinidade, I $\mathrm{l}_{02}$ é a altura do pico $002\left(2 \theta=\right.$ entre 22 e $23^{\circ}$ para a celulose tipo I e entre $2 \theta=18$ e $22^{\circ}$ para celulose tipo II), que representa ambas as regiões cristalina e amorfa. IMM $_{\mathrm{A}}$ é a altura mínima, localizada entre os picos 002 e $101\left(2 \theta=18\right.$ e $19^{\circ}$ para a celulose tipo I e entre $2 \theta=13$ e $15^{\circ}$ para a celulose tipo II), representa somente a região amorfa.

A utilização desta expressão parte da hipótese de que a intensidade de difração do material amorfo em $18^{\circ}$ e $23^{\circ}$ seja igual e que a celulose cristalina não difrate em $18^{\circ}$ (Segal et al. 1959, apud Thygensen et al. 2005).

Na figura 33, têm-se os difratogramas da celulose avicel antes e após as reações de modificação de sua superfície.

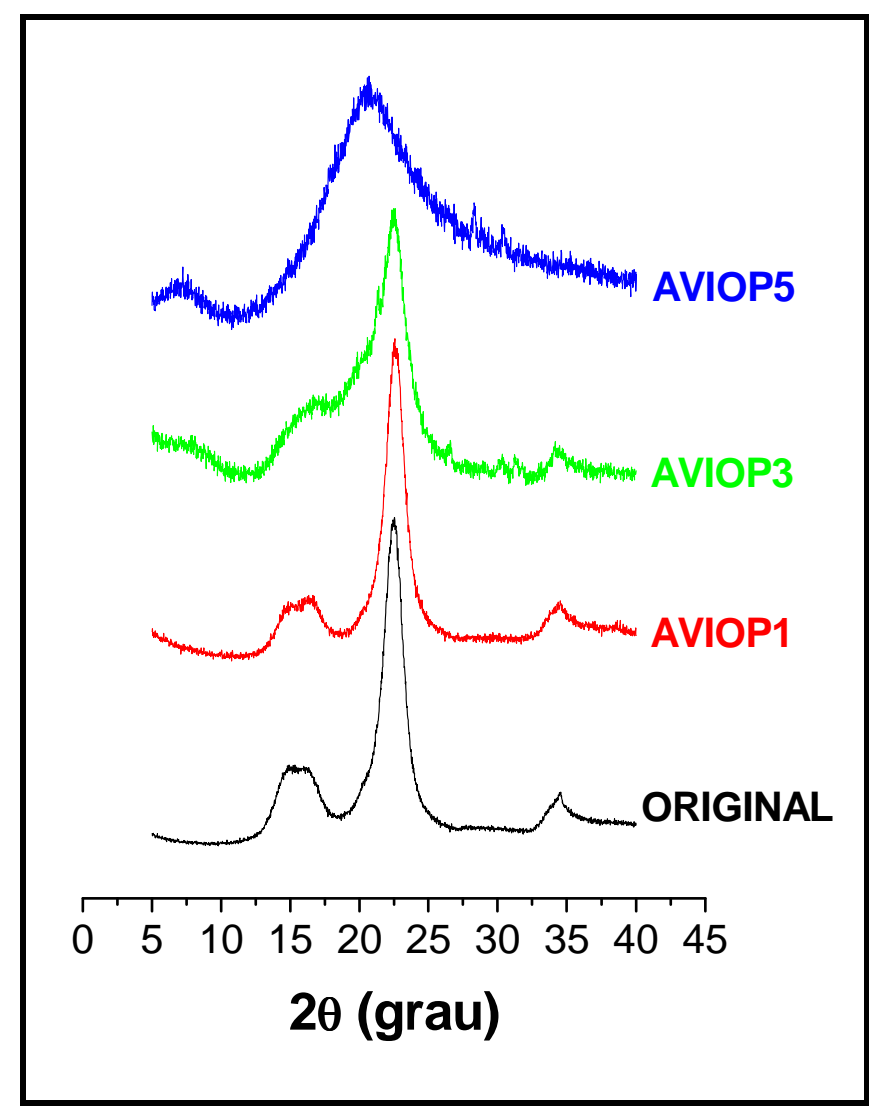

Figura 33: Difratograma de raios - X da celulose avicel microcristalina antes e após as reações de oxipropilação. 
Observa-se que o pico de maior intensidade está por volta de $23^{\circ}$. Este valor de $2 \theta$ corresponde à fração cristalina mais a fração amorfa da amostra. Nota-se também que a região por volta de $18^{\circ}$, correspondente somente à região amorfa, é de baixa intensidade quando comparado com o pico em torno de $23^{\circ}$, indicando que a celulose avicel possui alto índice de cristalinidade. O valor obtido através da equação (3) para amostra original foi de $92 \%$.

Para a celulose avicel modificada na proporção [OP]/[OHcel] igual a 1, observa-se um perfil semelhante a amostra original com índice de cristalinidade estimado foi de aproximadamente $92 \%$, indicando que nessas condições as regiões cristalinas não foram afetadas, resultado este desejado uma vez que as regiões cristalinas tem influência marcante nas propriedades mecânicas dos materiais compósitos. Para a amostra modificada na proporção [OP]/[OHcel] 3 observa-se mudança considerável no perfil do difratograma e um decréscimo significativo no índice de cristalinidade, $74 \%$.

Deve-se ressaltar que a amostra modificada na proporção [OP]/[OHcel] igual a 5, apresentou alargamento acentuado na região característica a fase cristalina, indicando que a reação nessa proporção induz um caráter amorfo significativo à amostra em conseqüência da desestruturação de uma fração considerável da fase cristalina atacada durante a reação, apresentando índice de cristalinidade de $28 \%$. Os valores de ângulo do plano de difração e de índice cristalino, das amostras em questão, são apresentados na Tabela 3 e os seus respectivos difratogramas de raios - X sobrepostos nas figuras 34 a 37. 
Tabela 3: Valores de ângulo de difração e índice de cristalinidade das amostras de celulose.

$2 \Theta(\mathrm{Grau}) \quad$ ÍNDICE DE

\begin{tabular}{cccc} 
AMOSTRAS & Máximo & Mínimo & CRISTALINIDADE (\%) \\
\hline AVI & 22,6 & 18,4 & 92 \\
AVOP1 & 22,6 & 18,4 & 92 \\
AVOP3 & 22,5 & 17,9 & 74 \\
AVOP5 & 22,5 & 18,0 & 28 \\
PF & 22,7 & 18,8 & 85 \\
PFOP1/KOH & 22,5 & 18,3 & 85 \\
PFOP3/KOH & 22,5 & 18,4 & 80 \\
PFOP5/KOH & 22,5 & 18,1 & 25 \\
PKVCP & 22,9 & 18,8 & 84 \\
PKVOP1 & 22,9 & 18,6 & 76 \\
PKVOP3 & 22,9 & 18,3 & 78 \\
PKVOP5 & 22,6 & 17,5 & 61 \\
CRR & 21,6 & 14,0 & 90 \\
CRROP1 & 22,0 & 14,2 & 83 \\
CRROP3 & 22,0 & 14,9 & 75 \\
CRROP5 & 22,0 & 14,9 & 70 \\
PFOP1/DABCO & 22,7 & 18,3 & 18,1 \\
PFOP3/DABCO & 22,3 & 17,9 & \\
PFOP5/DABCO & 22,1 & \\
\hline
\end{tabular}




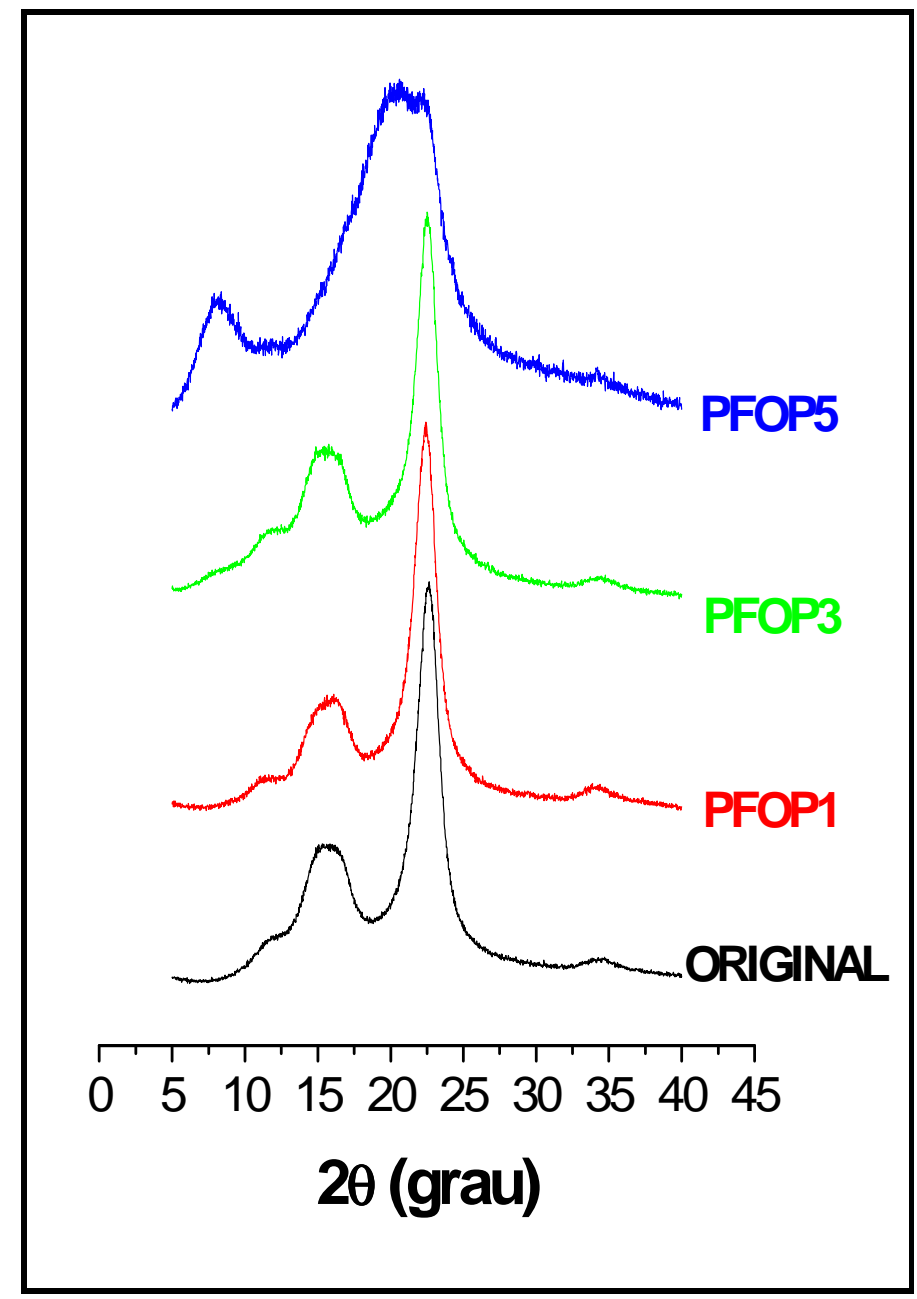

Figura 34: Difratogramas de raios - $X$ sobrepostos da celulose Papel Filtro antes e após reações de oxipropilação pré-tratadas com $\mathrm{KOH}$. 


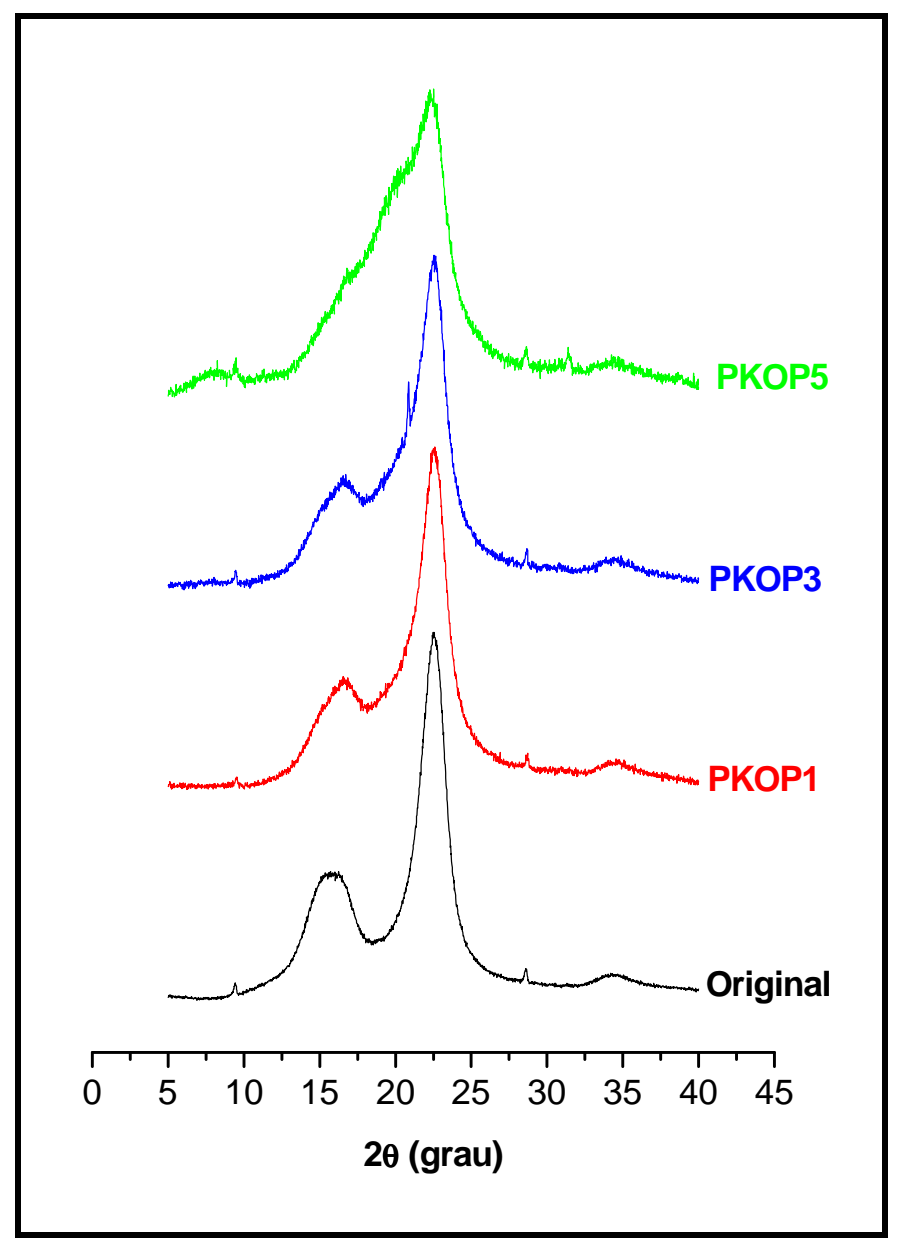

Figura 35: Difratogramas de raios - X sobrepostos da celulose Polpa Kraft VCP antes e após reações de oxipropilação pré-tratadas com $\mathrm{KOH}$. 


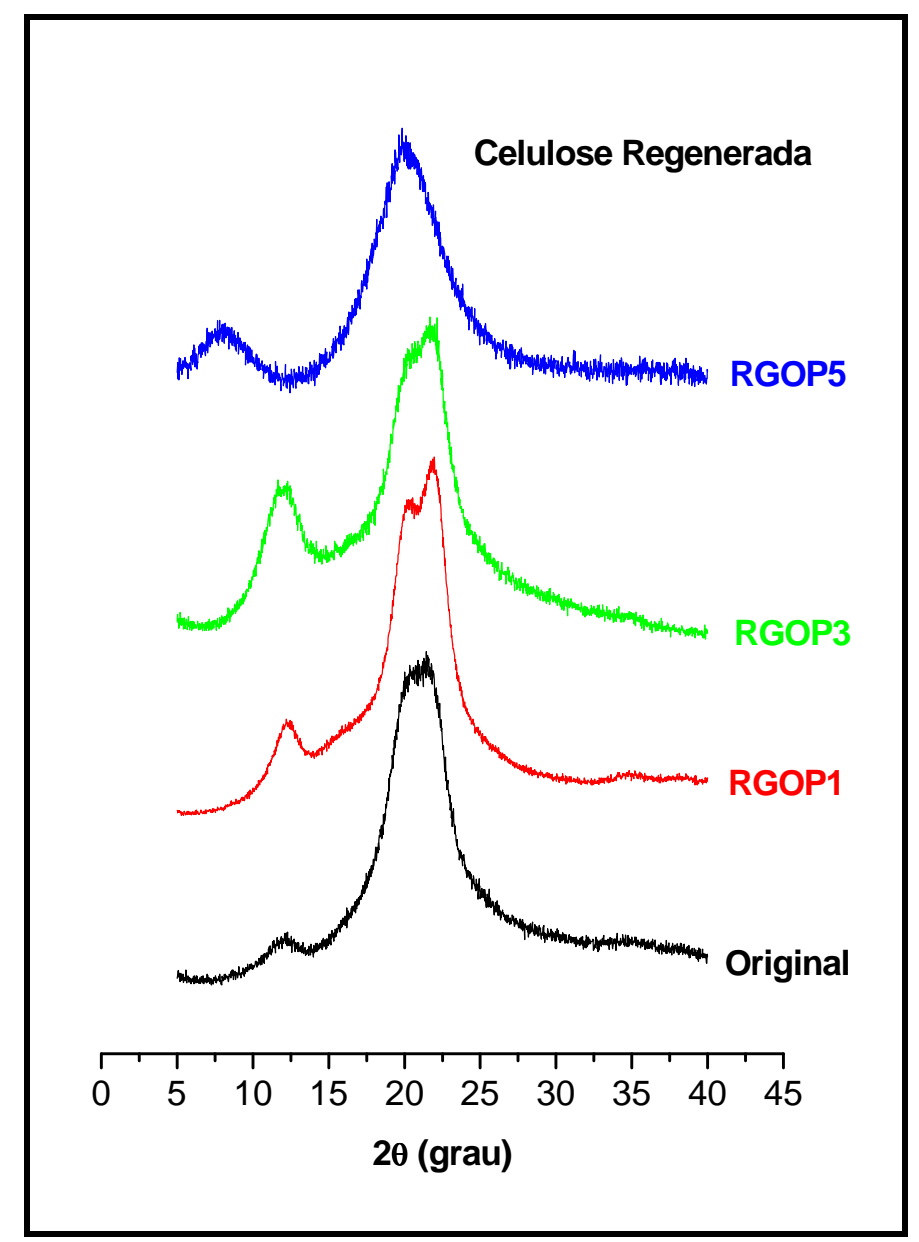

Figura 36: Difratogramas de raios - X sobrepostos da celulose Regenerada Rayon antes e após reações de oxipropilação pré-tratadas com $\mathrm{KOH}$. 


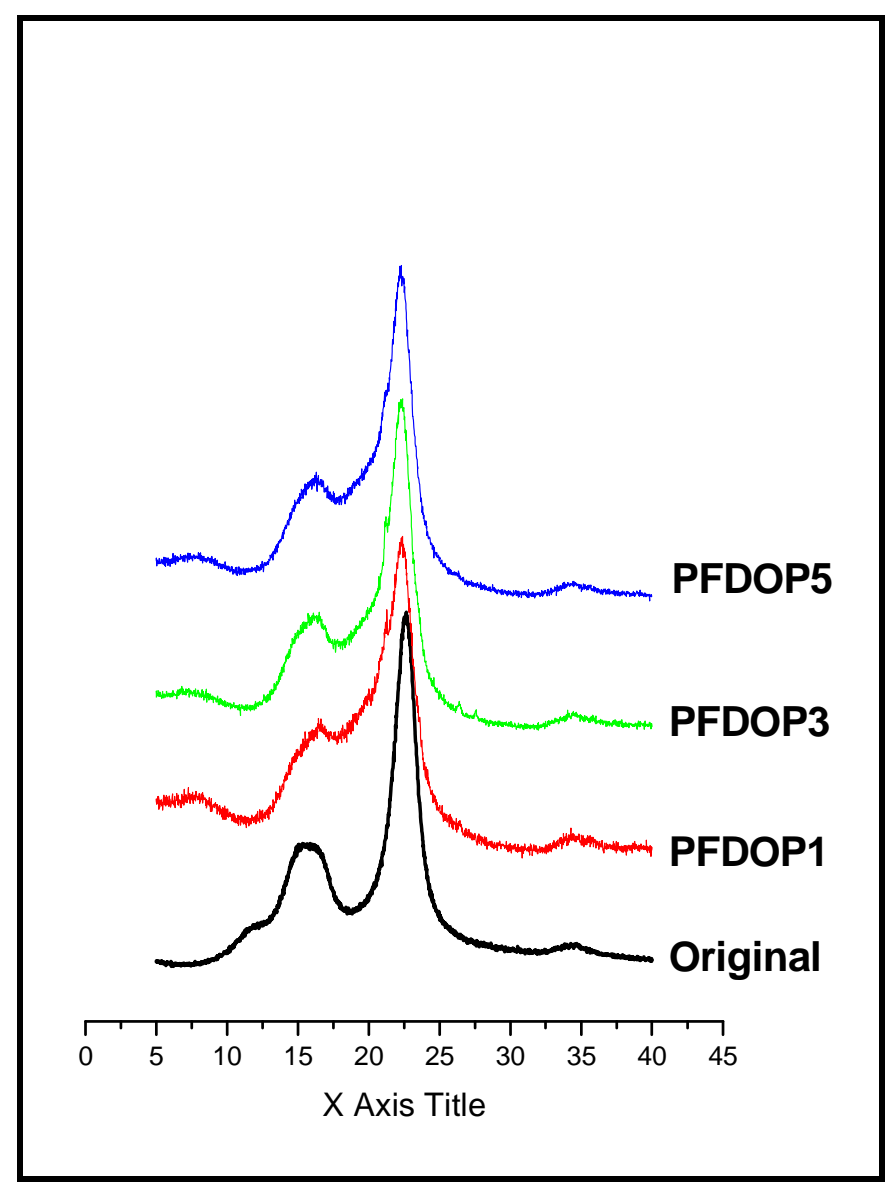

Figura 37: Difratogramas de raios - $X$ sobrepostos da celulose Papel Filtro antes e após reações de oxipropilação pré-tratadas com DABCO.

Como observado através dos dados apresentados na tabela 3 e das figuras 33 a 37, a reação de oxipropilação causa mudanças significativas na estrutura cristalina das celuloses em questão e espera-se que estes resultados sejam corroborados através das micrografias que serão apresentadas adiante. Com relação ao papel filtro pré-trado com $\mathrm{KOH}$ e $\mathrm{DABCO}$, ambos com razão molar igual a 5, observa-se que a amostra pré-tratada com $\mathrm{KOH}$ apresentou maior decréscimo no índice de cristalinidade (de $85 \%$ para $25 \%$ ) em relação a celulose pré-tratada com DABCO (de 85\% para 70\%), resultado esse atribuído ao tipo de base utilizada. Embora, deva-se ressaltar que para as amostras com razão molar 1 e 3 os resultados obtidos com $\mathrm{KOH}$ e DABCO foram semelhantes. É sabido que o $\mathrm{KOH}$ 
(base de bronsted) é uma base forte, portanto pouco seletiva, e o $\mathrm{OH}^{-}$atua também como nucleófilo podendo esse no momento da reação contribuir com a destruição da fase cristalina. Acredita-se que esse processo não ocorra quando o DABCO (base de Lewis) foi utilizado, pelo fato da mesma ser uma base fraca e também por apresentar uma estrutura volumosa, desfavorecendo sua penetração/difusão na fase cristalina. A estrutura do DABCO é apresentada na figura 38 e na figura 39 é apresentado o gráfico de índice de cristalinidade (IC) em função da razão molar utilizada, para melhor visualização dos dados apresentados na tabela 3.

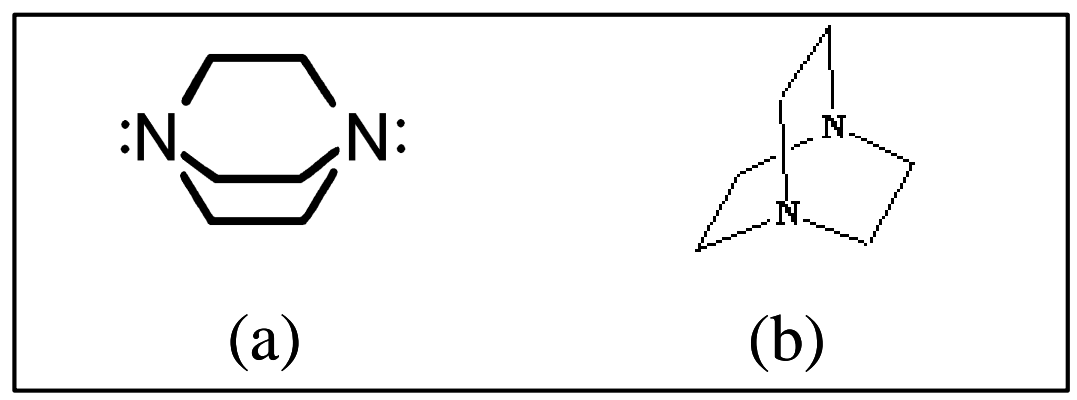

Figura 38: Estrutura química do DABCO no plano (a) e no espaço (b).

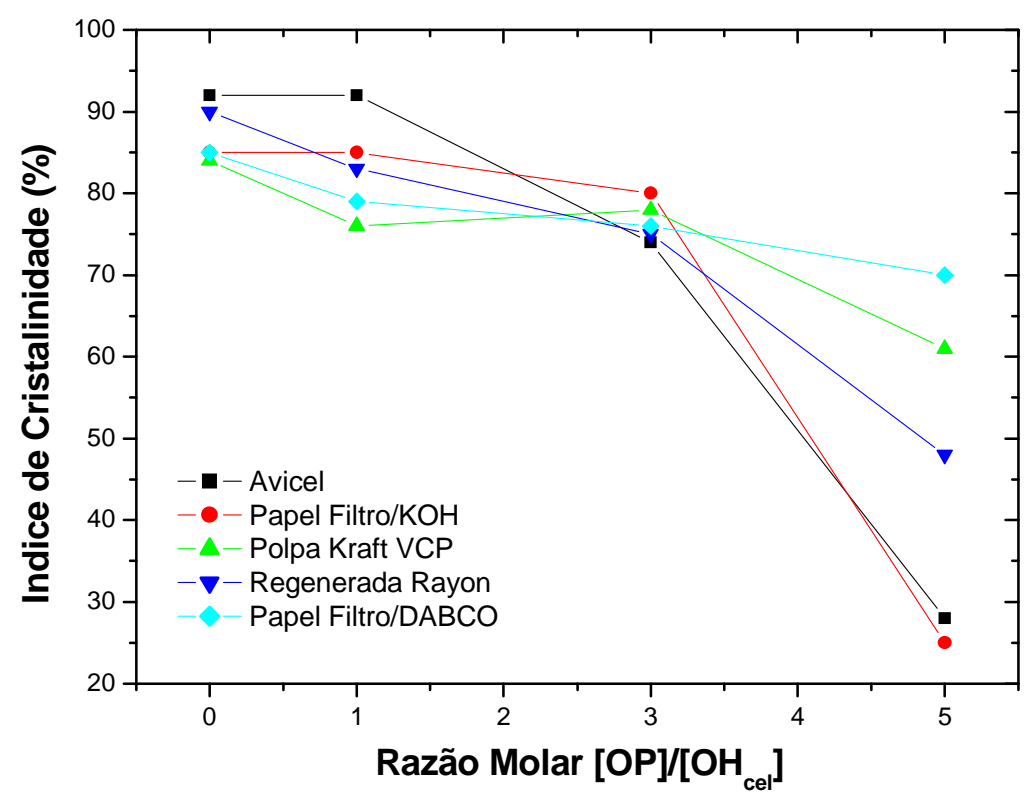

Figura 39: Gráfico de índice de cristalinidade (IC) em função da razão molar (RM). 
O índice de cristalinidade para o amido foi estimado através da razão entre o pico de difração a $17^{\circ}$ e a linha base dos difratogramas (Hulleman, 1999). O valor de índice de cristalinidade foi estimado apenas para a amostra original $(30,6 \%)$ e para a amostra modificada com razão molar igual a $1(16,4 \%)$. Nota-se decréscimo de aproximadamente $50 \%$ do valor inicial, indicando que ocorreu desestruturação dos grânulos de amido, tornando-o mais amorfo. Na figura 40 são apresentados os difratogramas de raios-X das amostras de amido antes e após a reação de oxipropilação.

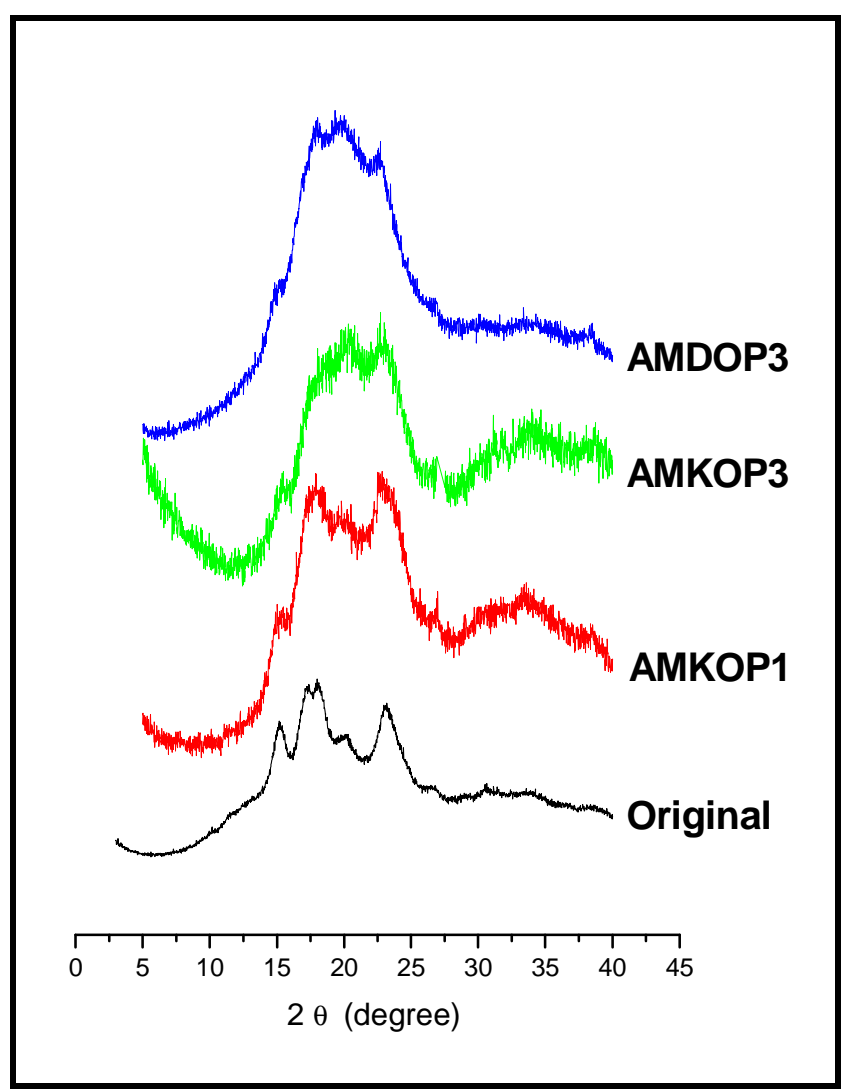

Figura 40: Difratogramas de raios - X sobrepostos do Amido de Milho antes e após reações de oxipropilação. 


\section{VI.4 - MICROSCOPIA ELETRÔNICA DE VARREDURA (MEV)}

Realizou-se análise de microscopia eletrônica de varredura com o intuito de avaliar a morfologia dos materiais obtidos. Nas figuras 41 e 42 são apresentadas as micrografias da celulose Avicel antes e após as reações de modificação.

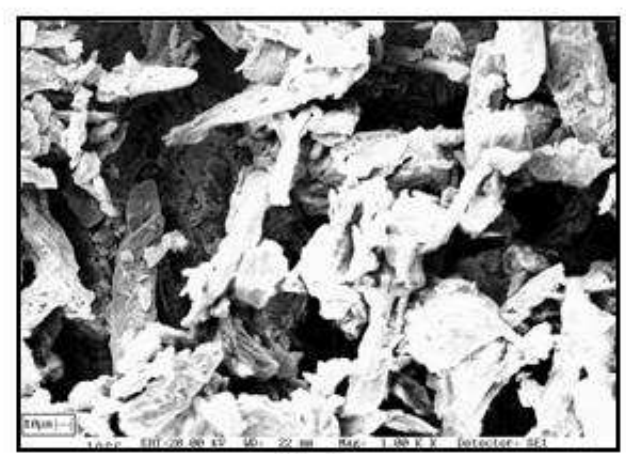

(a)

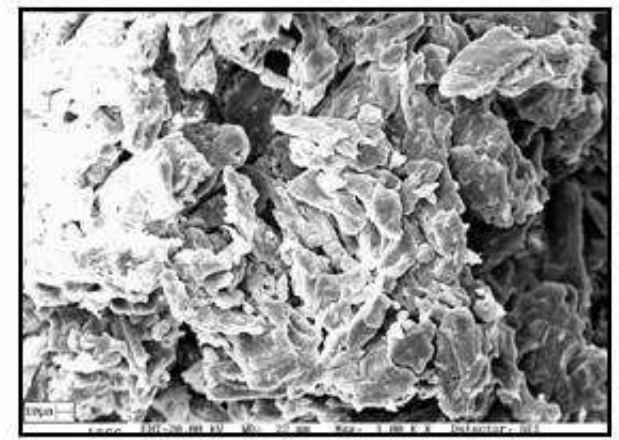

(c)

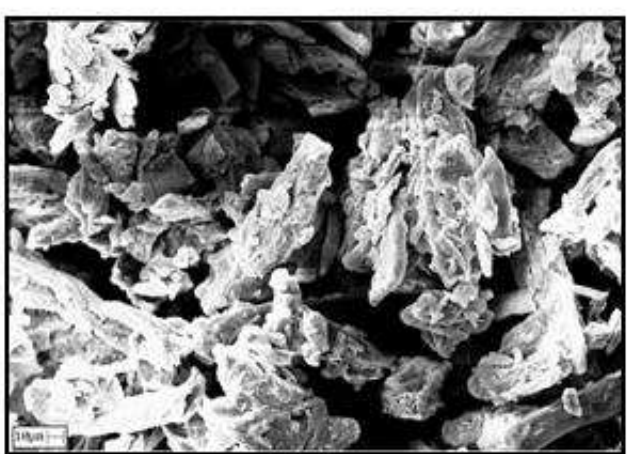

(b)

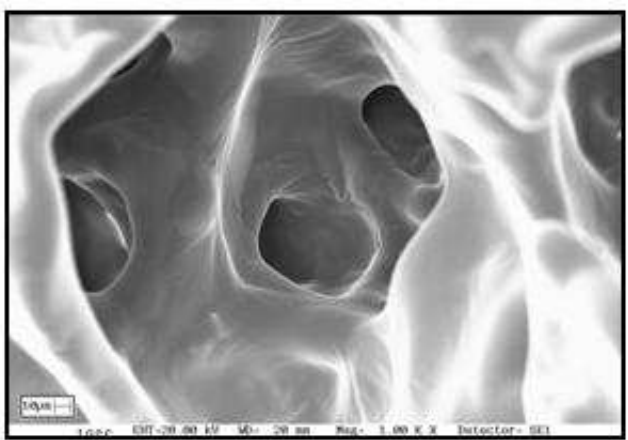

(d)

Figura 41: Micrografias da celulose Avicel não modificada (a), modificada com razão molar igual a 1 (b), 3 (c) e 5 (d), com ampliação de 1000 X. 


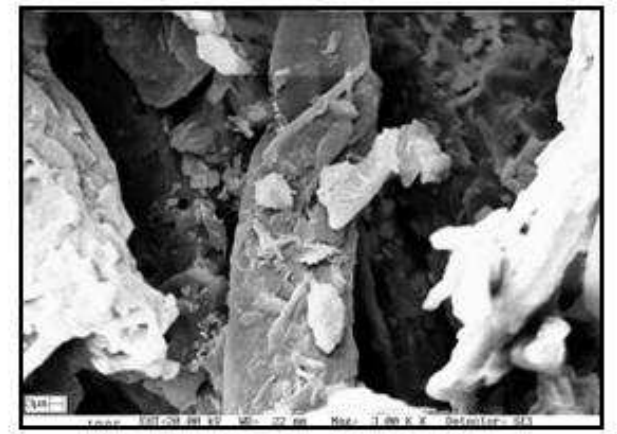

(a)

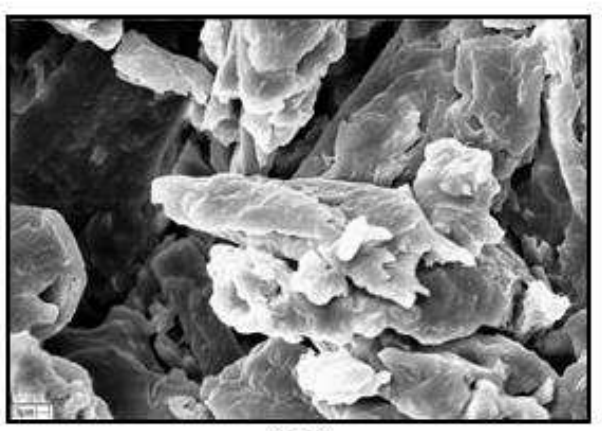

(c)

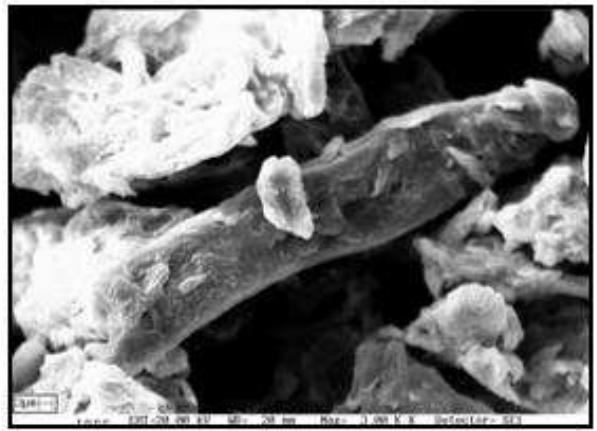

(b)

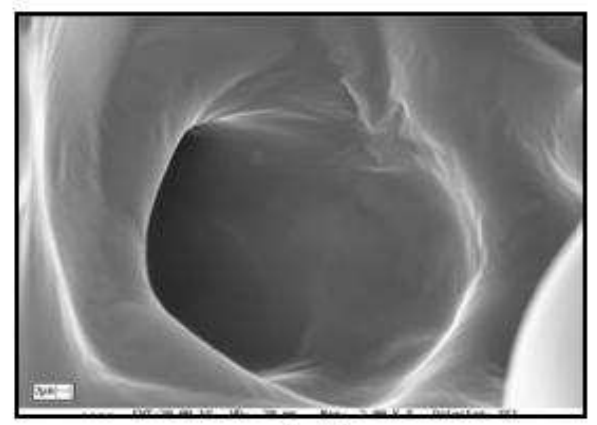

(d)

Figura 42: Micrografias da celulose Avicel não modificada (a), modificada com razão molar igual a 1 (b), 3 (c) e 5 (d), com ampliação de 3000 X.

Nota-se que o material após a modificação com razão molar [OP]/[OH cel] 1 apresenta uma leve camada termoplástica em sua superfície, corroborando com os dados de raios $-X$ de que a reação ocorreu na superfície, não agredindo a fase cristalina . Já para o material modificado com razão molar igual a 3 e 5, com decréscimo de 19.6 e $69.6 \%$, respectivamente, indicativo de que a reação ocorreu de forma considerável, tanto na fase amorfa quanto na fase cristalina, sendo mais pronunciado para a amostra com razão molar igual a 5. Na figura 43, micrografia da celulose Avicel com razão molar de [OP]/[ OHcel] igual a 5 e com aumento de $200 X$ e 500 X, observa-se que a reação foi bem efetiva, entretanto, a característica de particulado (pó) desse tipo de celulose não foi totalmente alterada. 

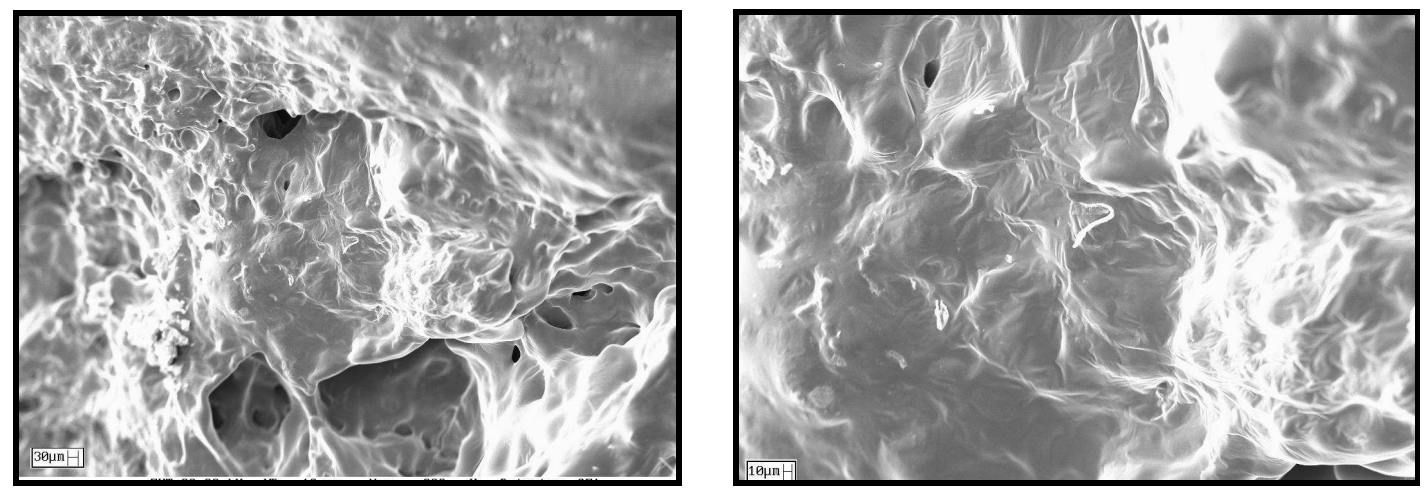

Figura 43: Micrografias da celulose Avicel com razão molar de [OP]/[OHcel] igual a 5 e com aumento $200 \times$ (a) e 500 X (b).

É importante observar que nas figuras $41 d$ e $42 d$ a presença de buracos, entretanto, nota-se que nas figuras $43 a$ e $43 b$ a presença destes é mínima. Após a termo-prensagem, figura 44, pode ser observada a ausência dos buracos, dando indícios de propriedade de fluidez do material quando submetido a pressão em uma dada temperatura.

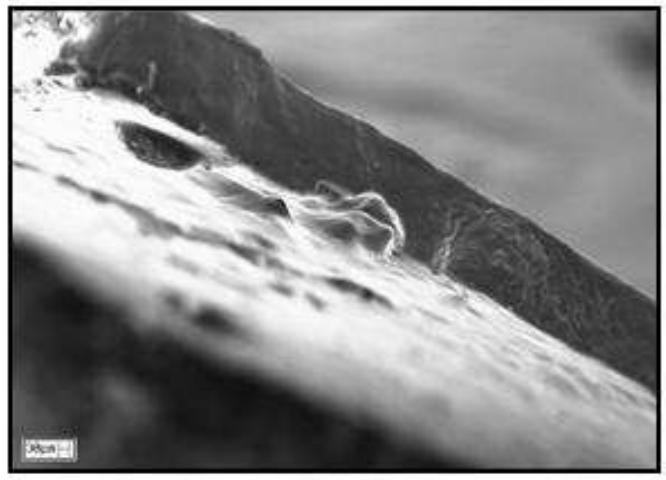

(a)

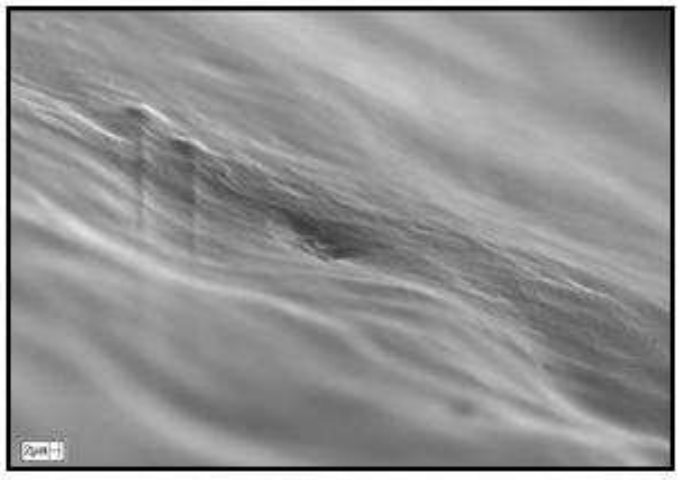

(b)

Figura 44: Micrografias da celulose Avicel com razão molar de [OP]/[ OHcel] igual a 5 em forma de filme e com aumento 200 X (a) e 3000 X (b). 
Nas figuras abaixo são apresentadas as micrografias para a celulose Papel Filtro antes da reação de oxipropilação e após a reação de oxipropilação prétratadas com $\mathrm{KOH}$.

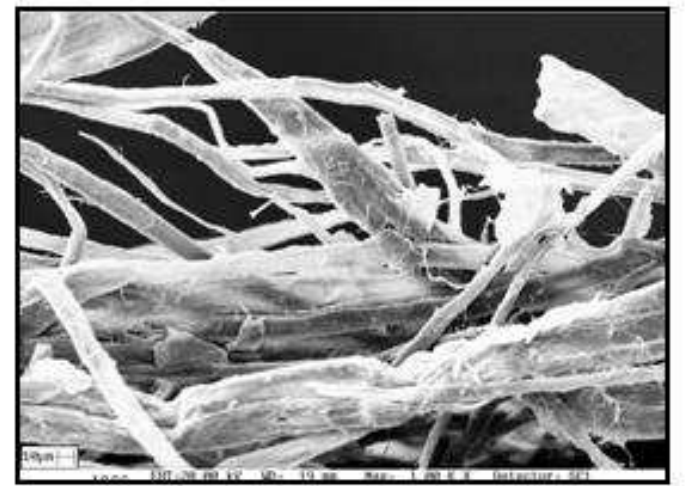

(a)

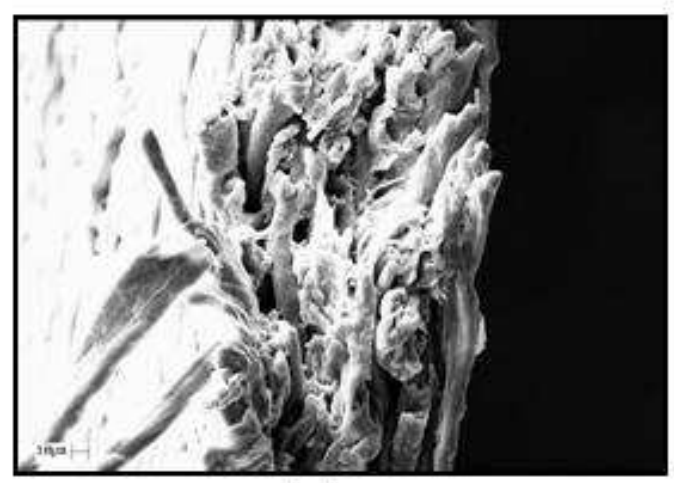

(c)

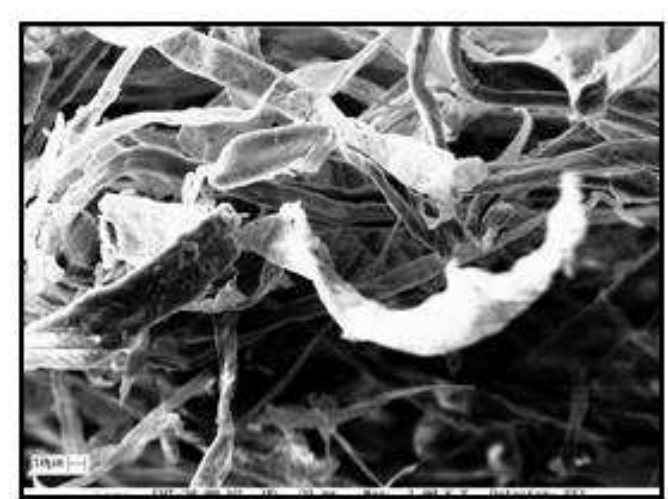

(b)

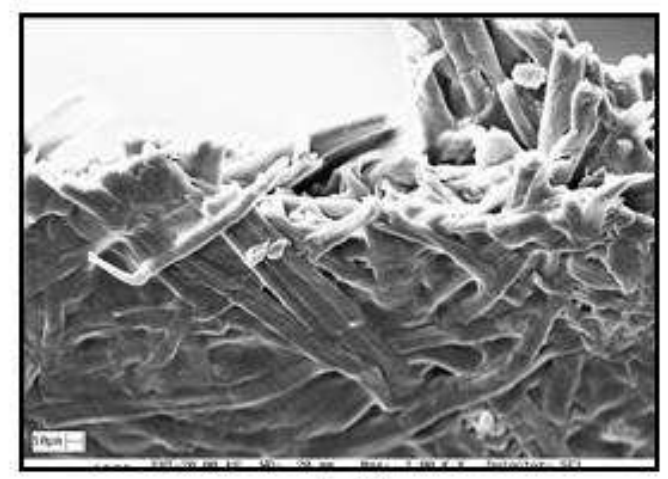

(d)

Figura 45: Micrografias da celulose Papel Filtro/KOH não modificada (a), modificada com razão molar igual a 1 (b), 3 (c) e 5 (d), com ampliação de 1000 X. 


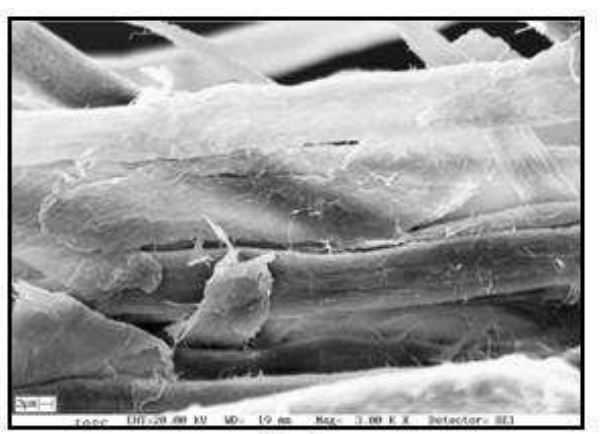

(a)

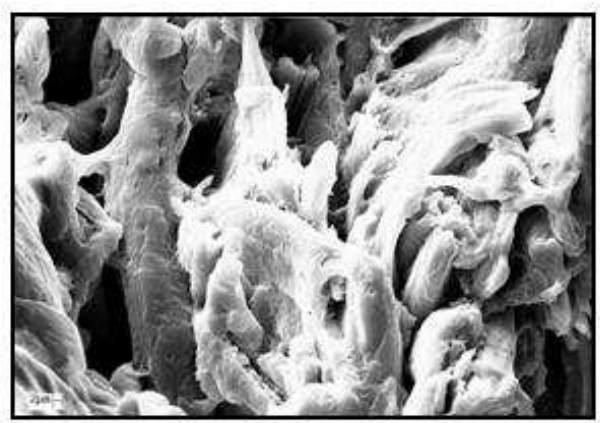

(c)

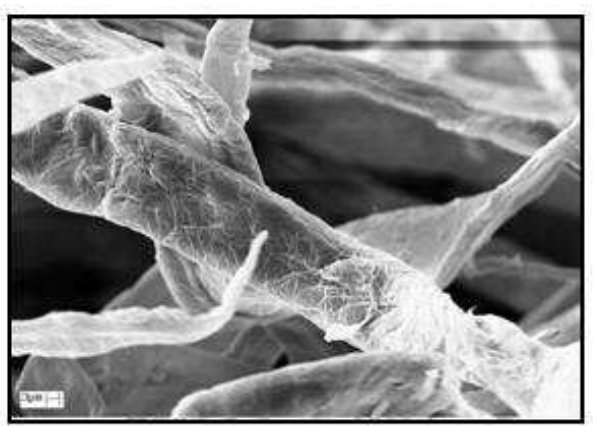

(b)

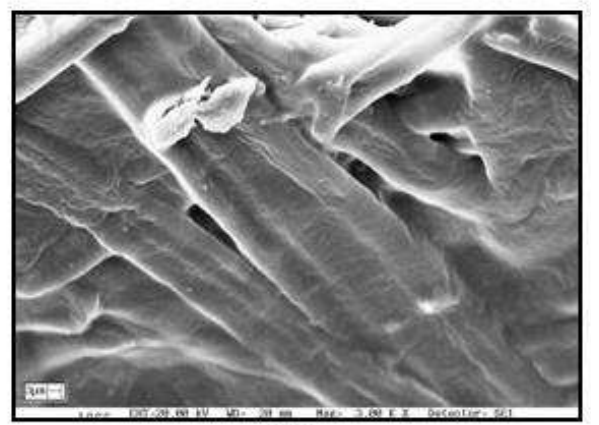

(d)

Figura 46: Micrografias da celulose Papel Filtro/KOH não modificada (a), modificada com razão molar igual a 1 (b), 3 (c) e 5 (d), com ampliação de 3000 X.

Para a celulose de papel filtro pré-tratadas com $\mathrm{KOH}$, figuras 45 e 46, observa-se que a característica fibrilar é conservada nas amostras modificadas, resultado esse desejado, uma vez que se espera que as fibras atuem como reforço no material compósito. A presença de uma camada superficial, proveniente do óxido de propileno, que as envolve proporcionando um caráter termoplástico é observável nas amostras modificadas com molar $[\mathrm{OP}] /[\mathrm{OH}$ celulose] igual a 3 e 5 . Em relação à comparação com os dados de raios - X, observa-se comportamento semelhante ao da celulose Avicel.

Nas figuras 47 e 48 são apresentadas as micrografias para a celulose Polpa Kraft VCP antes reação de oxipropilação e após a reação de oxipropilação prétratadas com $\mathrm{KOH}$. 


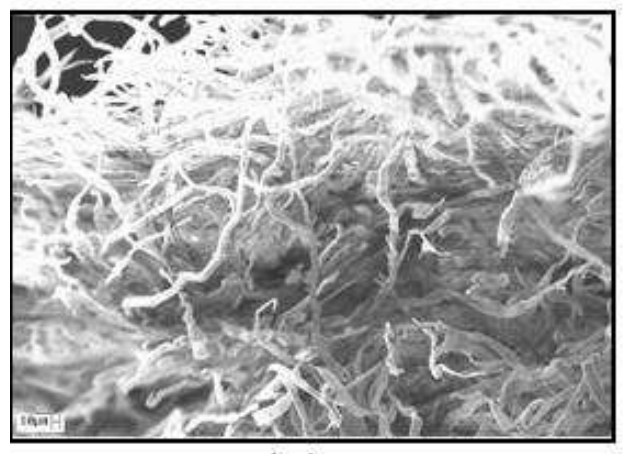

(a)

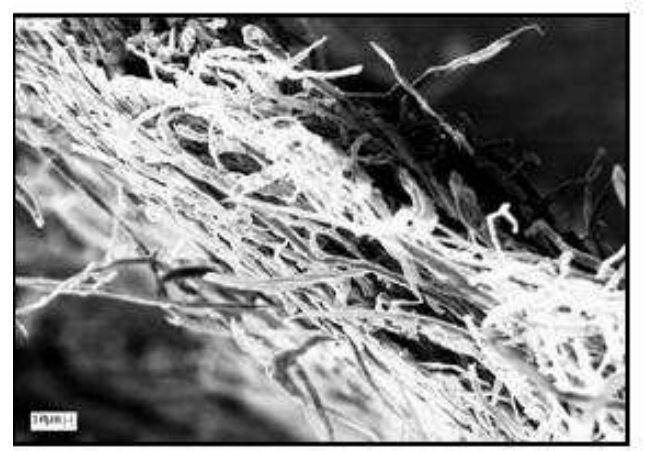

(c)

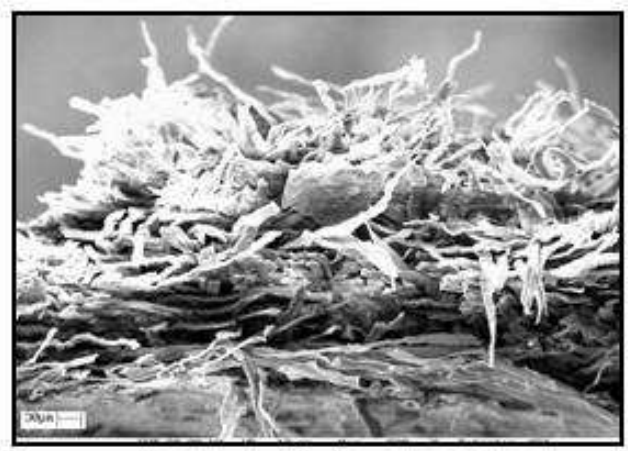

(b)

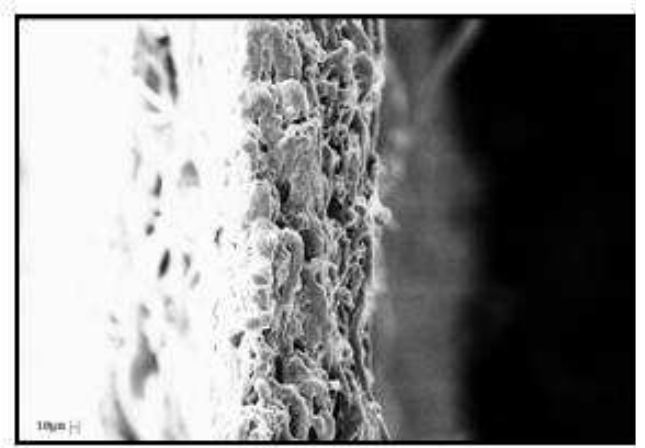

(d)

Figura 47: Micrografias da celulose Polpa Kraft VCP não modificada (a), modificada com razão molar igual a 1 (b), 3 (c) e 5 (d), com ampliação de 500 X. 


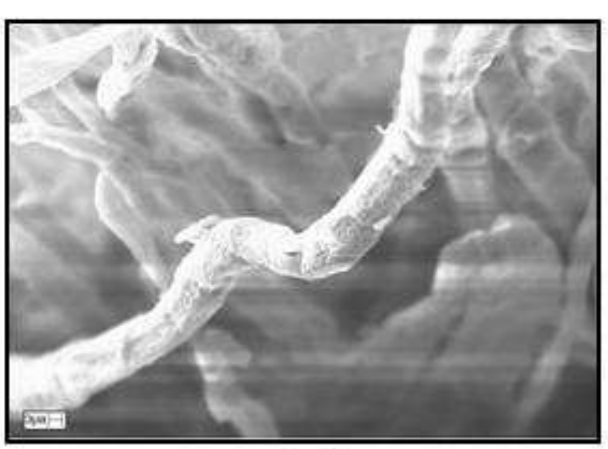

(a)

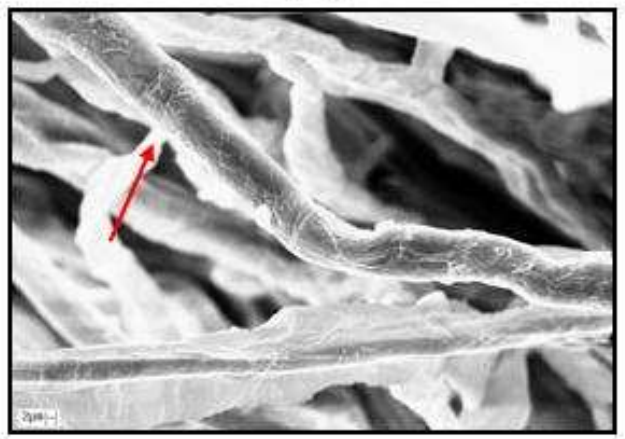

(c)

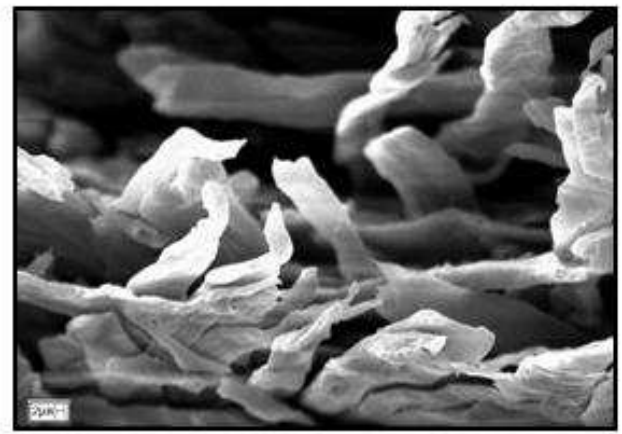

(b)

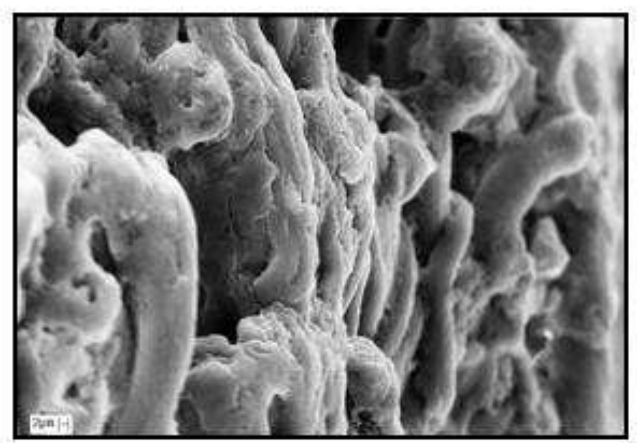

(d)

Figura 48: Micrografias da celulose Polpa Kraft VCP não modificada (a), modificada com razão molar igual a 1 (b), 3 (c) e 5 (d), com ampliação de 3000 X.

Na figura 48c, celulose polpa Kraft VCP modificada com razão molar igual a 3, fica evidente a camada termoplástica de celulose oxipropilada (seta indicativa) envolvendo a fibra de celulose.

Nas figuras 49 e 50 são apresentadas as micrografias para a celulose Regenerada Rayon. 


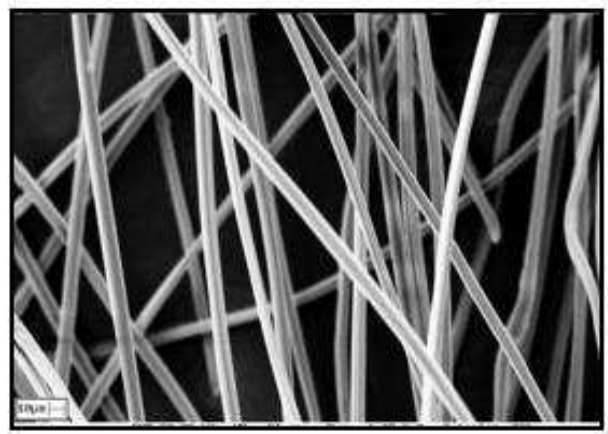

(a)

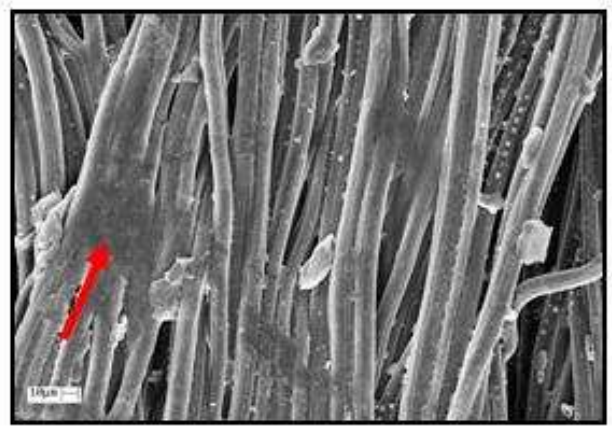

(c)

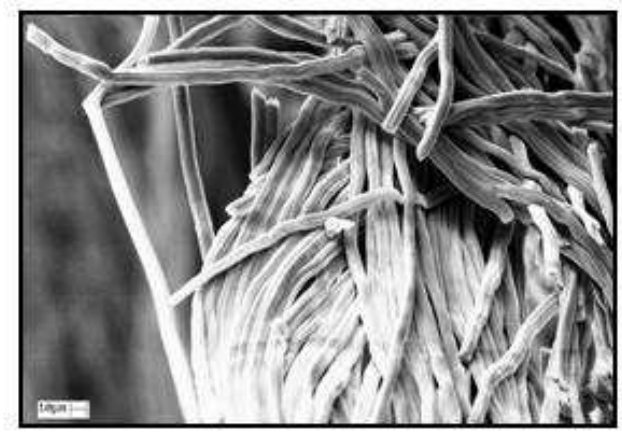

(b)

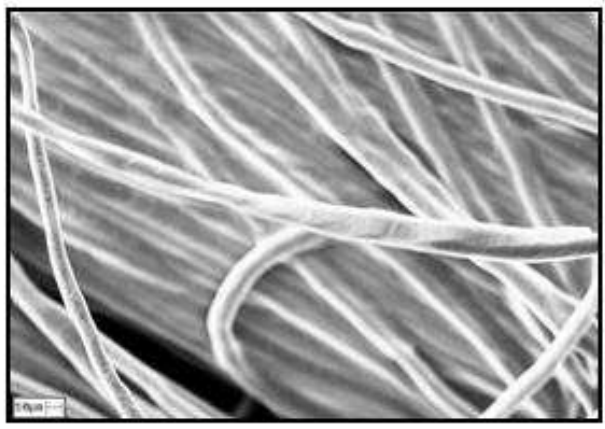

(d)

Figura 49: Micrografias da celulose Regenerada Rayon não modificada (a), modificada com razão molar igual a 1 (b), 3 (c) e 5 (d), com ampliação de 1000 X.

O comportamento observado para celulose polpa Kraft (figura 48c) pode ser também visualizado para a celulose regenerada rayon na figura 49c. Já na figura 51 são apresentadas as micrografias da celulose regenerada rayon, modificada com razão molar igual a 3 e a 5, após as mesma terem sido termo-prensadas. O objetivo dessa análise foi avaliar a homogeneidade do óxido de propileno incorporado sobre as fibras após a termo-prensagem. O mesmo pode ser observado na figura $46 \mathrm{~d}$. 


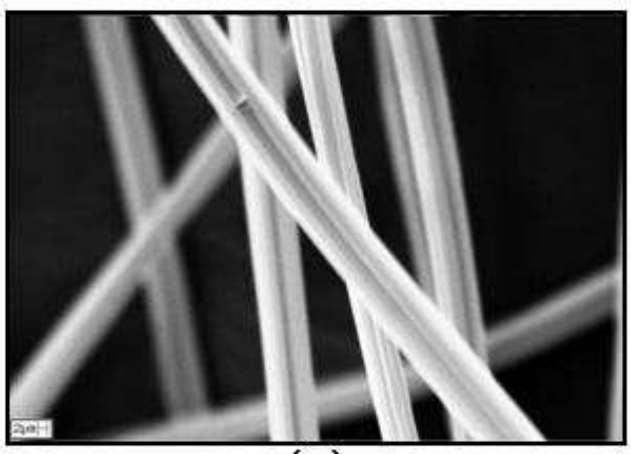

(a)

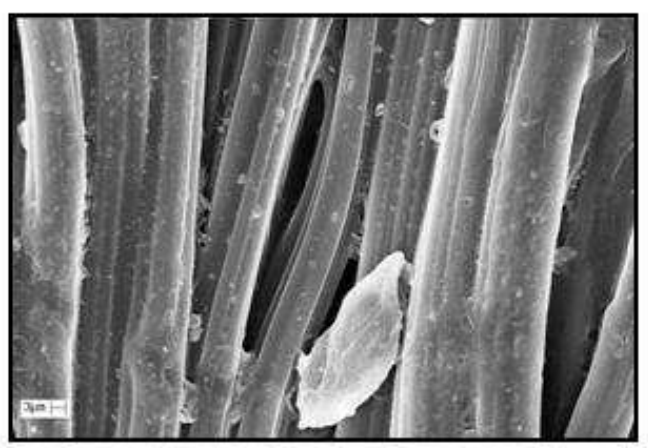

(c)

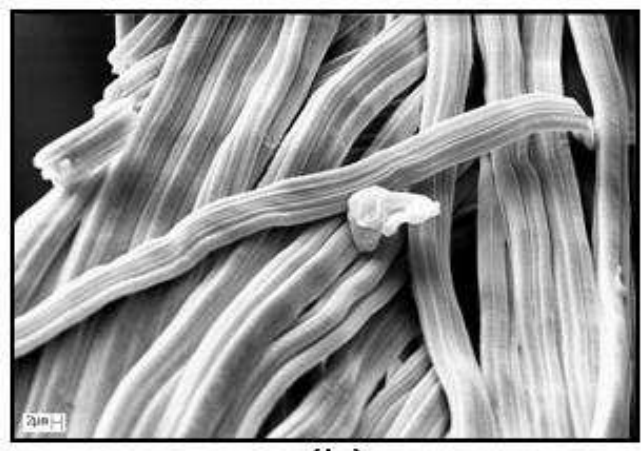

(b)

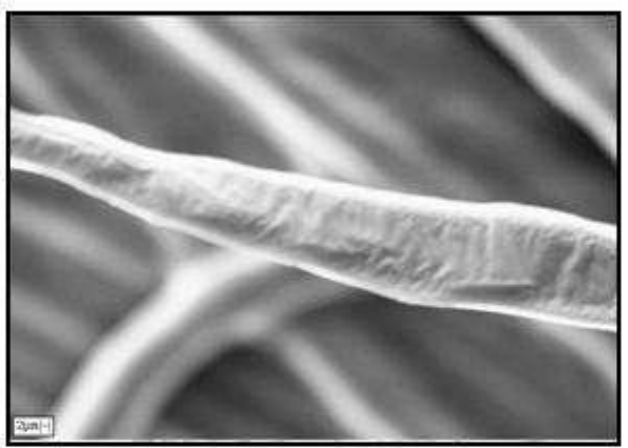

(d)

Figura 50: Micrografias da celulose Celulose Regenerada Rayon não modificada (a), modificada com razão molar igual a 1 (b), 3 (c) e 5 (d), com ampliação de 3000 X.

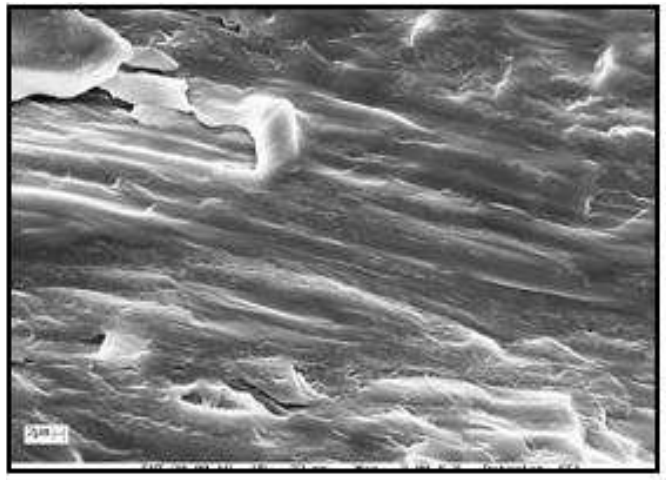

(a)

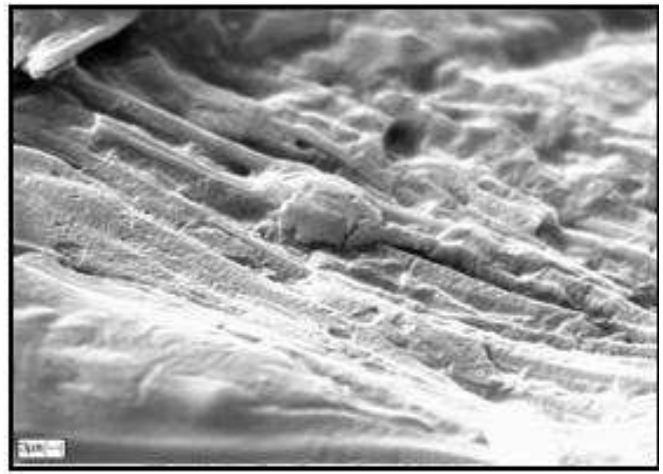

(b)

Figura 51: Micrografias da celulose Celulose Regenerada Rayon modificada com razão molar igual a 3 (c) e 5 (d) em forma de filme, com ampliação de $3000 \mathrm{X}$. 
Na figura abaixo são apresentadas as micrografias para a celulose Papel Filtro pré-tratadas com DABCO.

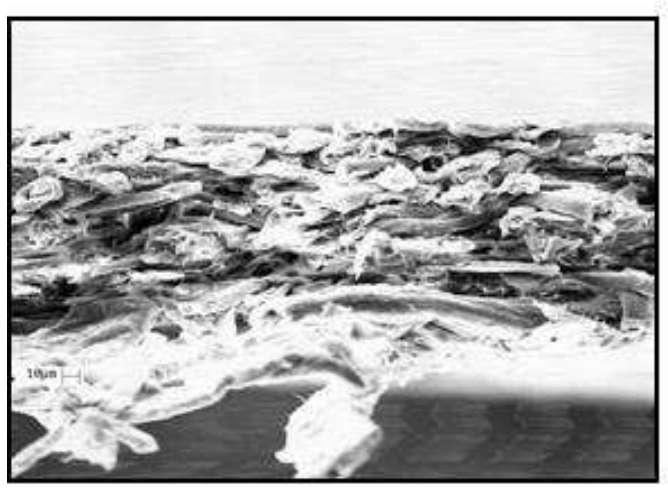

(a)

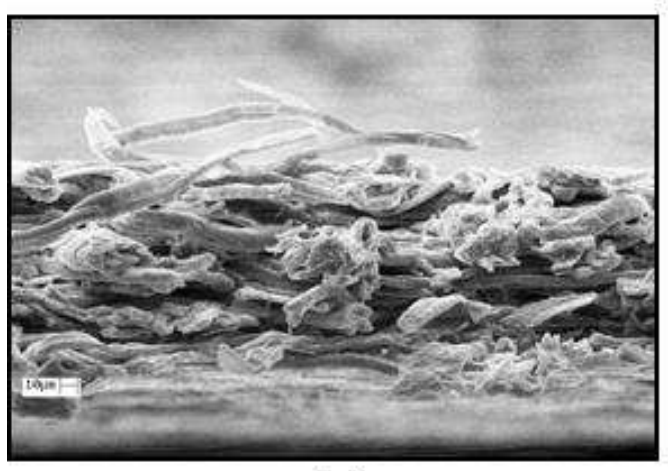

(c)

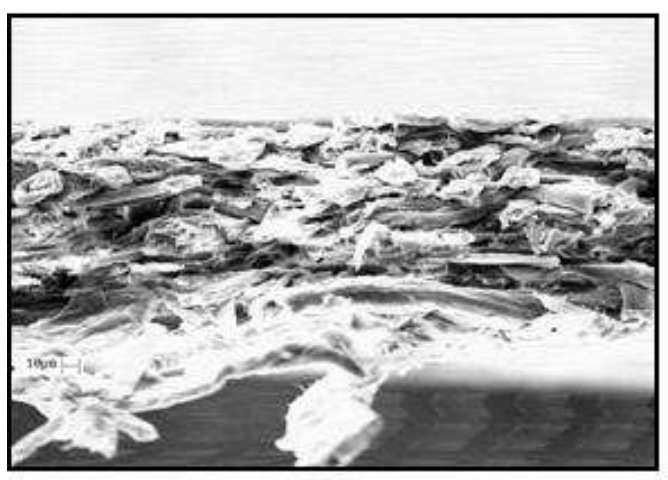

(e)

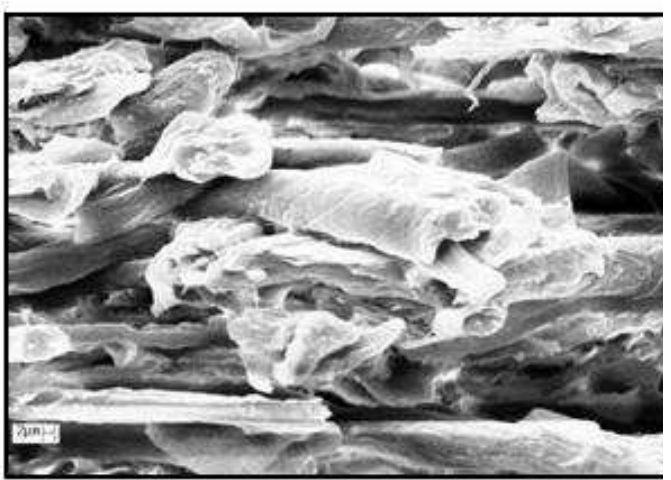

(b)

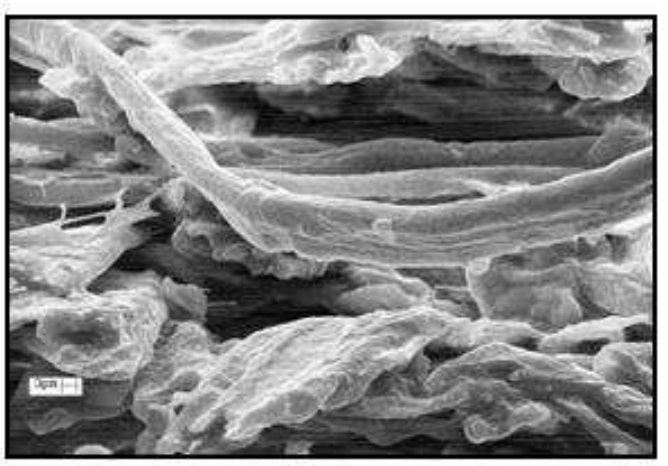

(d)

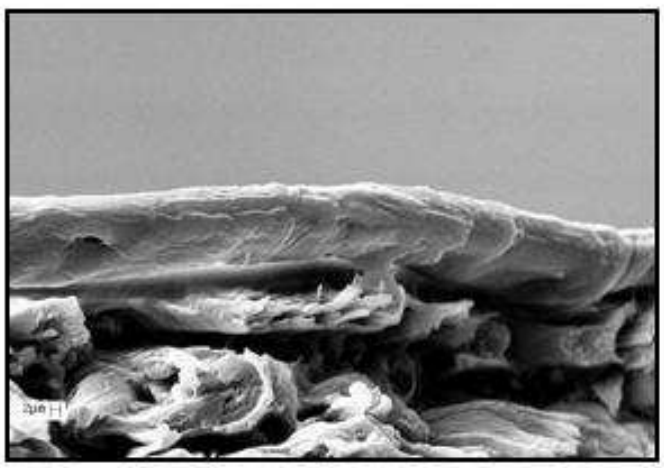

(f)

Figura 52: Micrografias da celulose Papel Filtro/DABCO modificada com razão molar igual a 1 (a) e (b); 3 (c) e (d) e 5 (e) e (f), com ampliação de $1000 \mathrm{X}$ e 3000, respectivamente. 
Observa-se comportamento semelhante ao da celulose Papel Filtro prétratadas com $\mathrm{KOH}$. Já na figura 53 são apresentadas as micrografias para o amido oxipropilado.

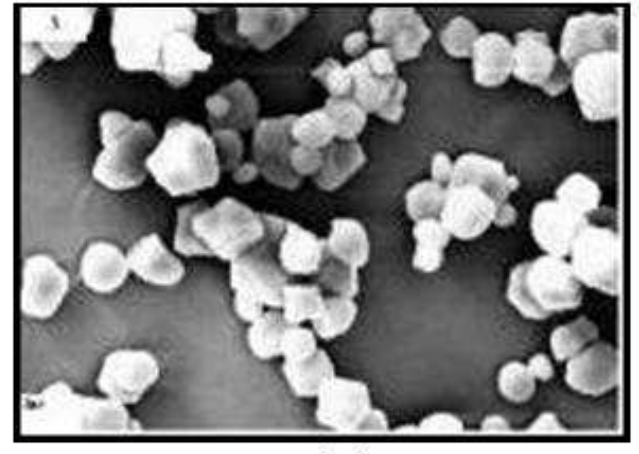

(a)

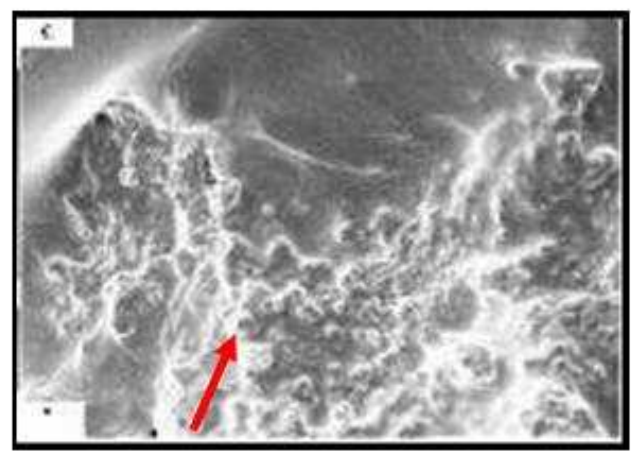

(c)

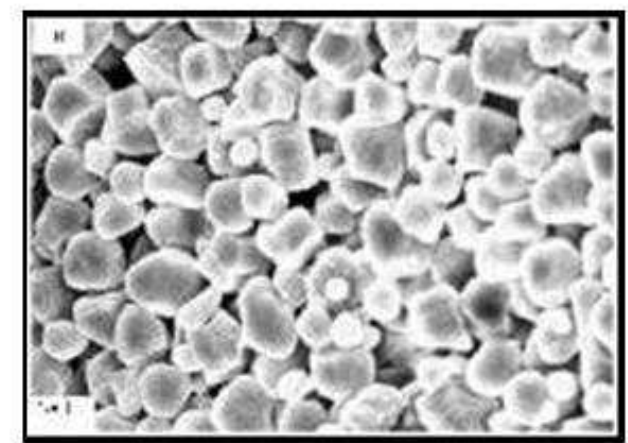

(b)

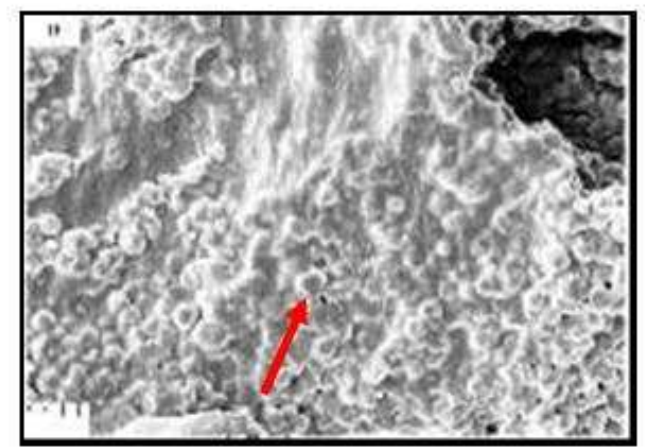

(d)

Figura 53: Micrografia do amido de milho não modificado (a), pré-tratado com $\mathrm{KOH}$ e modificado com razão molar [OP]/[OH amido] igual a 1 (b), pré-tratado com $\mathrm{KOH}$ e modificado com razão molar [OP]/[OH amido] igual a 3 (c) e pré-tratado com DABCO e modificado com razão molar [OP]/[OH amido] igual a 3 (d).

O comportamento para o amido de milho, figura 53, foi semelhante ao das fibras de celulose, onde uma camada termoplástica pode ser observada em torno do amido modificado. Nota-se também, após a termo-prensagem, que estes materiais apresentam alta adesão interfacial, ausente no material não modificado, e que a estrutura granular do amido (seta indicativa) foi parcialmente preservada. 


\section{VI.5 - GANHO DE MASSA}

Para uma análise precisa da extensão da reação decorrente da oxipropilação da celulose e do amido, a quantificação do número de monômeros de óxido de propileno introduzido deveria ser conhecido. Entretanto, devido à não uniformidade/homogeneidade do material obtido, este parâmetro torna-se difícil de ser medido através da análise do grau de substituição (DS). Uma possibilidade de avaliar a extensão da reação é a medida da porcentagem de Ganho de Massa (GM), que fornece a quantificação da incorporação do óxido de propileno na cadeia de celulose e amido, independente de como tenha ocorrido a distribuição nas cadeias de celulose ou amido. Os valores de ganho de massa em função da razão molar [OP]/[OH celulose] são apresentados nas figuras 54 a 58 e na tabela 4.

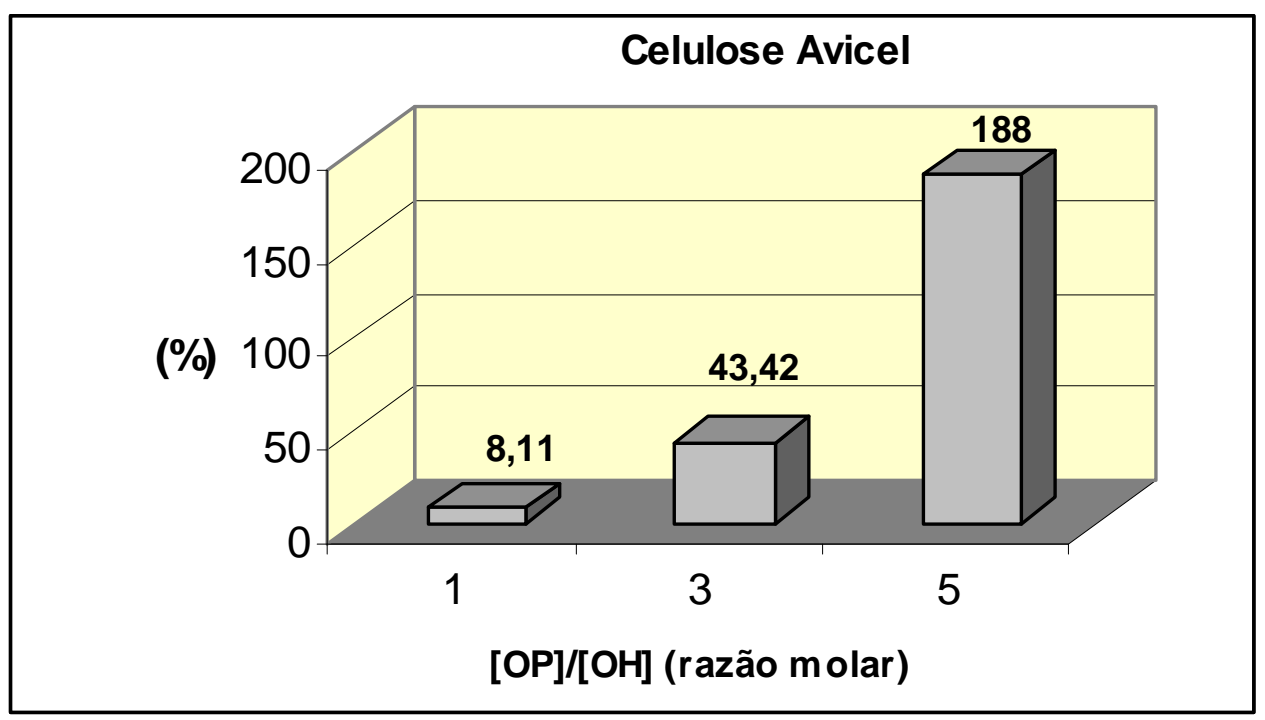

Figura 54: Gráfico de Ganho de Massa (\%) em função da razão molar [OP]/OH celulose] para a celulose Avicel pré-tratado com $\mathrm{KOH}$. 


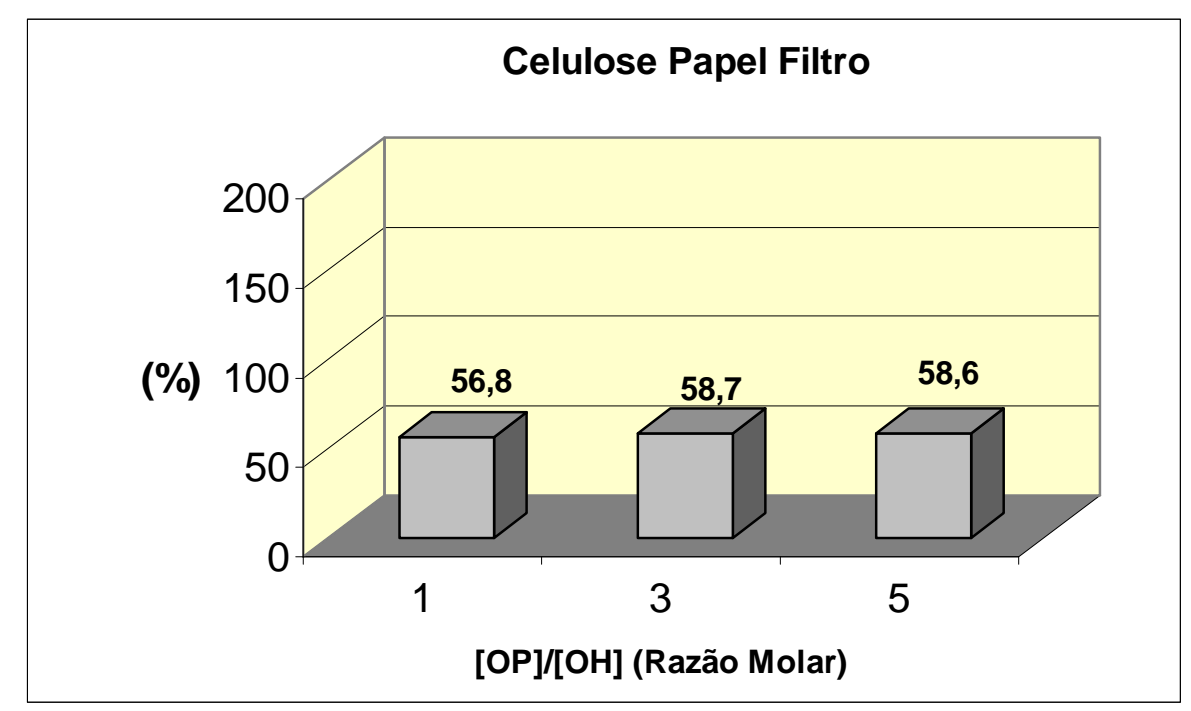

Figura 55: Gráfico de Ganho de Massa (\%) em função da razão molar [OP]/OH celulose] para celulose Papel Filtro pré-tratada com KOH.

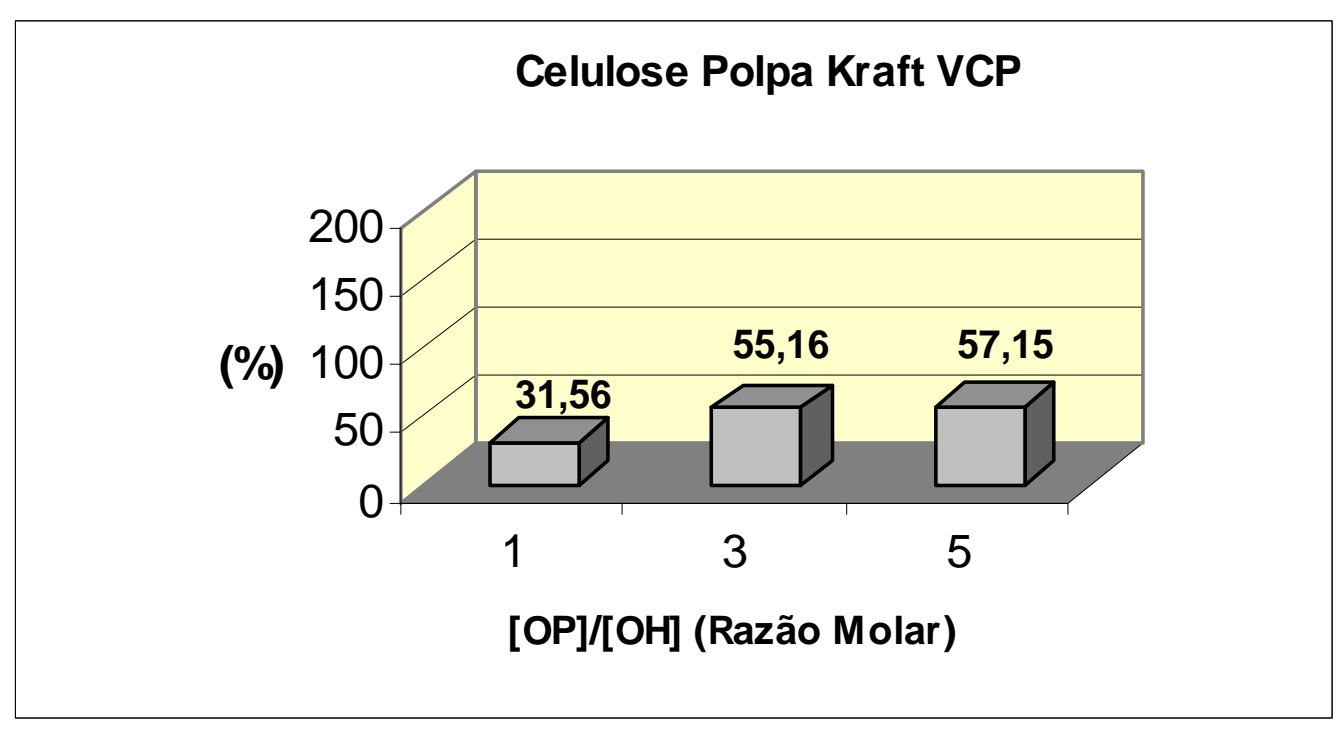

Figura 56: Gráfico de Ganho de Massa (\%) em função da razão molar [OP]/OH celulose] para celulose Polpa Kraft VCP pré-tratada com KOH. 


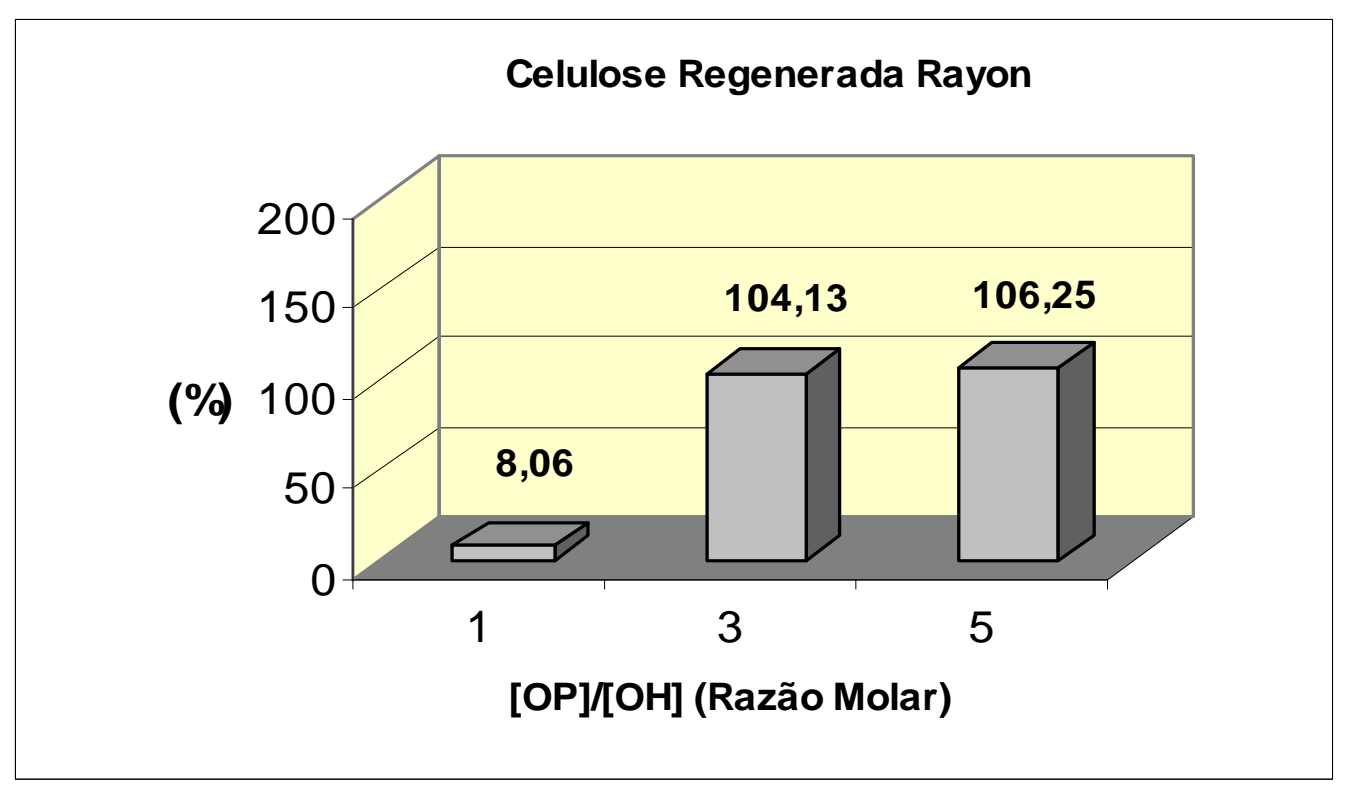

Figura 57: Gráfico de Ganho de Massa (\%) em função da razão molar [OP]/OH celulose] para celulose Regenerada Rayon pré-tratada com $\mathrm{KOH}$.

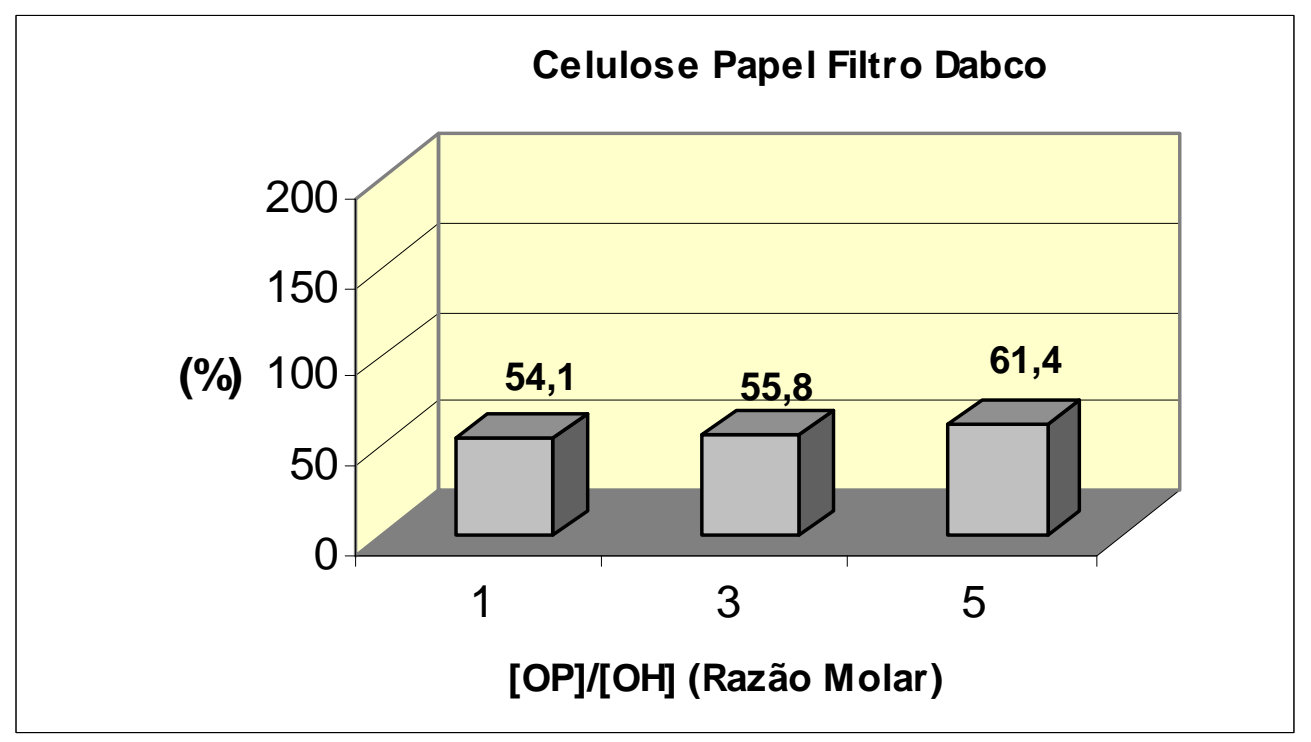

Figura 58: Gráfico de Ganho de Massa (\%) em função da razão molar [OP]/OH celulose] para celulose papel filtro pré-tratado com DABCO. 
Tabela 4: Valores de ganho de massa (GM) em função da razão molar (RM)

Amostras

GANHO DE MASSA (\%)

$$
\mathrm{RM}[\mathrm{OP}] /[\mathrm{OH}]=1 \quad \mathrm{RM}[\mathrm{OP}] /[\mathrm{OH}]=3 \quad \mathrm{RM}[\mathrm{OP}] /[\mathrm{OH}]=5
$$

\begin{tabular}{cccc}
\hline AVICEL & 8,1 & 43,4 & 188 \\
PF/KOH & 56,8 & 58,7 & 58,6 \\
PK/VCP & 31,5 & 55,1 & 57,1 \\
Rayon & 8,06 & 104,1 & 106,2 \\
PF/DABCO & 54,1 & 55,8 & 61,4 \\
\hline
\end{tabular}

O fato da celulose Avicel ter um ganho de massa elevado quando utiliza-se razão molar [OP]/OH celulose] igual a 5, quando comparado com os outros tipos de celulose, pode ser justificado devido a grande superfície de contato com o óxido propileno em decorrência da mesma ter sido utilizada na forma de pó. Para a razão molar 1 e 3 a o elevado índice de cristalinidade (IC) contribui para o baixo ganho de massa. Já pra celulose Rayon (tipo II), o fato de se trabalhar em temperatura mais alta (a reação não ocorre a $135{ }^{\circ} \mathrm{C}$ ) favorece o ganho de massa relativamente elevado. Comparando as amostras com razão molar [OP]/OH celulose] igual a 1, a celulose polpa Kraft e papel filtro apresentaram valores elevados, em relação a celulose avicel e rayon, o qual pode ser atribuído ao fato desse tipo de celulose apresentar maior acessibilidade aos grupos $\mathrm{OH}$ por serem mais amorfas, ou seja, o fato da celulose Avicel e rayon regenerada, apresentarem maior índice de 
cristalinidade, tendo em vista que a reação ocorre preferencialmente na região amorfa. Outro fator pode estar relacionado ao procedimento experimental de extração dos oligômeros em soxhlet, pois a celulose Avicel modificada nessas condições permaneceu na forma de pó após a reação, o que não ocorreu para as razão molar [OP]/OHcel] 3 e 5, que apresentaram-se na forma de aglomerado maleável, a qual pode ter sido arrastado pelo solvente de lavagem (hexano).

Finalizando, para a razão molar [OP]/OH celulose] igual a 3, observa-se que o valor no ganho de massa é próximo do valor medido para as amostras com razão molar [OP]/OH celulose] igual a 5, com exceção da celulose Avicel, indicando que a partir dessa proporção não ocorre mudanças significativas nessa propriedade, ou seja, esse pode ser um valor limite de razão molar para essas condições de trabalho, que pode ser atribuído a perda de reagente para a formação de homopolímero como demonstrado na tabela 5.

Para a celulose papel filtro pré-tratada com DABCO, figura 58 , observa-se comportamento semelhante ao papel filtro pré-tratado com $\mathrm{KOH}$, ficando o ganho de massa deste entre $50-60 \%$. 
Tabela 5: Valores de massa de homopolímero de POP formado em função da razão molar (RM)

\begin{tabular}{cccc}
\hline \multirow{2}{*}{ Amostras } & \multicolumn{3}{c}{ MASSA DE HOMOPOLÍMERO $(\mathrm{g})$} \\
\cline { 2 - 4 } & 0,3 & 2,2 & 0,5 \\
\hline AVICEL $[\mathrm{OP}] /[\mathrm{OH}]=1$ & $\mathrm{RM}[\mathrm{OP}] /[\mathrm{OH}]=3$ & $\mathrm{RM}[\mathrm{OP}] /[\mathrm{OH}]=5$ \\
PF/KOH & 0,1 & 0,4 & 1,7 \\
PK/VCP & 0,4 & 0,8 & 1,45 \\
Rayon & 0,2 & 0,4 & 1,9 \\
PF/DABCO & 0,6 & 1,3 & 2,0 \\
\hline
\end{tabular}

Através da figura 59, gráfico de Ganho de Massa em função da razão molar, pode-se observar o comportamento assintótico dessa propriedade. Esses valores são também apresentados na tabela 5.

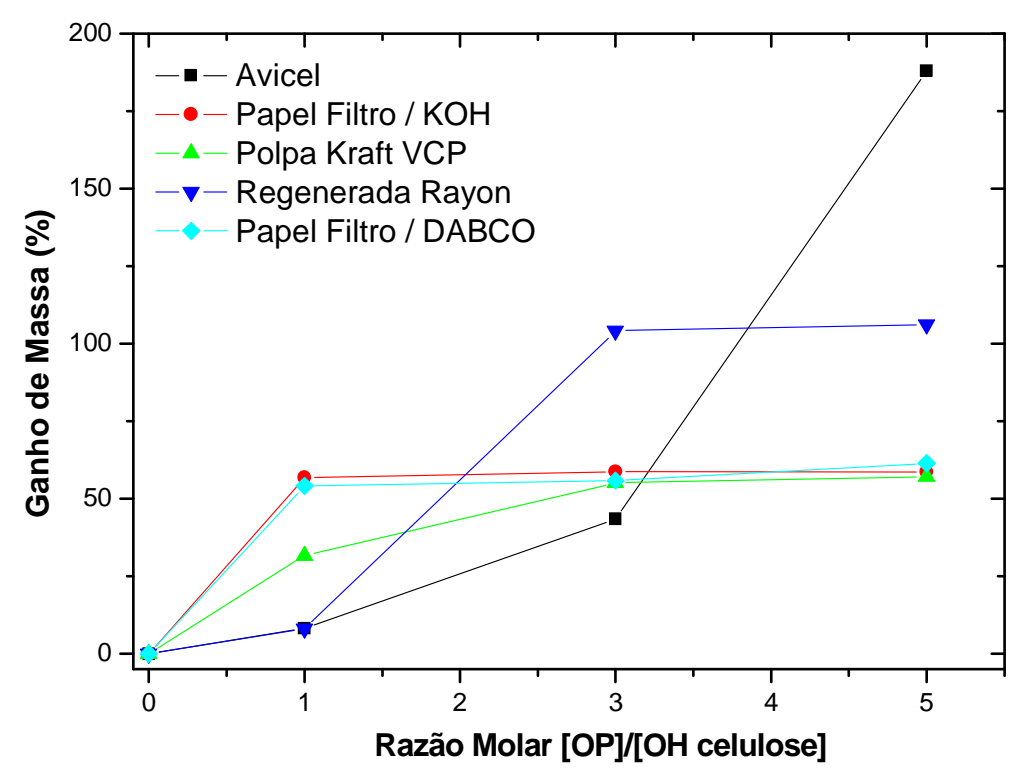

Figura 59: Ganho de Massa (\%) versus Razão molar [OP]/[OH celulose]. 
Outra abordagem realizada foi a do ganho de massa experimental $\left(\mathrm{GM}_{\mathrm{exp}}\right)$ em função do ganho de massa teórico $\left(\mathrm{GM}_{\mathrm{teo}}\right)$, tabela 6 . Esses valores foram calculados levando em consideração o valor máximo de ganho de massa, ou seja, se todo o óxido propileno fosse incorporado à cadeia. O valores de ganho de massa teórico $\left(\mathrm{GM}_{\text {teo }}\right)$ para as razões molares 1, 3 e 5 foram 107, 322 e 537\%, respectivamente, e a equação utilizada para representar a efetividade da reação está apresentada abaixo.

$$
\left[\mathrm{GM}_{\text {exp }} / \mathrm{GM}_{\text {teo }}\right] \times 100
$$

Os valores obtidos são também apresentados no gráfico da figura 60. De acordo com essa análise, nota-se que a eficiência na extensão da reação foi maior na extensão molar igual a 1 para as amostra de Papel Filtro/KOH e DABCO e polpa Kraft VCP. Entretanto, deve-se ficar atento ao fato de que o valor de ganho de massa teórico é maior para a razão molar 3 e maior ainda para a 5, decrescendo o rendimento nessas condições, com exceção da celulose Avicel, corroborando com a hipótese de limitação do reagente. 
Tabela 6: Valores de ganho de massa experimental $\left(G^{\exp }\right)$ em função do ganho de massa teórico $\left(\mathrm{GM}_{\text {teor }}\right)$.

$$
\left[\mathrm{GM}_{\mathrm{EXP}} / \mathrm{GM}_{\mathrm{TEO}}\right] \times 100
$$

Amostras

$$
\mathrm{RM}[\mathrm{OP}] /[\mathrm{OH}]=1 \quad \mathrm{RM}[\mathrm{OP}] /[\mathrm{OH}]=3 \quad \mathrm{RM}[\mathrm{OP}] /[\mathrm{OH}]=5
$$

\begin{tabular}{cccc}
\hline AVICEL & 7,6 & 13,5 & 35 \\
PF/KOH & 53,1 & 18,2 & 10,9 \\
PK/VCP & 29,5 & 17,1 & 10,6 \\
Rayon & 7,5 & 32,3 & 19,8 \\
PF/DABCO & 50,6 & 17,3 & 11,4 \\
\hline
\end{tabular}

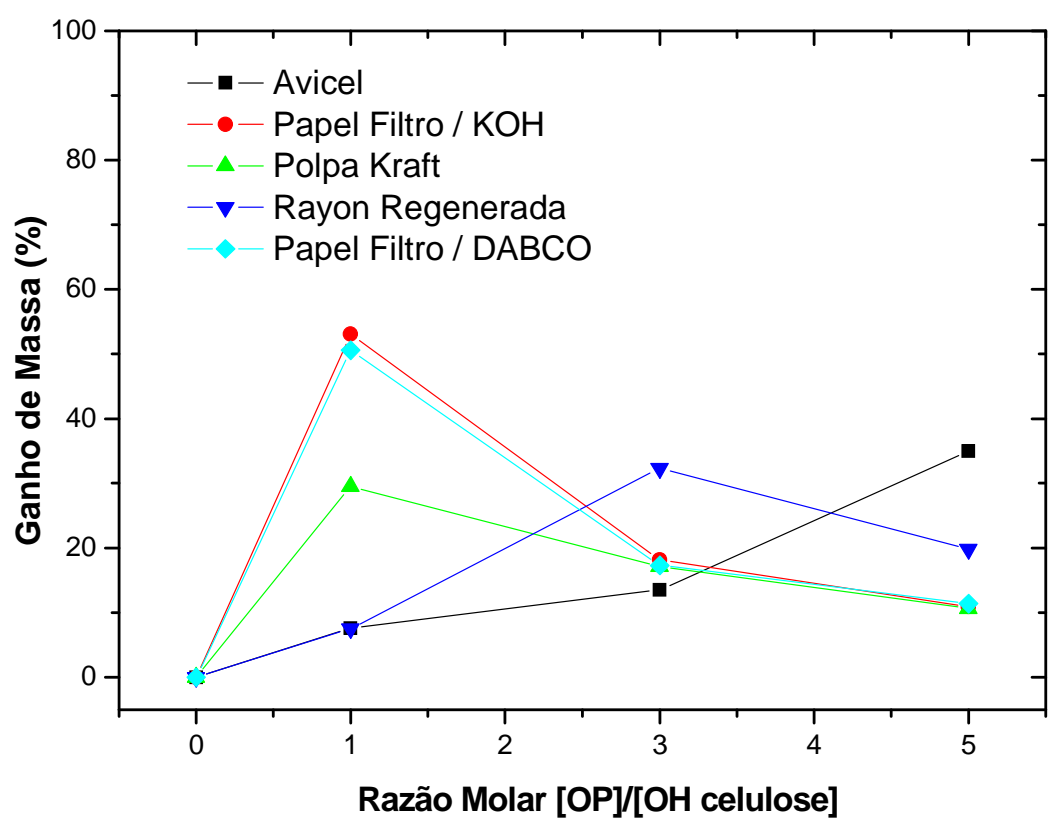

Figura 60: Gráfico dos valores de ganho de massa experimental $\left(G M_{\text {exp }}\right)$ em função do ganho de massa teórico $\left(\mathrm{GM}_{\text {teo }}\right)$. 
Os valores de ganho de massa em função da razão molar obtidos para o amido de milho oxipropilado pré-tratado com $\mathrm{KOH}$ na razão molar igual a 1 e 3 e prétratado com DABCO na razão molar igual a 3 são apresentados na figura 61 .

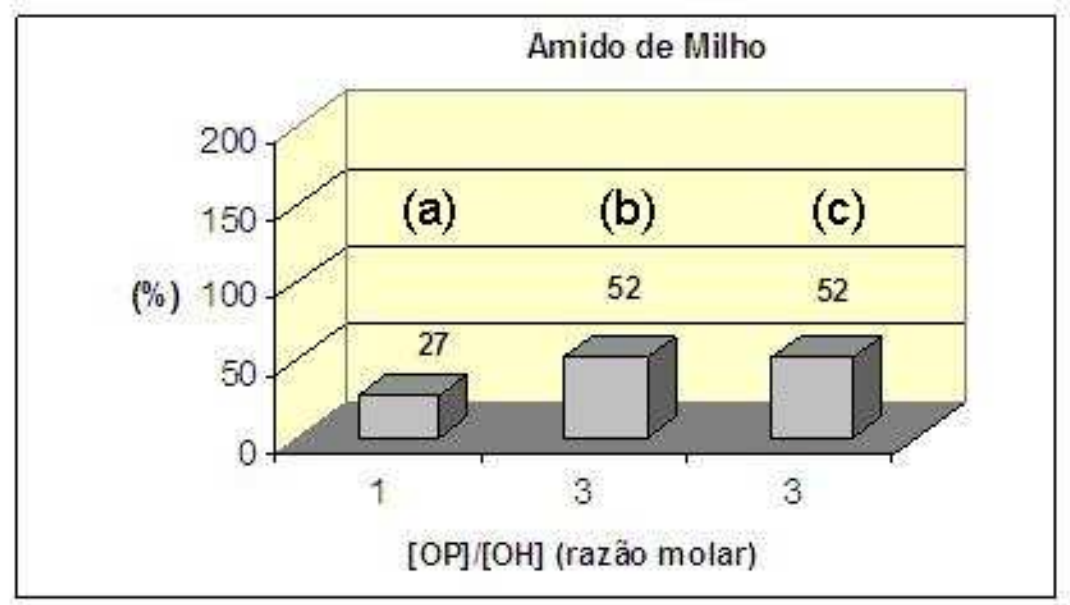

Figura 61: Ganho de massa versus razão molar para o amido de milho oxipropilado com razão molar igual a 1 e pré-tratado com $\mathrm{KOH}(\mathrm{a})$, razão molar igual a 3 prétratado com $\mathrm{KOH}(\mathrm{b})$ e razão molar igual a 3 pré-tratado com DABCO $(\mathrm{C})$.

A amostra modificada com razão molar igual a 1 e pré-tratada com $\mathrm{KOH}$ apresentou valor de ganho de massa foi expressivo (27\%) em relação ao amido não modificado, o qual pode ser atribuído ao índice de cristalinidade relativamente baixo do amido de milho $(30,6 \%)$ quando comparado com a celulose Avicel, também utilizada em forma de pó. Para a razão molar igual a 3 o ganho de massa de $52 \%$ para ambas as amostras, independente do tipo de base utilizada o ganho de massa não se altera, corrobora com a hipótese de que a reação ocorre preferencialmente na fase amorfa devido a acessibilidade dos grupos $\mathrm{OH}$ ser favorecida. Já com razão molar igual a 5 a reação foi agressiva gerando um líquido viscoso (poliol) como produto principal. 


\section{VI.6 - ANÁLISE TERMOGRAVIMÉTRICA (TGA)}

A análise termogravimétrica foi empregada para avaliar as alterações na estabilidade térmica das amostras, antes e após as reações de oxipropilação. Os resultados das análises termogravimétricas obtidas para as celuloses em questão são apresentados nas figuras abaixo e na tabela 7.

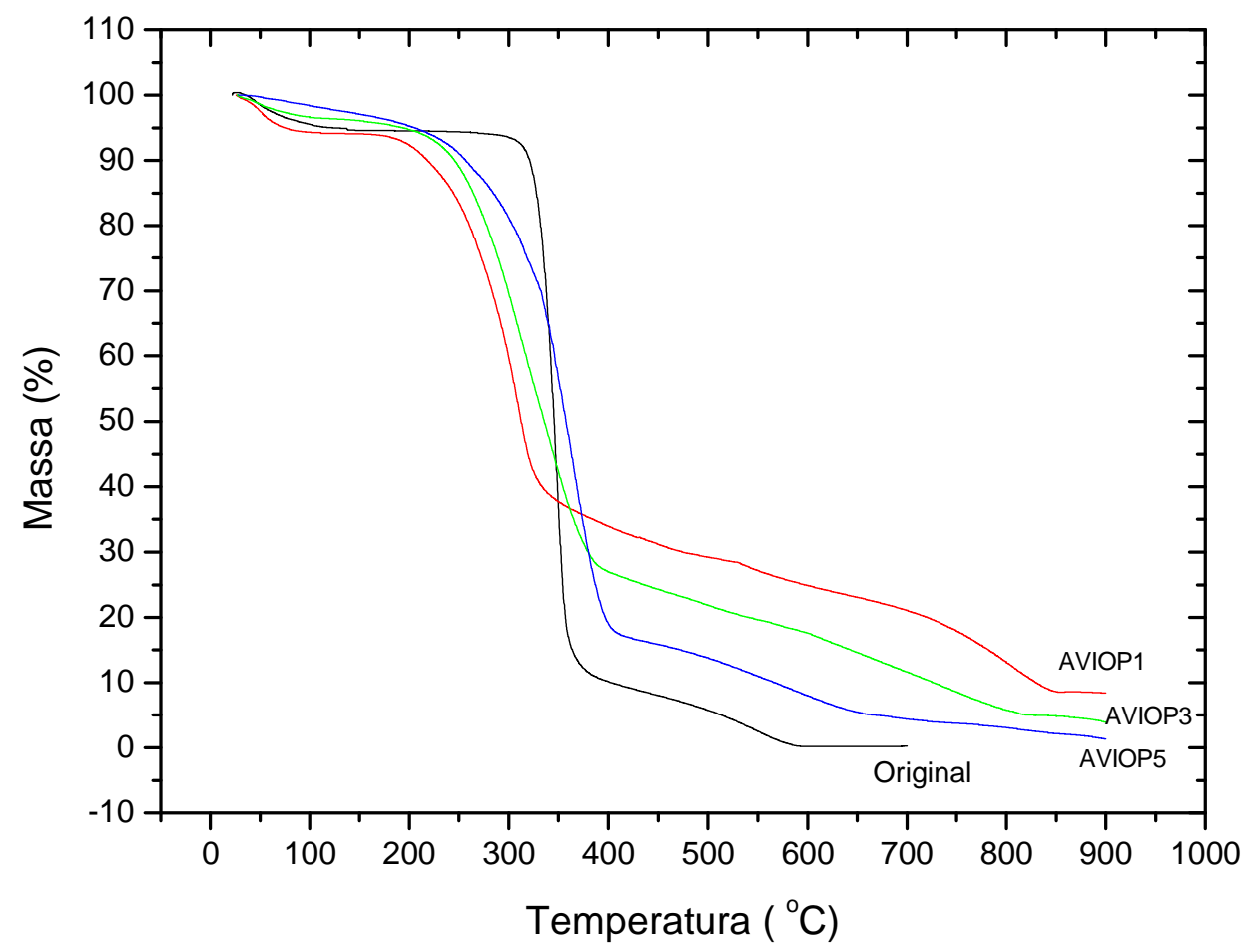

Figura 62: Curvas TG da celulose Avicel antes e após as reações de oxipropilação. 


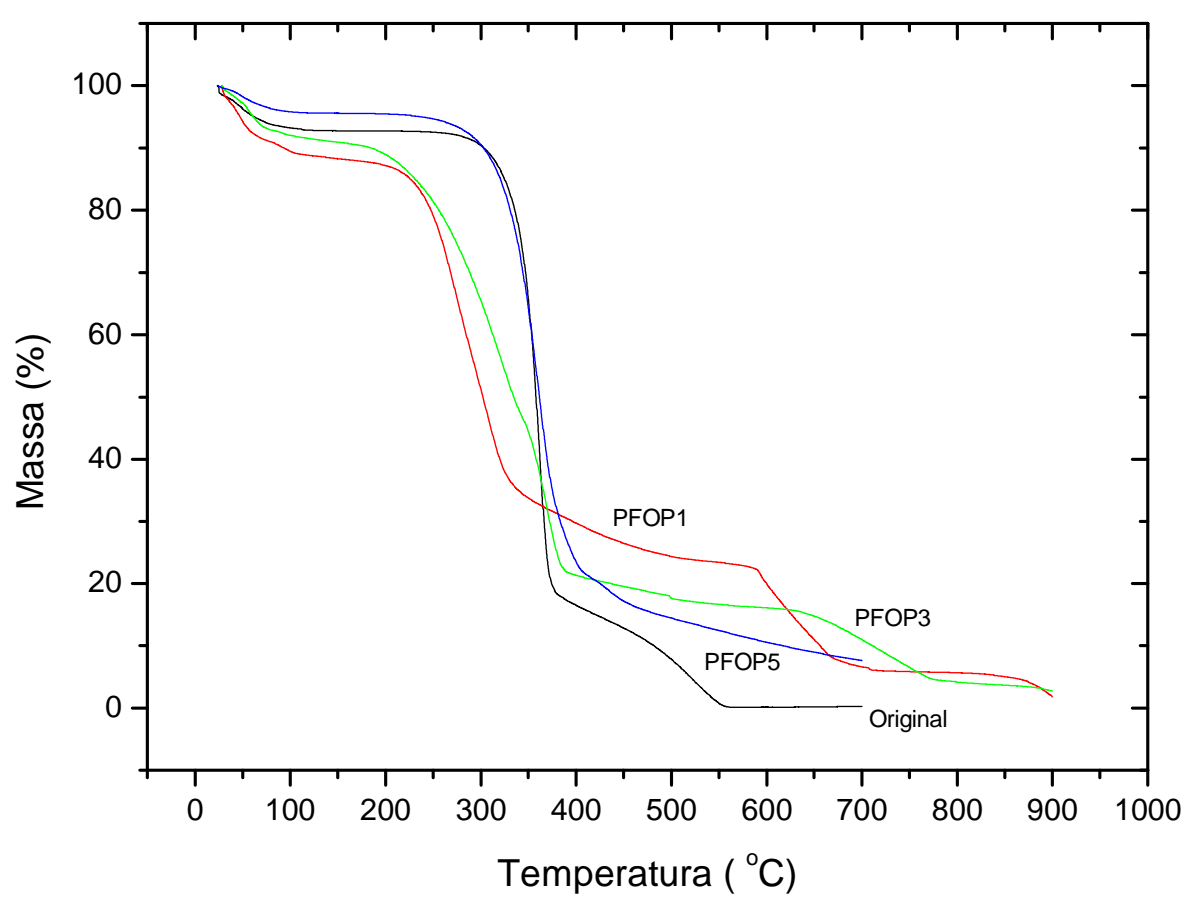

Figura 63: Curvas TG da celulose Papel Filtro/KOH antes e após as reações de oxipropilação.

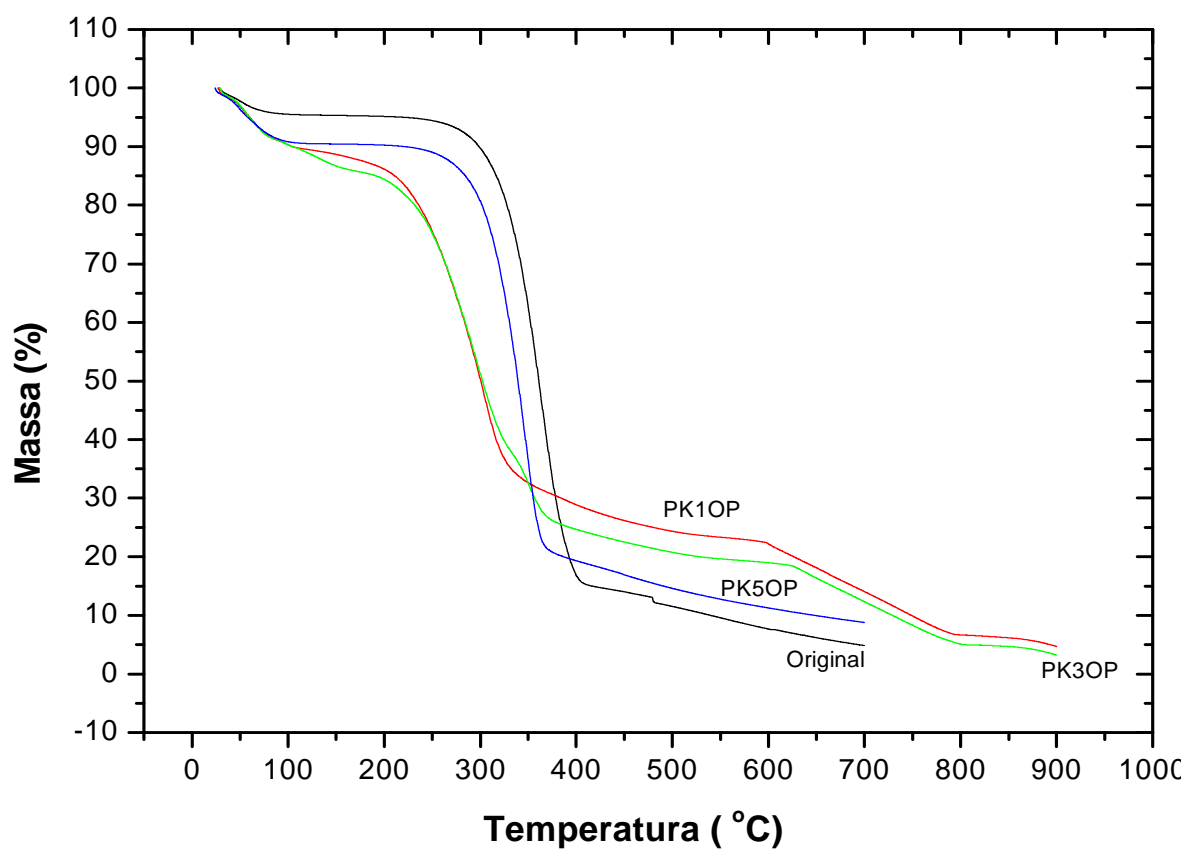

Figura 64: Curvas TG da celulose Polpa Kraft VCP antes e após as reações de oxipropilação. 


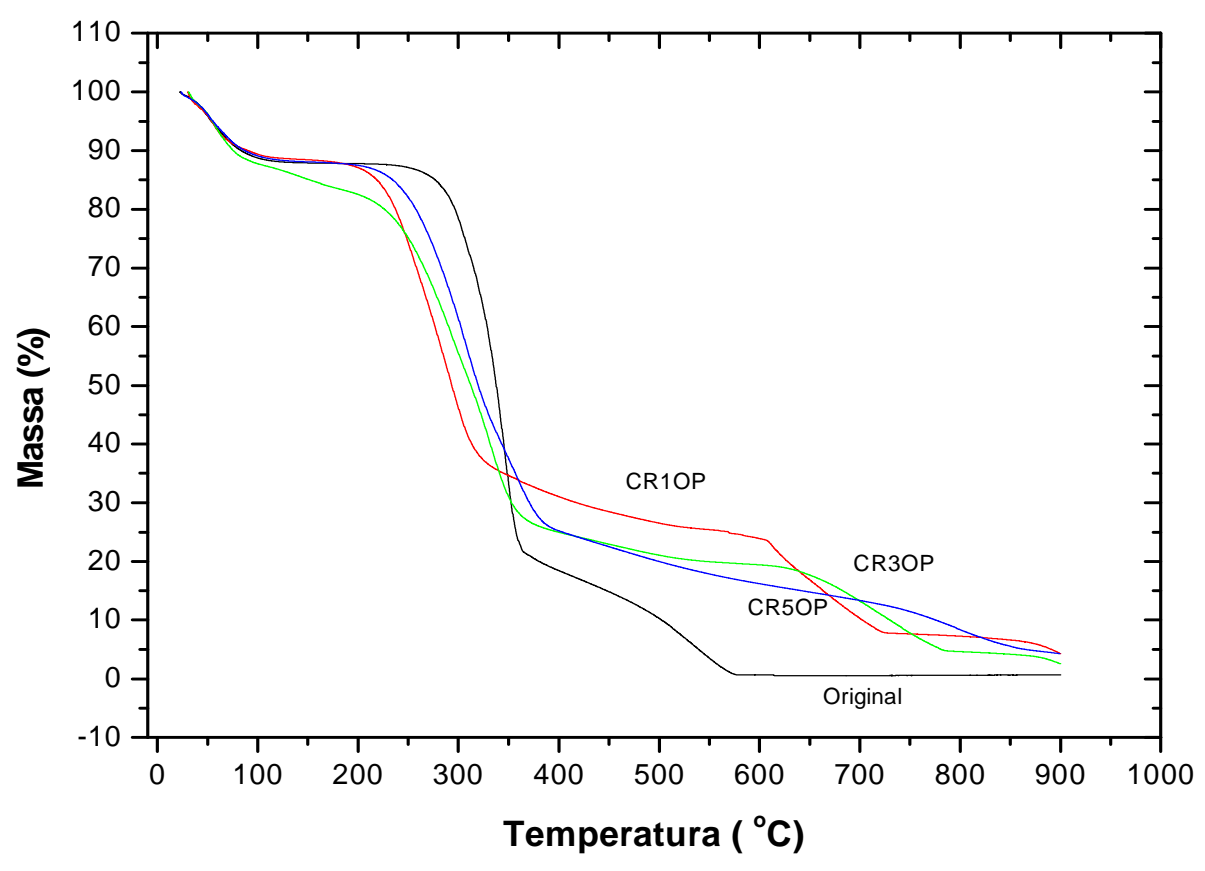

Figura 65: Curvas TG da celulose Regenerada Rayon antes e após as reações de oxipropilação.

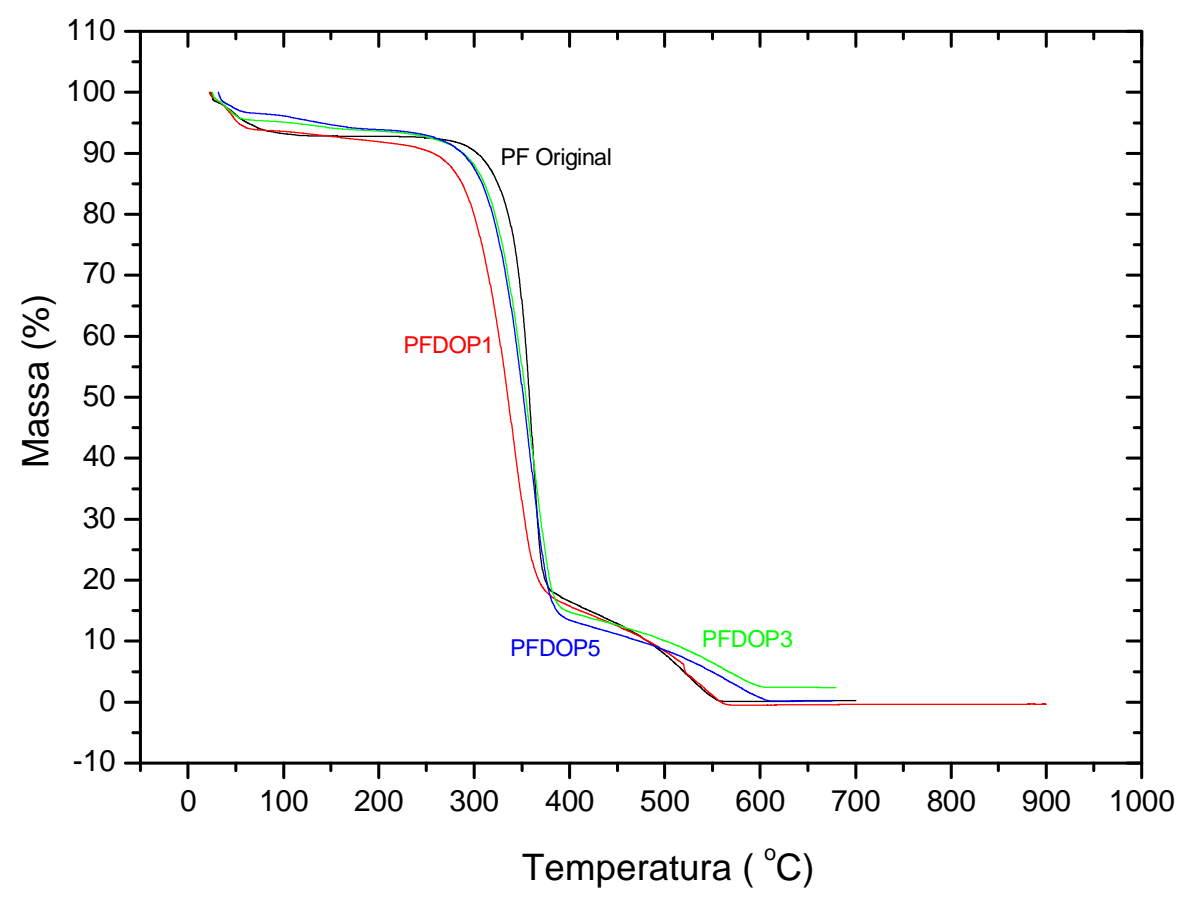

Figura 66: Curvas TG da celulose Papel Filtro/DABCO antes e após as reações de oxipropilação. 
Tabela 7: Valores de temperatura onset e endset de temperatura e perda de massa.

\begin{tabular}{|c|c|c|c|c|}
\hline Amostras & $\begin{array}{c}\text { Temperatura em } 2 \% \text { de } \\
\text { perda de Massa }\left({ }^{\circ} \mathrm{C}\right)\end{array}$ & Onset $\left({ }^{\circ} \mathrm{C}\right)$ & Endset $\left({ }^{\circ} \mathrm{C}\right)$ & $\begin{array}{c}\text { Perda de } \\
\text { Massa (\%) }\end{array}$ \\
\hline AVI & 315,5 & 325,0 & 368,6 & 82,0 \\
\hline AVOP1 & 204,2 & 238,5 & 345,0 & 57,3 \\
\hline AVOP3 & 200,4 & 257,6 & 377,7 & 68,6 \\
\hline AVOP5 & 169,0 & 297,7 & 398,5 & 81,2 \\
\hline PF & 297,1 & 342,6 & 374,4 & 73,7 \\
\hline PFOP1 & 210,9 & 237,4 & 328,0 & 53,4 \\
\hline PFOP3 & 200,1 & 257,0 & 389,0 & 69,7 \\
\hline PFOP5 & 271,0 & 327,8 & 383,0 & 76,0 \\
\hline PKVCP & 275,6 & 317,0 & 399,0 & 80,2 \\
\hline PKVOP1 & 183,0 & 237,0 & 325,0 & 56,0 \\
\hline PKVOP3 & 124,6 & 210,0 & 375,0 & 65,5 \\
\hline PKVOP5 & 255,8 & 308,9 & 366,3 & 71,0 \\
\hline CRR & 268,3 & 303,6 & 366,9 & 66,1 \\
\hline CRROP1 & 207,5 & 226,6 & 320,3 & 53,4 \\
\hline CRROP3 & 140,8 & 237,9 & 360,5 & 61,4 \\
\hline CRROP5 & 225,1 & 234,0 & 383,1 & 63,4 \\
\hline PFDOP1 & 223,3 & 300,5 & 366,8 & 74,6 \\
\hline PFDOP3 & 257,2 & 308,9 & 388,7 & 79,0 \\
\hline PFDOP5 & 266,6 & 312,4 & 384,9 & 79,8 \\
\hline
\end{tabular}


Observa-se através das curvas TG, independentemente do tipo de celulose, que os eventos térmicos ocorrem em alguns casos em três diferentes estágios, comportamento esse observado por Ferreira et al. 2003 para amostras de fibras de sisal benziladas com menores tempos de reação, uma (1) e duas (2) horas. 0 primeiro estágio ocorre entre 25 e $100{ }^{\circ} \mathrm{C}$, está relacionado com a desidratação das amostras, com perdas de massa entre 3-7\%. Apesar das amostras não terem sido condicionadas em ambientes com umidade controlada, observa-se que a amostra de celulose Avicel OP5 não apresentou este estágio inicial de perda de massa, apresentando o mesmo comportamento observado por Ferreira et al. 2003 e Da Roz et al. 2004, para amostra benziladas com tempos de reação maiores que três (3) horas.

Este comportamento pode ser atribuído a uma maior resistência à absorção/adsorção de água devido ao decréscimo do acesso e da disponibilidade dos sítios de interação com as moléculas de água devido a grande quantidade de óxido de propileno incorporado na cadeia, demonstrado através do ganho de massa.

O segundo estágio está associado à degradação da estrutura química das amostras. Nessa etapa observa-se maior perda de massa, entre 50 - $80 \%$, e ocorre em faixas de temperatura diferentes, dependendo do tipo de amostra. Os valores de temperatura de degradação apresentados na tabela 3 foram tomados na região de perda de massa igual a $2 \%$, descartando a perda de massa decorrente da desidratação (Glasser et al., 1999). Já os valores de perda de massa, referentes ao segundo e principal estágio de degradação, foram obtidos através do ponto de intersecção entre as tangentes às curvas antes e após o início da transição observada (onset) e antes e após o término da transição observada (endset) 
(Hatakeyama e Quinn 1994). No terceiro e último estágio, que ocorre em torno de $400{ }^{\circ} \mathrm{C}$ e estende próximo a $700{ }^{\circ} \mathrm{C}$ para algumas amostras e $900{ }^{\circ} \mathrm{C}$ para outras, está relacionado ao processo de carbonização destas. Nas figuras 67 e 68, são apresentados os valores de perda de massa no segundo estágio (degradação) e de temperatura em $2 \%$ de perda de massa, ambas em função da razão molar [OP]/[OH celulose].

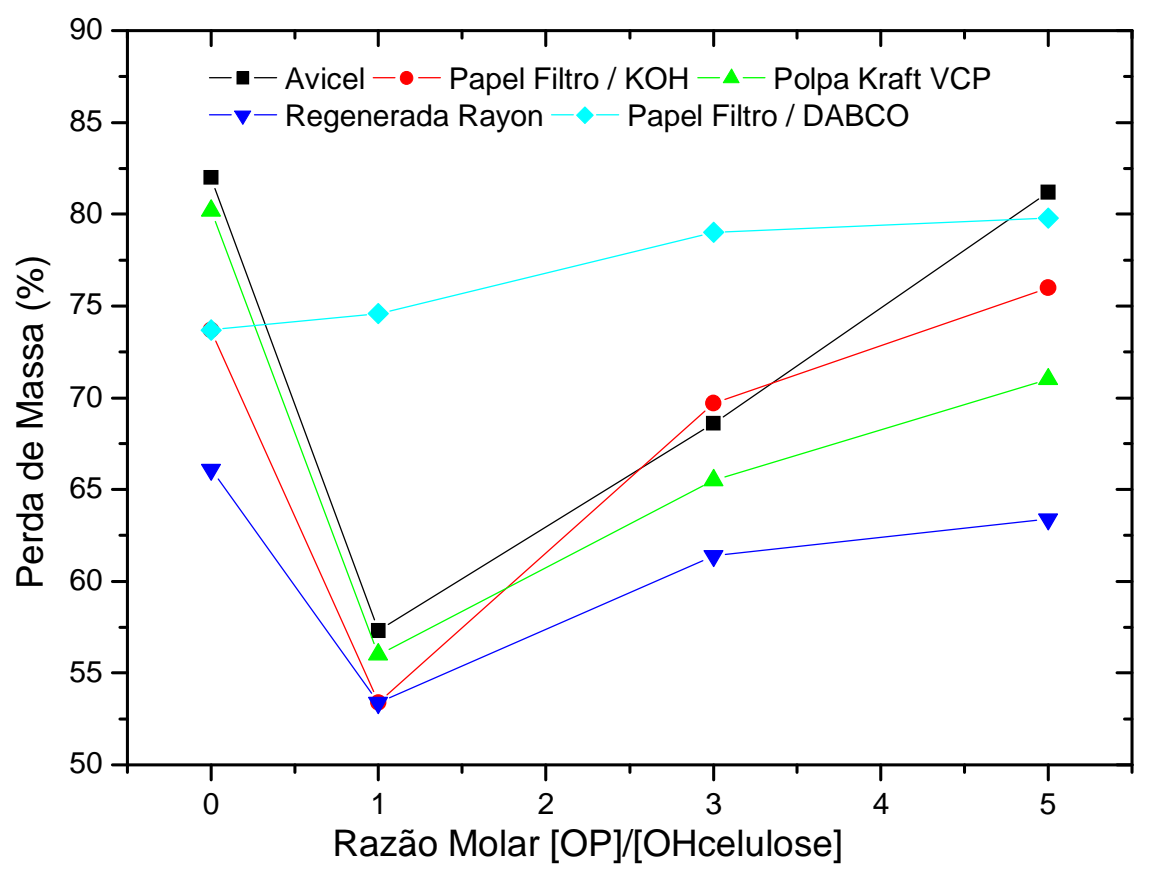

Figura 67: Perda de massa no segundo estágio (degradação) versus da razão molar $[\mathrm{OP}] /[\mathrm{OH}$ celulose].

Nota-se um comportamento semelhante, com exceção da celulose Papel Filtro/DABCO, para amostras em relação a perda de massa no segundo estágio, ou seja, na etapa principal de degradação das amostras. O menor valor de perda de massa observado para as amostras de celulose Avicel e Rayon, ambas oxipropiladas com razão molar igual a 1, pode ser atribuído a menor quantidade de oxipropileno incorporado, justificado através do ganho de massa em torno de $10 \%$. 
Ao comparar as amostras de Papel Filtro/KOH e Polpa Kraft VCP, que apresentaram ganho de massa considerável também na razão molar igual a 1, com a celulose Papel Filtro/DABCO, que apresentou o valor de perda de massa maior, pode-se fazer a seguinte análise. Considerando o fato de o $\mathrm{KOH}$ ser uma base mais forte, portanto menos seletiva, que o DABCO seria razoável supor que a distribuição do óxido de propileno na celulose pré-tratada com KOH é mais abrangente, ou seja, DS maior do que para a celulose pré-tratada com DABCO, porém, com o valor de MS menor, para valor de ganho de massa semelhante. Levando em consideração essa hipótese, esperar-se-ia um maior valor de perda de massa para a celulose prétratada com DABCO, pois nesse estágio de degradação, a fração modificada será degradada primeiramente.

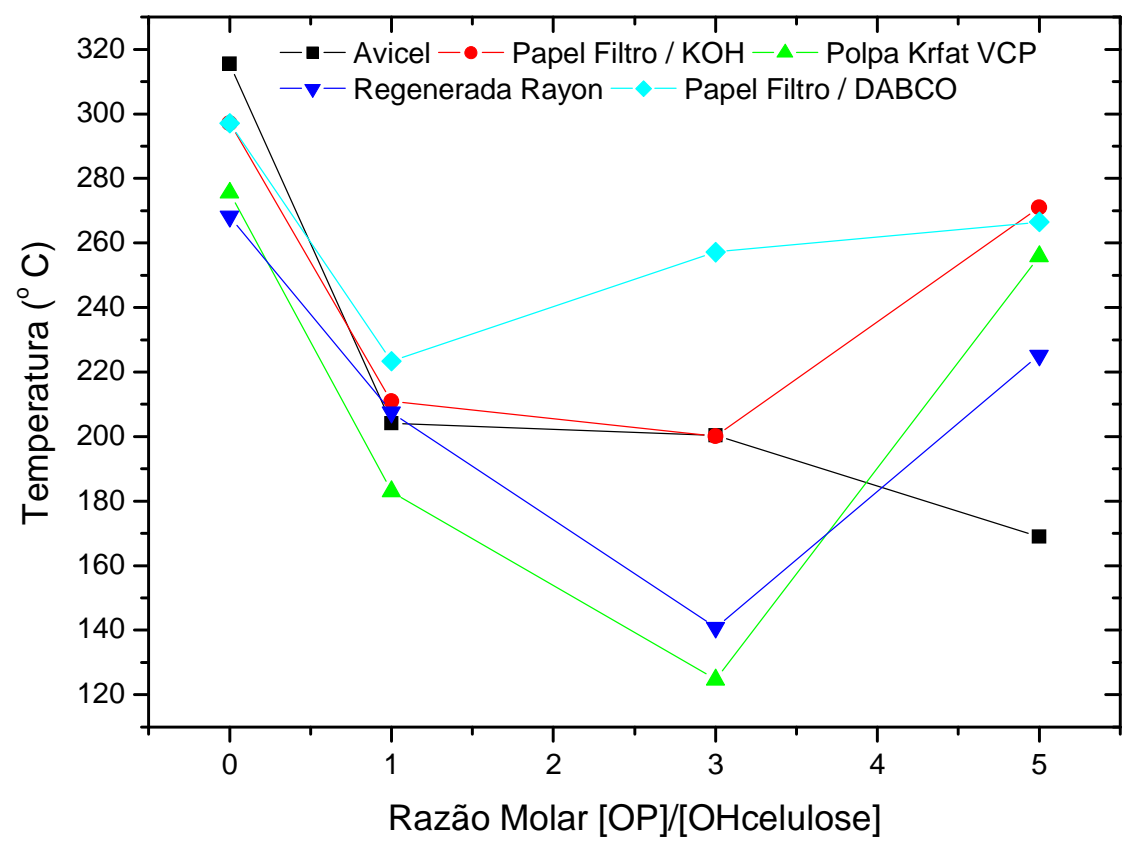

Figura 68: Temperatura em $2 \%$ de perda de massa versus da razão molar [OP]/[OH celulose]. 
Tendo em vista que a temperatura de degradação da celulose diminui após as mesmas serem modificadas, já era esperado o decréscimo na estabilidade térmica e consequentemente aumento da perda de massa, como observado nas amostras modificadas com razão molar $[\mathrm{OP}] /[\mathrm{OH}$ cel] igual a 3 e 5, apesar de um aumento considerável da estabilidade térmica para algumas amostras modificadas com razão molar igual a 5. Como discutido inicialmente, esses dados são corroborados pelos dados de ganho de massa, uma vez que ocorre considerável aumento no valor destes.

As curvas TG para amido de milho antes e após a reação de oxipropilação são apresentadas na figura 69.

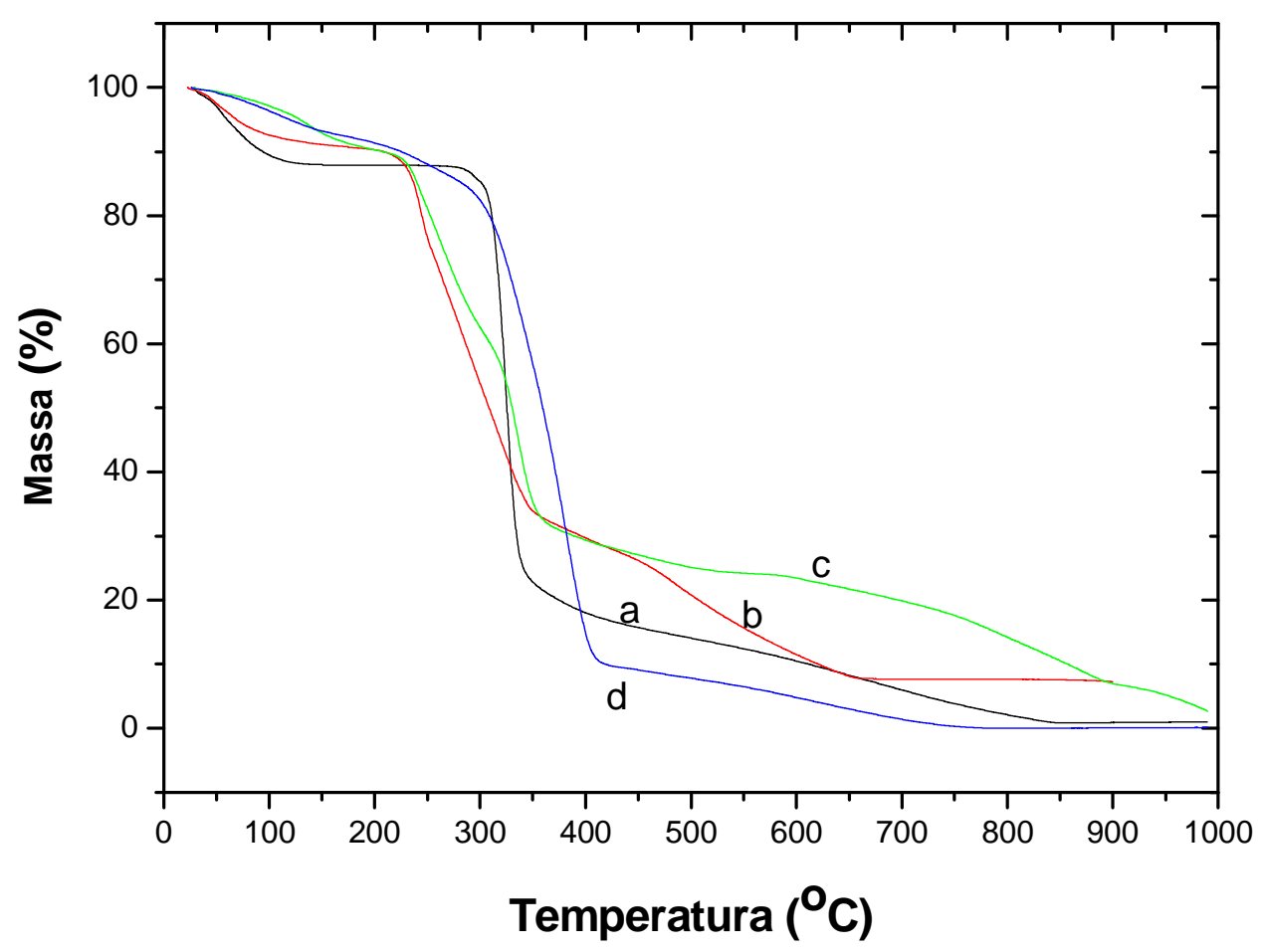

Figura 69: Curvas TG do amido de milho não modificado (a), oxipropilado com razão molar igual a 1 e pré-tratado com $\mathrm{KOH}(\mathrm{b})$, razão molar igual a 3 pré-tratado com $\mathrm{KOH}(\mathrm{c})$ e razão molar igual a 3 pré-tratado com DABCO (d). 
O amido apresenta perfil semelhante as amostras de celulose, ou seja, os eventos térmicos são os mesmos. Entretanto, nota-se que para as amostra modificadas com razão molar igual a 3 não ocorre o estágio inicial de perda de massa, correspondente a umidade contida no amido, dando indícios que o material modificado nessas condições apresenta maior resistência a absorção de água. Esse resultado é atribuído a menor acessibilidade dos grupos $\mathrm{OH}$ após a reação, ou seja, a grande quantidade de enxerto diminui a acessibilidade da água aos grupos $\mathrm{OH}$ do amido. Esse comportamento também é observado para a celulose Avicel modificada com razão molar igual a 5 e são corroboradas pelo ganho de massa elevado.

Deve-se salientar que a análise termogravimétrica propiciou conhecer a estabilidade térmica dos materiais em questão e, conseqüentemente, a temperatura limite de utilização destes materiais, sem que os mesmos sofram algum tipo de termodegradação ou perda de algum tipo de propriedade em conseqüência da exposição desses materiais quando submetidos à condição de uso envolvendo temperatura acima da temperatura ambiente. 


\section{VI.7 - CALORIMETRIA EXPLORATÓRIA DIFERENCIAL (DSC)}

A análise por calorimetria exploratória diferencial permite determinar as temperaturas onde ocorrem as transformações de fases das substâncias observadas através da perda e/ou ganho de calor, complementando a técnica de termogravimetria. Cada amostra foi analisada com objetivo de avaliar os diferentes comportamentos térmicos dos materiais obtidos, dependendo da extensão da reação. Nas figuras 70 e 71 são apresentadas as curvas DSC para a celulose Papel Filtro antes e após a reação de oxipropilação pré-tratadas com $\mathrm{KOH}$ e DABCO, respectivamente.

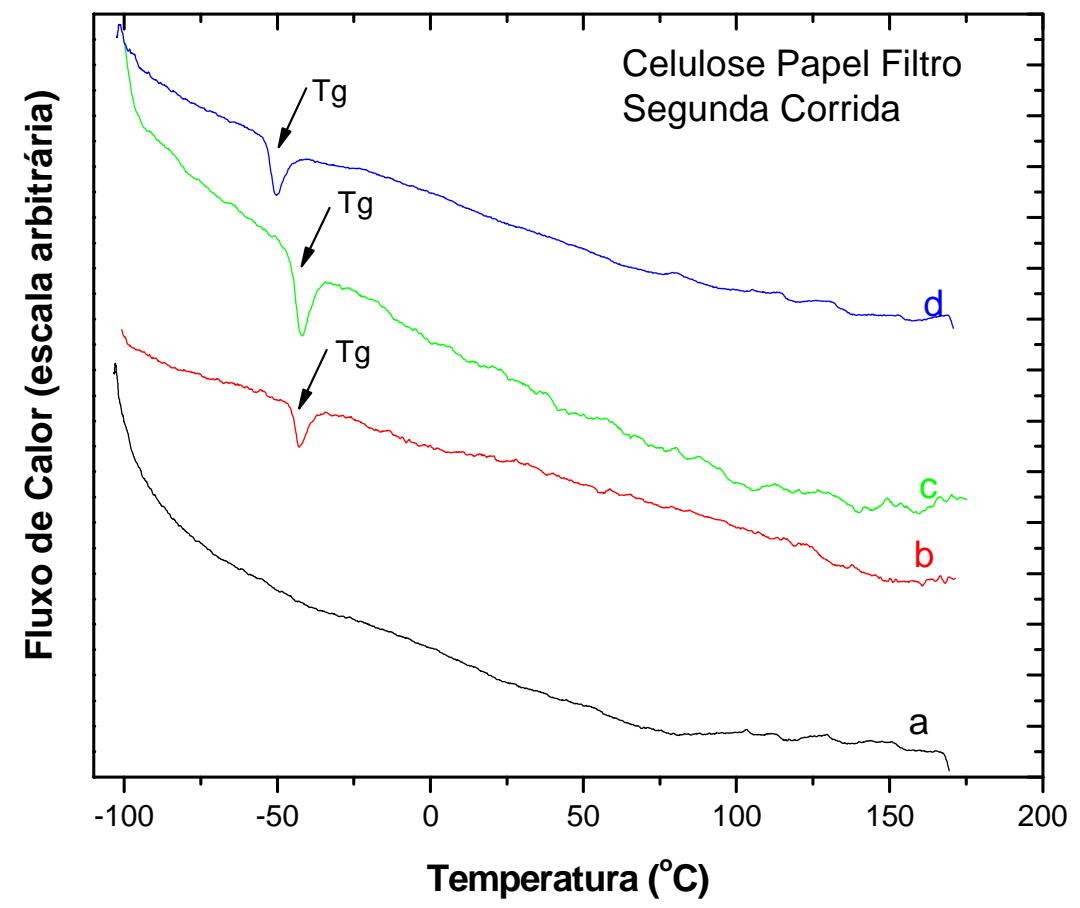

Figura 70: Curvas DSC da celulose Papel Filtro/KOH antes da modificação (a), modificado com razão molar [OP]/[OH celulose] igual a 1 (b), 3 (c) e 5 (d). 


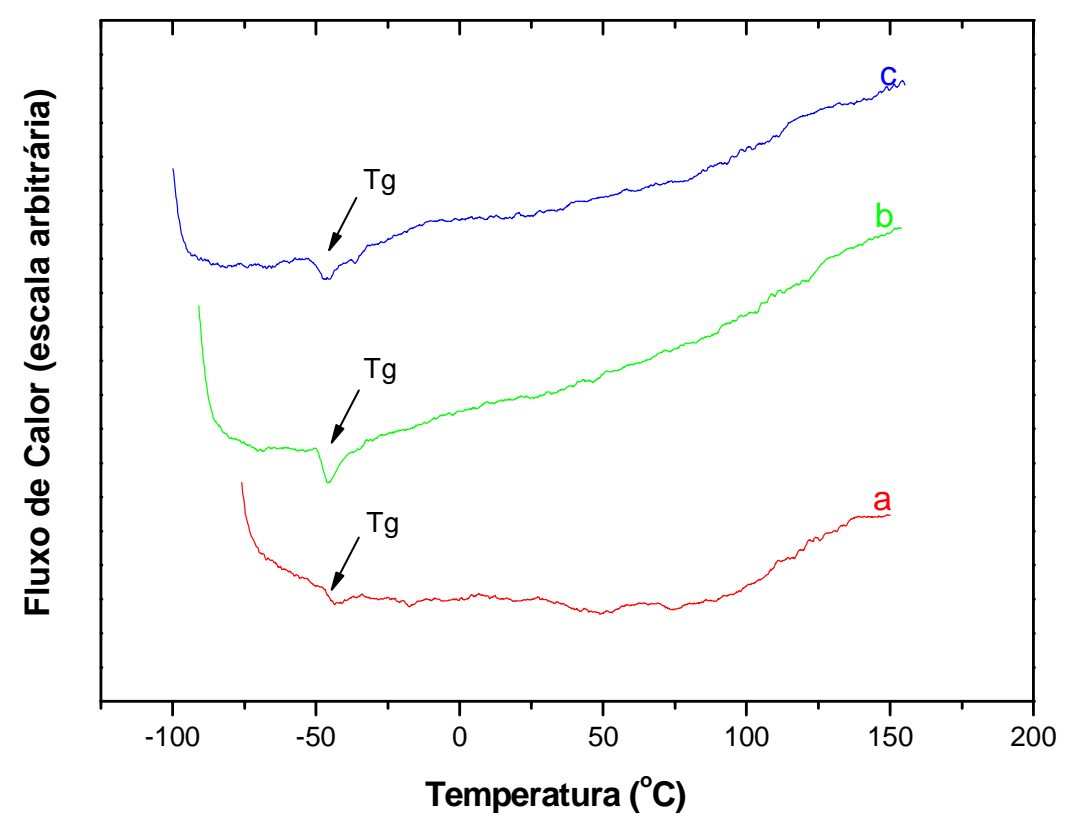

Figura 71: Curvas DSC da celulose Papel Filtro/DABCO modificado com razão molar $[\mathrm{OP}] /[\mathrm{OH}$ celulose] igual a 1 (a), 3 (b) e 5 (c).

Observa-se, que as amostras de Papel Filtro modificadas apresentaram transição na faixa de -50 a $-40{ }^{\circ} \mathrm{C}$, a qual pode ser atribuída à temperatura de transição vítrea (Tg). Esta transição, figuras 70 e 71, é atribuída a porção modificada das fibras, a qual não é observada para o material de partida (figura 70). As curvas DSC para o restante das amostras de celulose utilizadas neste trabalho não são apresentadas pelo fato desta transição não ter sido observada para estas.

O resultado obtido através da técnica de DSC para as amostra de celulose Papel Filtro está de acordo com a Tg do poli (oxido propileno - POP) amorfo, em torno de $-70{ }^{\circ} \mathrm{C}$ e corrobora com os resultados de Velazquez-Morales et al.1998, para quitosana oxipropilada, em que a $\mathrm{Tg}$ encontrada está na faixa de $-40 \mathrm{a}-10^{\circ} \mathrm{C}$, dependendo da extensão de oxipropilação, ou seja, quanto maior a extensão da reação menor o valor da $\mathrm{Tg}$. É importante comentar que Jain et al. 2001, encontrou valores de $\mathrm{Tg}$ acima de $100{ }^{\circ} \mathrm{C}$ para xilanas oxipropiladas com DS igual a 0,3 , 
entretanto, essa variação no valor de Tg é aceitável devido ao fato de que ela é extremamente influenciada pelo grau de modificação, condição de reação, matriz utilizada na modificação e a distribuição/dispersão dos grupos incorporados na fibra de celulose.

No trabalho realizado por Gómez-Carracedo et al., 2003, verificou-se que a Tg depende fortemente da estrutura do éter de celulose. Em geral, com aumento no grau de substituição dos grupos $\mathrm{OH}$ da celulose, as ligações de hidrogênio diminuem, especialmente quando os substituintes não podem fazer ligações de hidrogênio, diminuindo conseqüentemente o valor de $\mathrm{Tg}$. No caso dos grupos hidroxipropil incorporados, esperar-se-ia inicialmente verificar um aumento no valor da Tg quando comparados com substituintes que não fazem ligações de hidrogênio, devido ao aumento das ligações de hidrogênio entre esses grupos. Porém, a intensidade das ligações de hidrogênio é bem menor que a da celulose não modificada, além de reduzir a intensidade entre os grupos $\mathrm{OH}$ primários não substituídos da cadeia de celulose, tornando o material mais amorfo (dados de raios - X), diminuindo consequentemente o valor da Tg. Esta hipótese justifica os diferentes valores de Tg em função do grau de substituição.

A celulose Papel Filtro pré-tratada com DABCO, figura 71, apresentou comportamento semelhante ao da celulose Papel Filtro pré-tratada com $\mathrm{KOH}$, indicando que essa propriedade não foi influenciada pelo uso de diferentes bases. Deve-se salientar que a HPC comercial apresenta DS igual a 3 e grau de substituição molar igual 5,6. ou seja, todos os grupos $\mathrm{OH}$ presentes reagiram com um (1) monômero de óxido de propileno e estes por sua vez reagiram com mais cinco (5) monômeros cada, gerando um substituinte de tamanho considerável. 
Para o amido de milho oxipropilado com razão molar igual a 3 e pré-tratado com DABCO, figura 72 , nota-se o valor de $\operatorname{Tg}$ entre -45 a $-25{ }^{\circ} \mathrm{C}$. O fato de não se ter observado essa propriedade para o amido de milho oxipropilado com razão molar igual a 1 e 3 , pré-tratados com $\mathrm{KOH}$, pode ser justificado pelo fato de que $\mathrm{O} \mathrm{KOH}$ ser uma base forte, causando degradação parcial do amido. Esta hipótese baseia-se nos dados obtidos para a quitosana por Velazquez-Morales et al.1998. Estes autores afirmam que a quantidade ótima deste catalisador $(\mathrm{KOH})$ é de $2 \% \mathrm{w} / \mathrm{w}$, ocorrendo degradação da quitosana quando utiliza-se maiores concentrações. Já no presente trabalho utilizou-se razão molar de $[\mathrm{KOH}] /\{\mathrm{OH}$ amido] igual a 0,1 , ou seja, $10 \%$ do total de grupos $\mathrm{OH}$.

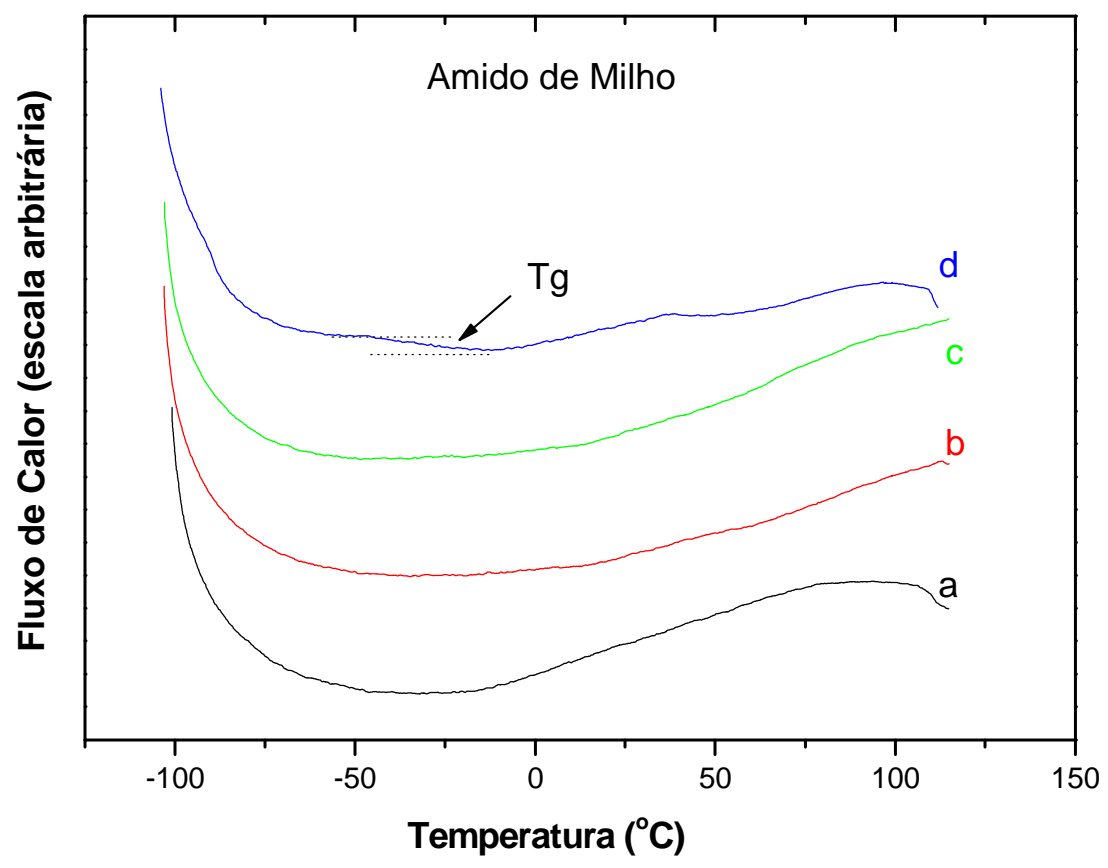

Figura 72: Curvas DSC do amido de Milho não modificado (a) e modificado com razão molar [OP]/[OH celulose] igual a 1 e pré-tratado com $\mathrm{KOH}$ (b), igual a 3 e prétratado com $\mathrm{KOH}$ (c) e igual a 3 e pré-tratado com DABCO (d). 


\section{VI.8 - ÂNGULO DE CONTATO}

A análise por ângulo de contato pode oferecer informações importantes sobre o comportamento hidrofílico/hidrofóbico de superfícies. Para que os resultados sejam confiáveis é necessário que as superfícies sejam lisas e homogêneas. Nas medidas realizadas por Trejo-O'Reilly et al., 1998, por ângulo de contato dinâmico, a deposição de uma gota de formamida sobre a superfície de papel modificado com diferentes agentes químicos, observou-se que para o papel não modificado o valor de ângulo de contato de aproximadamente $42^{\circ}$, o qual diminuiu rapidamente com o tempo, indicando boa interação entre a formamida e o papel que apresentava alta hidrofilicidade.

Para o papel tratado com o copolímero estireno-anidrido maleico, estes autores que o ângulo de contato apresentava valor inicial de $50^{\circ}$, que permaneceu inalterado com o tempo, dando indícios que a alteração realizada introduziu caráter hidrofóbico ao material. O mesmo comportamento foi observado quando utilizou-se água no lugar de formamida. Os autores calcularam neste trabalho os valores das energias de superfície utilizando a aproximação de Owens-Wendt bem como as contribuições das componentes polar e dispersiva ou não polar para cada material estudado. Os resultados demonstraram valores elevados para a componente polar e dispersiva para o substrato celulósico, comportamento esperado para superfícies ricas em grupos $\mathrm{OH}$. Com a introdução de grupos não polares a contribuição dispersiva permaneceu inalterada, enquanto a polar sofreu um decréscimo considerável. 
No presente trabalho foram medidos os ângulos de contato para celulose Avicel, Papel Filtro, polpa Kraft VCP, celulose Regenerada Rayon e Amido de Milho com quatro diferentes líquidos (água, formamida, etileno glicol e diiodometano), a fim de se determinar as contribuições dispersiva e polar da energia de superfície desses materiais. Para isto foi utilizada a aproximação proposta por Owens e Wendt 1969.

$$
W_{S L}=\gamma_{L}(1+\cos \theta)=2\left(\gamma_{L}^{d} \gamma_{S}^{d}\right)^{1 / 2}+2\left(\gamma_{L}^{p} \gamma_{S}^{p}\right)^{1 / 2} \text { equação (5) }
$$

Assumindo a condição de que $\gamma_{s}=\gamma^{d} s+\gamma_{s}^{p}$ seja obedecida, a equação 5 pode ser rearranjada da seguinte forma:

$$
W_{S L}=\gamma_{L}(1+\cos \theta) / 2\left(\gamma_{L}^{d}\right)^{1 / 2}=\left(\gamma_{L}^{p} \gamma_{S}^{p}\right)^{1 / 2} /\left(\gamma_{L}^{d}\right)^{1 / 2}+\left(\gamma_{S}^{d}\right)^{1 / 2}
$$

onde $W_{S L}$ é o trabalho de adesão entre o sólido e o líquido, $\theta$ é o ângulo de contato interno entre o líquido e a superfície sólida (figura 73), $\gamma_{\mathrm{L}}$ energia de superfície do líquido (valor tabelado) e $\gamma_{L}^{d}, \gamma_{S}^{d}, \gamma_{L}^{p_{L}}$ e $\gamma_{S}^{p_{S}}$ são as contribuições dispersiva e polar do líquido e da superfície sólida, respectivamente.

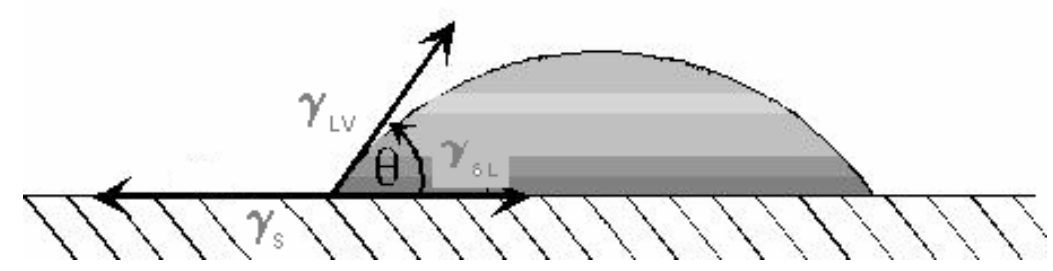

Figura 73: Representação do ângulo de contato entre uma gota de um líquido qualquer e uma superfície sólida e horizontal. 
Construindo um gráfico de $\gamma_{\mathrm{L}}(1+\cos \theta) / 2\left(\gamma_{\mathrm{L}}^{\mathrm{d}}\right)^{1 / 2}$ versus $\left(\gamma^{\mathrm{D}} \mathrm{L} \gamma^{\mathrm{d}} \mathrm{L}\right)^{1 / 2}$ o qual deve apresentar comportamento linear com coeficiente angular igual $\left(\gamma^{\mathrm{p}} \mathrm{s}\right)^{1 / 2}$ e coeficiente linear igual a $\left(\gamma^{d} s\right)^{1 / 2}$.

Este método de aproximação foi utilizado por Botaro e Gandini, 1998, para determinar as energias de superfície de vários substratos celulósicos, entre eles papel, após estes terem sido modificados com 3 -isopropenil- $\alpha, \alpha$-dimetilbenzil isocianato (TMI) e 2-isocianatoetil metacrilato (IEM) para posterior reação com estireno ou metacrilato de metila através da polimerização radicalar. Essas moléculas de enxertia apresentam caráter apolar, ou seja, com energia de superfície predominantemente dispersiva. Os resultados obtidos demonstraram queda na componente polar das celuloses modificadas, isto é, considerável aumento no caráter hidrofóbico do substrato de celulose resultando em uma melhor adesão entre as fibras e matrizes com energia de superfície predominantemente dispersiva.

Os valores de ângulo de contato e energias de superfície para as celuloses em questão são apresentados nas tabelas 8 a 11 . Os valores apresentados são valores médios de três (3) medidas realizadas com baixo desvio padrão. A mudança de $\theta$ em função do aumento da razão molar [OP]/OHcel] são refletidas nas correspondentes mudanças entre as contribuições dispersiva e polar da energia de superfície das amostras após as reações de modificação. 
Tabela 8: Valores dos ângulos de contato e energia de superfície das fibras de celulose Avicel antes e após modificação química por oxipropilação.

\begin{tabular}{|c|c|c|c|c|c|c|c|}
\hline \multirow[b]{2}{*}{ Amostra } & \multicolumn{4}{|c|}{ Ângulos de Contato $\left({ }^{\circ}\right)$} & \multirow[b]{2}{*}{$\begin{array}{c}\gamma^{p} s \\
\left(m J \cdot m^{-2}\right)\end{array}$} & \multirow[b]{2}{*}{$\begin{array}{c}\gamma^{d} s \\
\left(m J \cdot m^{-2}\right)\end{array}$} & \multirow[b]{2}{*}{$\begin{array}{c}\gamma_{\mathrm{s}}^{\top} \\
\left(\mathrm{mJ} \cdot \mathrm{m}^{-2}\right)\end{array}$} \\
\hline & Água & Formamida & $\begin{array}{c}\text { Etileno } \\
\text { Glicol }\end{array}$ & Diiodometano & & & \\
\hline AVI & 34 & 33 & 27 & 23 & 32,23 & 24,23 & 56,46 \\
\hline AVOP1 & 31 & 32 & 32 & 22 & 34,06 & 23,19 & 57,25 \\
\hline AVOP3 & 44 & 36 & 43 & 28 & 26,07 & 24,33 & 50,39 \\
\hline AVOP5 & 76 & 70 & 68 & 34 & 6,13 & 26,71 & 32,84 \\
\hline
\end{tabular}

A superfície da celulose original, não tratada, apresentou valores elevados para a componente polar, comportamento esperado para superfícies ricas em grupos $\mathrm{OH}$, devido ao fato destes substratos serem mais aptos a estabelecerem ligações de hidrogênio devido ao caráter altamente hidrofílico, que é caracterizado pelo baixo ângulo medido inicialmente Trejo-O’Reilly et al., 1998, além do rápido decréscimo com o tempo (gráfico não apresentado).

Tabela 9: Valores dos ângulos de contato e energia de superfície das fibras de celulose de Papel Filtro/KOH antes e após modificação química por oxipropilação.

\begin{tabular}{|c|c|c|c|c|c|c|c|}
\hline \multirow[b]{2}{*}{ Amostra } & \multicolumn{4}{|c|}{ Ângulos de Contato $\left({ }^{\circ}\right)$} & \multirow[b]{2}{*}{$\begin{array}{c}\gamma^{p} s \\
\left(m J . m^{-2}\right)\end{array}$} & \multirow[b]{2}{*}{$\begin{array}{c}\gamma_{s}^{d} \\
\left(m J \cdot m^{-2}\right)\end{array}$} & \multirow[b]{2}{*}{$\begin{array}{c}\gamma_{s}^{\top} \\
\left(m J \cdot m^{-2}\right)\end{array}$} \\
\hline & Água & Formamida & $\begin{array}{l}\text { Etileno } \\
\text { Glicol }\end{array}$ & Diiodometano & & & \\
\hline $\mathrm{PF}$ & 42 & 36 & 36 & 40 & 30,76 & 21,12 & 51,88 \\
\hline PFOP1 & 42 & 69 & 62 & 35 & 31,89 & 13,32 & 45,21 \\
\hline PFOP3 & 47 & 61 & 60 & 31 & 26,05 & 17,61 & 43,66 \\
\hline PFOP5 & 78 & 65 & 70 & 41 & 5,83 & 26,46 & 32,29 \\
\hline
\end{tabular}


Comportamento semelhante foi observado para os diferentes tipos de celulose, porém com valores distintos.

Tabela 10: Valores dos ângulos de contato e energia de superfície das fibras de celulose Polpa Kraft VCP antes e após modificação química por oxipropilação

\begin{tabular}{|c|c|c|c|c|c|c|c|}
\hline \multirow[b]{2}{*}{ Amostra } & \multicolumn{4}{|c|}{ Ângulos de Contato $\left({ }^{\circ}\right)$} & \multirow[b]{2}{*}{$\begin{array}{c}\gamma^{p} s \\
\left(m J \cdot m^{-2}\right)\end{array}$} & \multirow[b]{2}{*}{$\begin{array}{c}\gamma_{s}^{d} \\
\left(m J \cdot m^{-2}\right)\end{array}$} & \multirow[b]{2}{*}{$\begin{array}{c}\gamma_{s}^{\top} \\
\left(m J \cdot m^{-2}\right)\end{array}$} \\
\hline & Água & Formamida & $\begin{array}{c}\text { Etileno } \\
\text { Glicol }\end{array}$ & Diiodometano & & & \\
\hline PKVCP & 50 & 41 & 41 & 28 & 21,59 & 26,24 & 47,83 \\
\hline PKVOP1 & 55 & 56 & 60 & 44 & 22,21 & 18,08 & 40,49 \\
\hline PKVOP3 & 69 & 64 & 63 & 42 & 11,40 & 22,82 & 34,23 \\
\hline PKVOP5 & 73 & 40 & 41 & 32 & 6,35 & 38,10 & 44,45 \\
\hline
\end{tabular}

Tabela 11: Valores dos ângulos de contato e energia de superfície das fibras de celulose Regenerada Rayon antes e após modificação química por oxipropilação.

\begin{tabular}{|c|c|c|c|c|c|c|c|}
\hline \multirow[b]{2}{*}{ Amostra } & \multicolumn{4}{|c|}{ Ângulos de Contato ( $\left.{ }^{\circ}\right)$} & \multirow[b]{2}{*}{$\begin{array}{c}\gamma_{s}^{p} \\
\left(m J \cdot m^{-2}\right)\end{array}$} & \multirow[b]{2}{*}{$\begin{array}{c}\gamma^{d} s \\
\left(m J \cdot m^{-2}\right)\end{array}$} & \multirow[b]{2}{*}{$\begin{array}{c}\gamma^{\top} s \\
\left(m J \cdot m^{-2}\right)\end{array}$} \\
\hline & Água & Formamida & $\begin{array}{c}\text { Etileno } \\
\text { Glicol }\end{array}$ & Diiodometano & & & \\
\hline CRR & 46 & 26 & 36 & 31 & 24,68 & 26,70 & 51,37 \\
\hline CRROP1 & 48 & 43 & 50 & 47 & 28,52 & 18,21 & 46,73 \\
\hline CRROP3 & 57 & 60 & 68 & 41 & 20,24 & 17,74 & 37,98 \\
\hline CRROP5 & 78 & 78 & 88 & 41 & 6,44 & 19,77 & 26,21 \\
\hline
\end{tabular}


Para as amostras oxipropiladas com razão molar igual a 1, esperar-se-ia um pequeno decréscimo na contribuição polar, entretanto, não foi esse o comportamento observado e sim o aumento desta. $\mathrm{O}$ aumento desse caráter polar pode ser atribuído ao fato da maior exposição dos grupos $\mathrm{OH}$, devido a melhor distribuição do óxido propileno incorporado, ou seja, um suposto maior DS.

As amostra modificadas com razão molar igual a 3 e 5 demonstraram o esperado decréscimo na contribuição polar $\left(\gamma^{P} s\right)$, com decréscimo mais pronunciado para as amostras oxipropilada com razão molar [OP]/OHcel] igual a 5. Apesar do óxido de propileno incorporado nas fibras de celulose ser hidrofóbico e insolúvel em água, este retém um caráter polar devido aos grupos éter e $\mathrm{OH}$ em sua estrutura, gerados durante a reação, o qual pode justificar o pequeno aumento ocorrido para as amostras modificadas com razão molar igual a 1 em relação a amostra original.

Esse comportamento de decréscimo na componente polar deveria ser esperado para as amostras modificadas com razão molar igual a 3 e 5, apesar destas também apresentarem esses grupos em sua estrutura, devido ao fato do elevado ganho de massa contribuir com aumento de número de cadeia carbônica, reduzindo por sua vez o número de ligações de hidrogênio, diminuindo nessas condições o valor da contribuição polar $\left(\gamma^{\mathrm{P}} \mathrm{s}\right)$ quando comparadas com as amostras modificadas com razão molar igual 1. A grande quantidade de óxido propileno incorporados na cadeia da celulose ocasionaria um decréscimo na disponibilidade de sítios de interação com líquidos polares. Nas tabelas 12 e 13 são apresentados os valores para a celulose Papel Filtro oxipropilada, pré-tratadas com DABCO, e para o amido de Milho oxipropilado. 
Tabela 12: Valores dos ângulos de contato e energia de superfície das fibras de celulose de Papel Filtro/DABCO antes e após modificação química por oxipropilação.

\begin{tabular}{|c|c|c|c|c|c|c|c|}
\hline \multirow[b]{2}{*}{ Amostra } & \multicolumn{4}{|c|}{ Ângulos de Contato $\left({ }^{\circ}\right)$} & \multirow[b]{2}{*}{$\begin{array}{c}\gamma^{p} \mathrm{~s} \\
\left(\mathrm{~mJ} \cdot \mathrm{m}^{-2}\right)\end{array}$} & \multirow[b]{2}{*}{$\begin{array}{c}\gamma^{\mathrm{d}} \mathrm{s} \\
\left(\mathrm{mJ} \cdot \mathrm{m}^{-2}\right)\end{array}$} & \multirow[b]{2}{*}{$\begin{array}{c}\boldsymbol{\gamma}_{\mathrm{S}}^{\top} \\
\left(\mathrm{mJ} \cdot \mathrm{m}^{-2}\right)\end{array}$} \\
\hline & Água & Formamida & $\begin{array}{l}\text { Etileno } \\
\text { Glicol }\end{array}$ & Diiodometano & & & \\
\hline $\mathrm{PF}$ & 42 & 36 & 36 & 40 & 30,76 & 21,12 & 51,88 \\
\hline PFDOP1 & 75,7 & 55,4 & 67,5 & 20,5 & 4,53 & 34,08 & 38,61 \\
\hline PFDOP3 & 103,0 & 82,8 & 75,9 & 40,7 & 0,03 & 35,71 & 35,74 \\
\hline PFDOP5 & 109,1 & 86,5 & 96,5 & 45,7 & 0,38 & 31,46 & 31,84 \\
\hline
\end{tabular}

Tabela 13: Valores dos ângulos de contato e energia de superfície das fibras de Amido de Milho antes e após modificação química por oxipropilação.

\begin{tabular}{|c|c|c|c|c|c|c|c|}
\hline \multirow[b]{2}{*}{ Amostra } & \multicolumn{4}{|c|}{ Ângulos de Contato $\left({ }^{\circ}\right)$} & \multirow[b]{2}{*}{$\begin{array}{c}\gamma^{p} s \\
\left(m J \cdot m^{-2}\right)\end{array}$} & \multirow[b]{2}{*}{$\begin{array}{c}\gamma^{\mathrm{d}} \mathrm{s} \\
\left(\mathrm{mJ} \cdot \mathrm{m}^{-2}\right)\end{array}$} & \multirow[b]{2}{*}{$\begin{array}{c}\boldsymbol{\gamma}^{\top} \mathrm{s} \\
\left(\mathrm{mJ} \cdot \mathrm{m}^{-2}\right)\end{array}$} \\
\hline & Água & Formamida & $\begin{array}{c}\text { Etileno } \\
\text { Glicol }\end{array}$ & Diiodometano & & & \\
\hline Amidex & 50 & 31 & 43 & 31 & 21,94 & 26,86 & 48,80 \\
\hline AOP1/KOH & 58 & 50 & 51 & 43 & 19,63 & 21,84 & 41,47 \\
\hline $\mathrm{AOP} 3 / \mathrm{KOH}$ & 82 & 74 & 77 & 48 & 5,31 & 22,27 & 27,58 \\
\hline AOP1/DABCO & 78 & 64 & 74 & 46 & 6,77 & 23,96 & 30,73 \\
\hline
\end{tabular}

Para as amostras de celulose Papel Filtro pré-tratadas com DABCO observase queda na componente polar para a razão molar igual a 1, corroborando com a hipótese levantada na discussão dos dados de TG sobre melhor distribuição do óxido propileno na cadeia de celulose para o pré-tratamento com $\mathrm{KOH}$ em relação 
ao DABCO, ou seja, maior DS e menor MS, causando maior exposição dos grupos $\mathrm{OH}$ para pré-tratamento com $\mathrm{KOH}$. Os valores elevados de ângulo de contato para a celulose Papel filtro/DABCO corrobora com a hipótese de que o ganho de massa elevado ocasiona um decréscimo na disponibilidade de sítios de interação com líquidos polares. Nas figuras 74 a 76 são apresentados os valores de energias em função da razão molar, para melhor visualização do comportamento. Os valores obtidos para o Amido de Milho podem ser justificados ao considerável ganho de massa, isto é, decréscimo na acessibilidade dos grupos $\mathrm{OH}$.

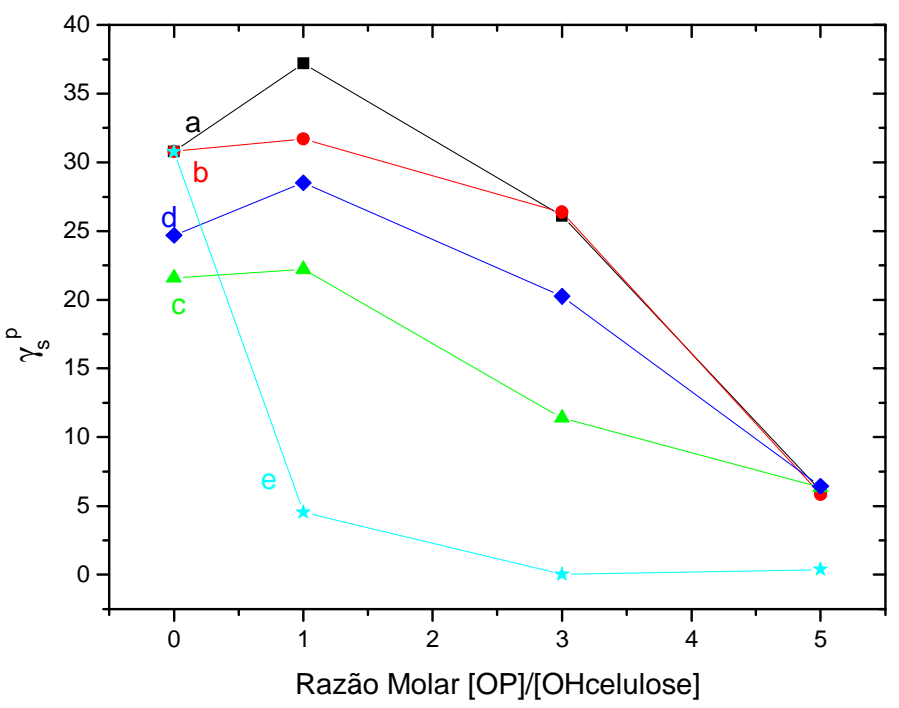

Figura 74: Gráfico componente polar de superfície versus razão molar [OP]/[OHcelulose] para celulose Avicel (a), Papel Filtro/KOH (b), Polpa Kraft VCP (c), Regenerada Rayon (d) e Papel Filtro/DABCO (e). 


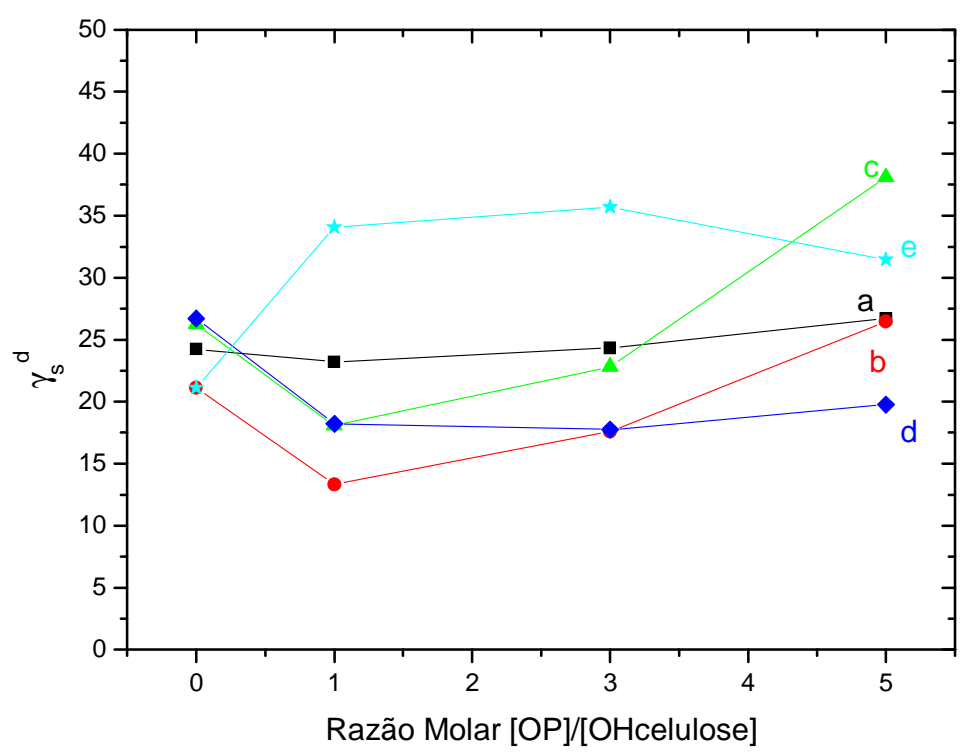

Figura 75: Gráfico componente dispersiva de superfície versus razão molar [OP]/[OHcelulose] para celulose Avicel (a), Papel Filtro/KOH (b), Polpa Kraft VCP (c), Regenerada Rayon (d) e Papel Filtro/DABCO (e).

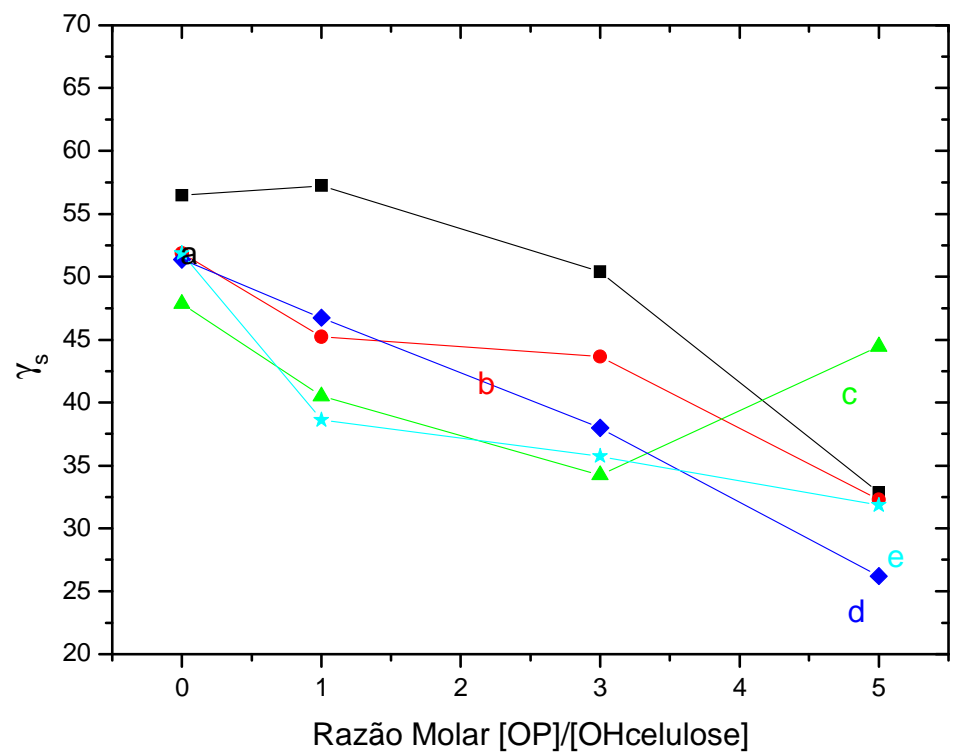

Figura 76: Gráfico energia total de superfície versus razão molar [OP]/[OHcelulose] para celulose Avicel (a), Papel Filtro/KOH (b), Polpa Kraft VCP (c), Regenerada Rayon (d) e Papel Filtro/DABCO (e).. 
Como discutido anteriormente para as outras técnicas utilizadas, sobre a influência da utilização da base no pré-tratamento, nota-se que as propriedades de superfície são também influenciadas e corrobora com a hipótese de que a utilização da base de Bronsted $(\mathrm{KOH})$ como catalisador pode causar algum nível de degradação no material quando estes são submetidos a reação a altas temperatura, neste caso, $135{ }^{\circ} \mathrm{C}$. Esta hipótese está fundamentada quando compara-se os resultados obtidos para a celulose de papel filtro pré-tratados com $\mathrm{KOH}$ (base forte de Bronsted) e DABCO (base fraca de Lewis). Quanto a componente dispersiva, com exceção da celulose Papel Filtro/KOH e celulose Polpa Kraft VCP, os valores após a modificação com razão molar igual a 1 foram praticamente constantes. 


\section{VI.9 - ENSAIOS DE TRAÇÃO VERSUS DEFORMAÇÃO}

As propriedades mecânicas dos polímeros são caracterizadas pela resposta que estes apresentam quando submetidos à tensões ou deformações. A natureza dessa resposta depende da estrutura química, temperatura, tempo e da história (condições) de processamento do polímero. A estrutura molecular dos polímeros pode proporcionar um comportamento viscoso, como os líquidos, superposto com um comportamento elástico, como os sólidos Hookeanos. Esse fenômeno é denominado de viscoelasticidade e ocorre para os plásticos e para as fibras.

Em função dos polímeros possuírem uma estrutura molecular particular, quando comparados com materiais como metais e cerâmicas, o seu comportamento mecânico é único. Para os polímeros, as tensões e deformações não são relacionadas através de simples constantes de proporcionalidade, como o módulo de elasticidade. As respostas destes as solicitações mecânicas são acentuadamente dependentes de fatores estruturais e de variáveis externas. Além da composição química, podem ser citados os seguintes fatores estruturais que globalmente afetam as propriedades mecânicas desta classe de materiais: massa molar; ramificações e ligações cruzadas; cristalinidade, incluindo morfologia cristalina; copolimerização, incluindo tipo de copolímero; blendas poliméricas; orientação molecular, reforços, cargas, plastificantes e outros aditivos.

As principais variáveis externas que afetam o comportamento mecânico dos polímeros são: temperatura; tempo ou velocidade de deformação (ou velocidade de aplicação da tensão); nível de solicitação mecânica; tipo de solicitação; etc. 
No presente trabalho realizou-se medidas de tensão sob tração versus deformação para as amostras de Papel Filtro pré-tratadas com KOH e DABCO. Os gráficos obtidos para as amostras pré-tratadas com $\mathrm{KOH}$ são apresentados nas figuras 77 a 80 . As diferentes cores indicam o número de medidas efetuadas para cada amostra. Os valores correspondentes de resistência a tração $(\sigma)$, deformação (ع) e módulo de elasticidade ou de Young (E) para estas amostras são apresentadas na tabela 14. Fez-se medidas apenas para esses materiais, pois foram os únicos que permitiram a obtenção de filmes homogêneos por termo-prensagem. A temperatura utilizada na termo-prensa foi de $135{ }^{\circ} \mathrm{C}$ durante sete (7) minutos, os quais foram divididos da seguinte forma: três (3) minutos de fusão sem aplicar pressão, dois (2) minutos com pressão de duas e meia $(2,5)$ toneladas métricas e por fim dois (2) minutos com pressão de cinco (5) toneladas métricas.

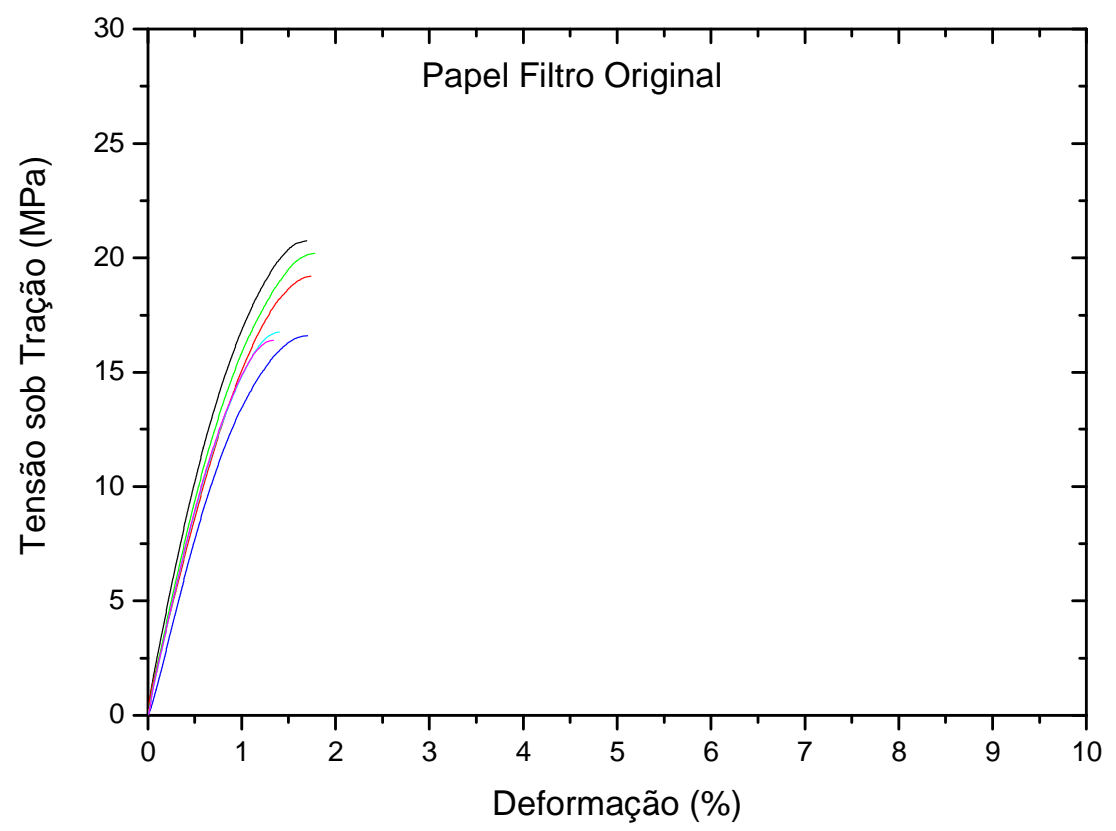

Figura 77: Curvas de tensão sob tração versus deformação para amostra de celulose de Papel Filtro Original. 


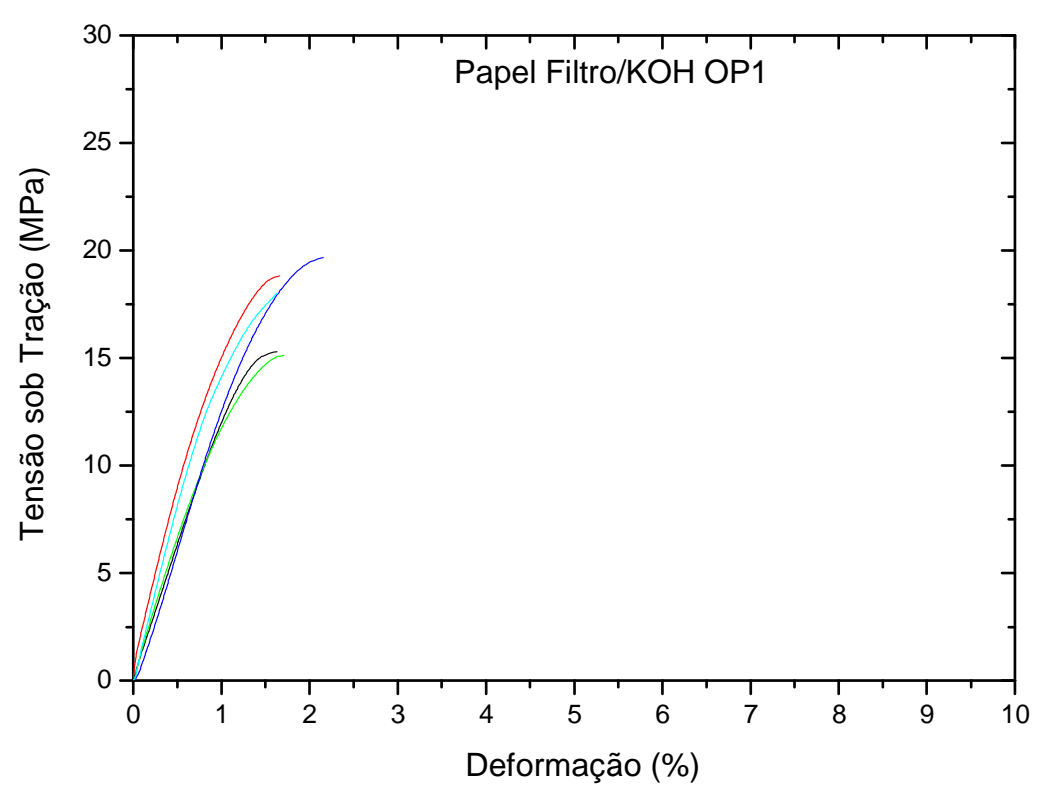

Figura 78: Curva de tensão sob tração versus deformação pra celulose de Papel Filtro/KOH oxipropilada com razão molar de [OP]/[ OHcel] igual a 1.

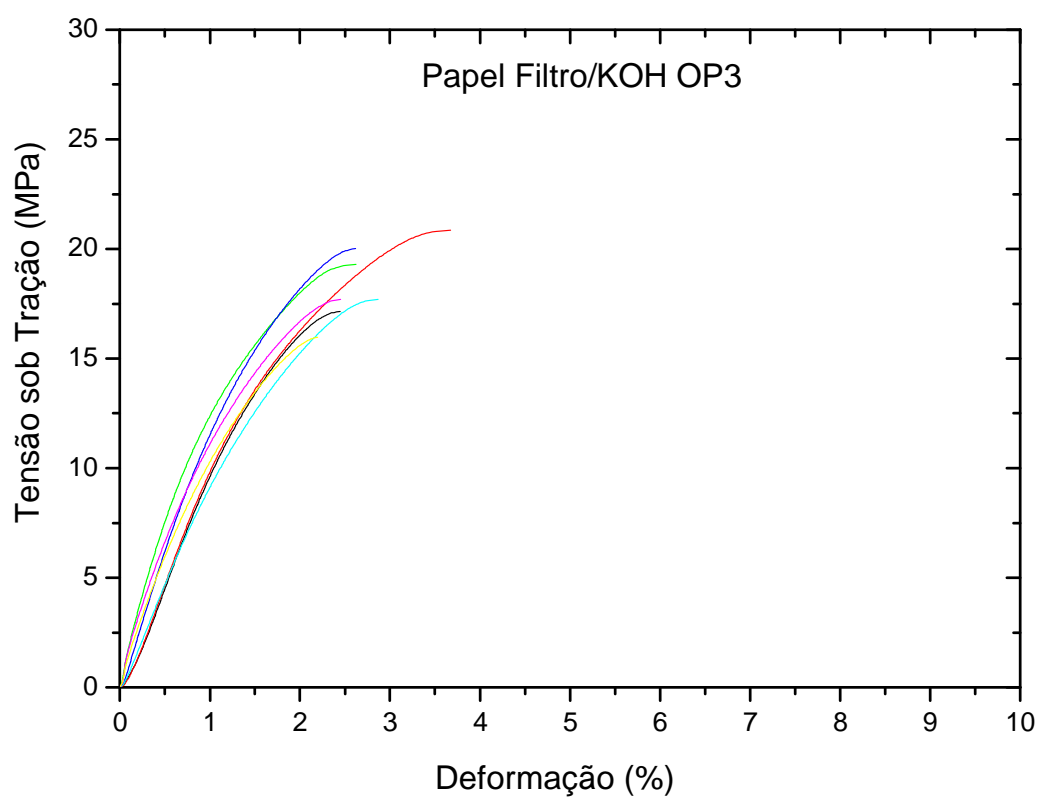

Figura 79: Curva de tensão sob tração versus deformação pra celulose de Papel Filtro/KOH oxipropilada com razão molar de [OP]/[ OHcel] igual a 3. 


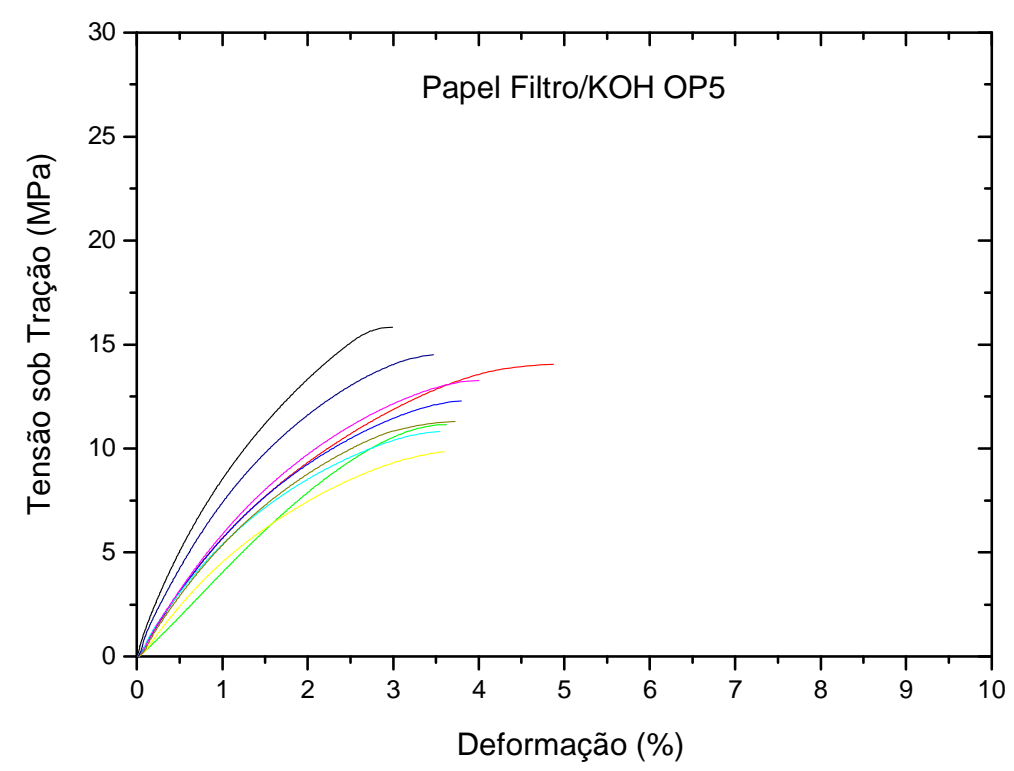

Figura 80: Curva de tensão sob tração versus deformação pra celulose de Papel Filtro/KOH oxipropilada com razão molar de [OP]/[ OHcel] igual a 5.

Tabela 14: Dados de ensaio de tensão sob tração versus deformação para celulose Papel Filtro/KOH antes e após modificação.

\begin{tabular}{cccc}
\hline Celulose & $\begin{array}{c}\text { Resistência à tração } \\
(\mathrm{Mpa})\end{array}$ & Elongação (\%) & $\begin{array}{c}\text { Módulo de Elasticidade } \\
\text { (Gpa) }\end{array}$ \\
\hline PF & $18,2 \pm 2,0$ & $1,61 \pm 0,2$ & $1,77 \pm 0,14$ \\
PFOP1 & $17,3 \pm 2,0$ & $1,76 \pm 0,2$ & $1,41 \pm 0,21$ \\
PFOP3 & $18,7 \pm 1,5$ & $2,70 \pm 0,5$ & $1,18 \pm 0,16$ \\
PFOP5 & $13,1 \pm 1,7$ & $3,74 \pm 0,5$ & $0,55 \pm 0,07$ \\
\hline
\end{tabular}

Nota-se que os valores de resistência à tração decrescem, exceção da amostra modificada com razão molar igual a 3, com aumento da razão molar, porém, o ganho de massa foi praticamente constante para todas as amostras. Observa-se também que o módulo de elasticidade decresce e a elongação cresce com o aumento da razão molar. Avaliando-se em relação ao ganho de massa, esperar-se- 
ia que não houvesse variações nessas propriedades após as reações de oxipropilação, já que o ganho de massa permaneceu constante. Matsumura, 2000, através dos estudos com nanocompósitos de hexanoato de celulose observou inicialmente o aumento de resistência a tração com o aumento do grau de substituição, DS entre 0,5 e 1,0, e o decréscimo com valores maiores. O mesmo comportamento foi observado para o módulo de elasticidade e para a elongação notou-se crescimento com o aumento de DS.

Para celulose Papel Filtro pré-tratadas com DABCO, figuras 81 a 83, observase comportamento distinto em relação à celulose pré-tratada com $\mathrm{KOH}$. Os valores correspondentes de resistência a tração $(\sigma)$, deformação $(\varepsilon)$ e módulo de elasticidade ou de Young (E) para estas amostras são apresentadas na tabela 15.

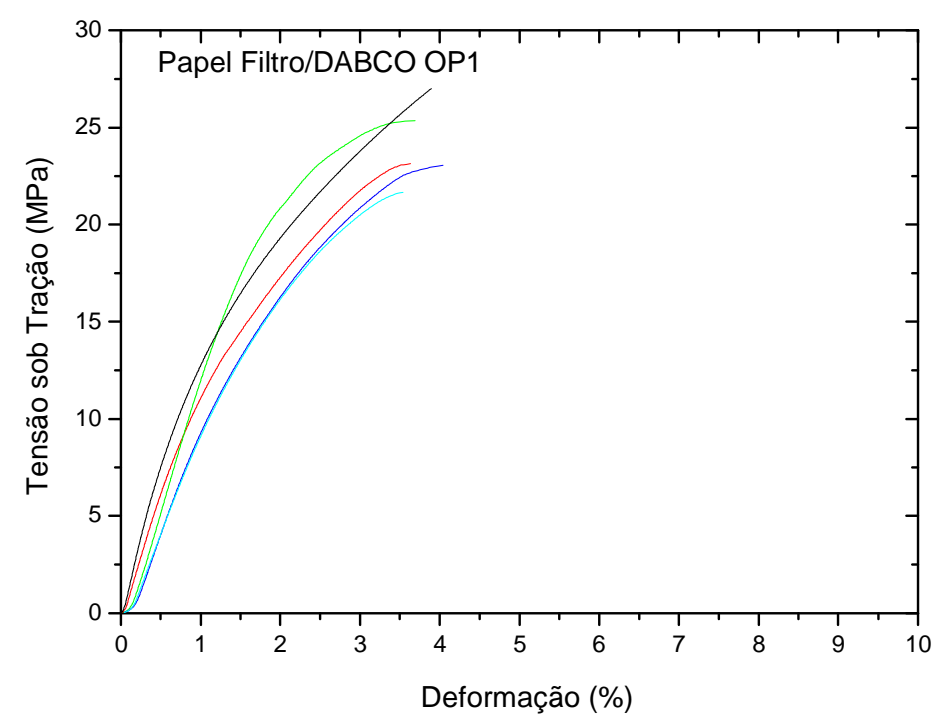

Figura 81: Curva de tensão sob tração versus deformação pra celulose de Papel Filtro/DABCO oxipropilada com razão molar de [OP]/[ OHcel] igual a 1. 


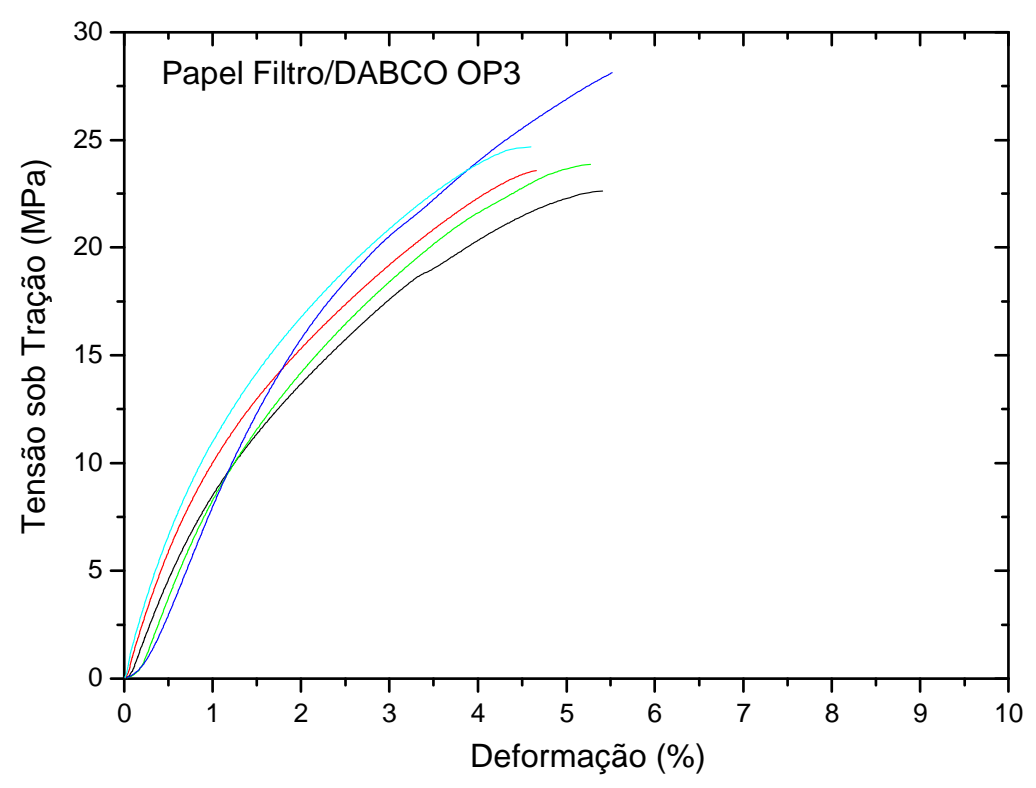

Figura 82: Curva de tensão sob tração versus deformação pra celulose de Papel Filtro/DABCO oxipropilada com razão molar de [OP]/[ OHcel] igual a 3.

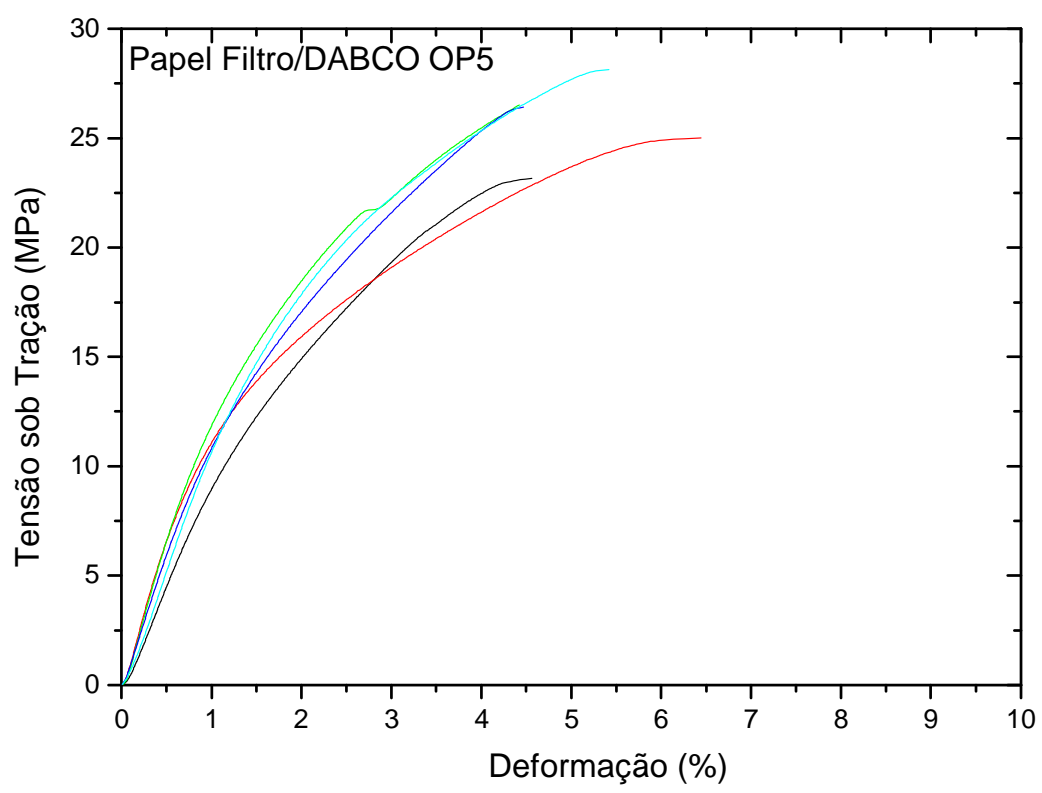

Figura 83: Curva de tensão sob tração versus deformação pra celulose de Papel Filtro/DABCO oxipropilada com razão molar de [OP]/[ OH cel] igual a 5. 
Tabela 15: Dados de ensaio de tensão sob tração versus deformação para celulose Papel Filtro/DABCO antes e após modificação.

\begin{tabular}{cccc}
\hline Celulose & $\begin{array}{c}\text { Resistência à tração } \\
(\mathrm{Mpa})\end{array}$ & Elongação (\%) & $\begin{array}{c}\text { Módulo de Elasticidade } \\
(\mathrm{Mpa})\end{array}$ \\
\hline PF & $18,2 \pm 2,0$ & $1,61 \pm 0,2$ & $1,77 \pm 0,14$ \\
PFOP1 & $23,5 \pm 2,0$ & $3,82 \pm 0,2$ & $1,37 \pm 0,41$ \\
PFOP3 & $24,5 \pm 2,1$ & $5,09 \pm 0,4$ & $1,21 \pm 0,10$ \\
PFOP5 & $25,7 \pm 1,8$ & $4,91 \pm 0,6$ & $1,31 \pm 0,12$ \\
\hline
\end{tabular}

Observa-se crescimento tanto nos valores de resistência a tração quanto nos valores de elongação com aumento da razão molar, contudo, o ganho de massa foi praticamente constante para estas amostras e próximo dos valores obtidos para a celulose Papel Filtro pré-tratada com $\mathrm{KOH}$. Conseqüentemente seria de se esperar propriedades mecânicas semelhantes. Entretanto, deve-se atentar ao fato de que a variação no índice de cristalinidade (IC) em função da reação em diferentes razões molares não foi semelhante. Tendo em vista que a fração cristalina atua como "reforço" nos materiais compósitos, essa propriedade influencia consideravelmente nas propriedades mecânicas, como pode ser observado nos gráficos das figuras abaixo. 


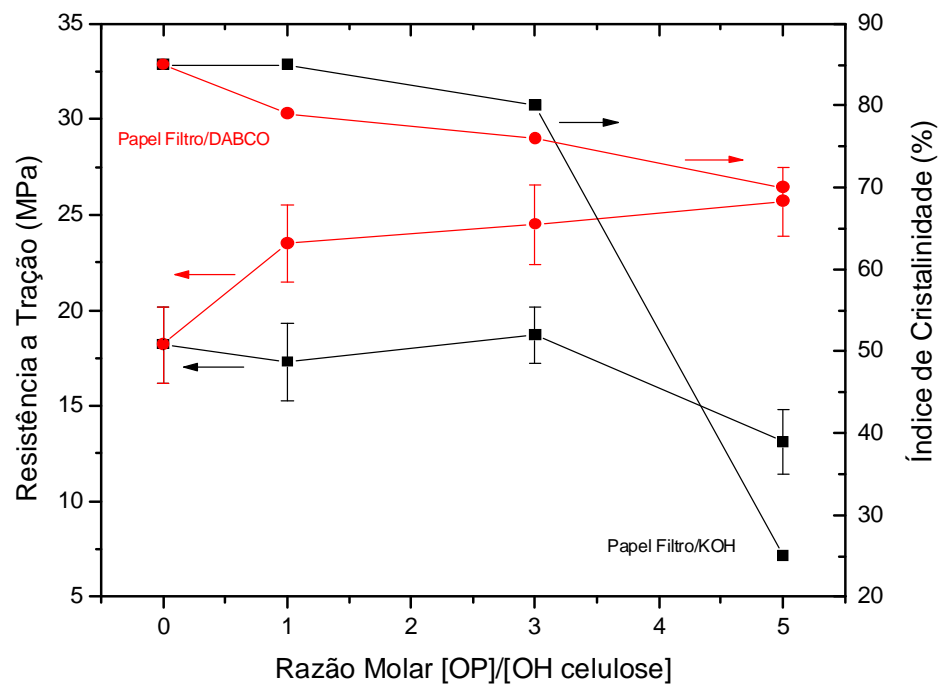

Figura 84: Gráfico de tensão sob tração na ruptura versus razão molar [OP]/[OH celulose] para celulose Papel Filtro.

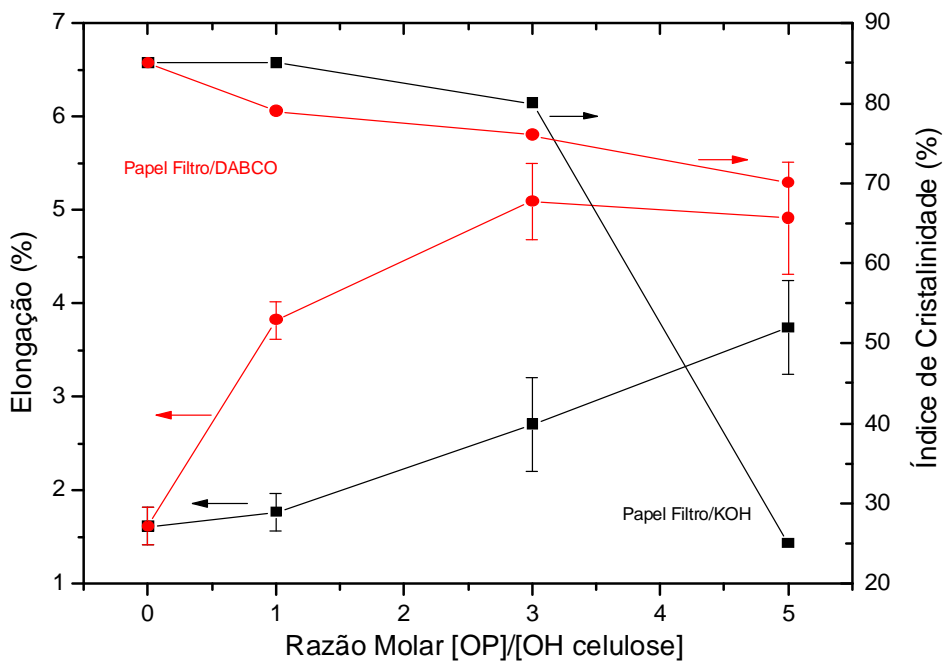

Figura 85: Gráfico de elongação versus razão molar [OP]/[OH celulose] para celulose Papel Filtro. 


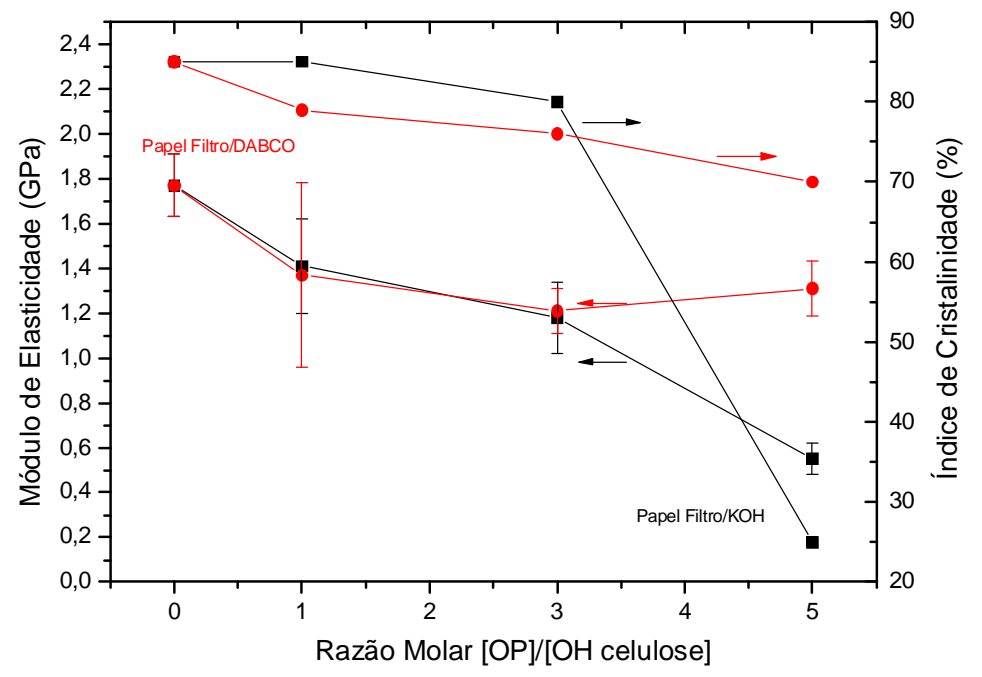

Figura 86: Gráfico do Módulo Elástico versus razão molar [OP]/[OH celulose] para celulose Papel Filtro.

A diferença nos valores obtidos entre a celulose Papel Filtro pré-tratadas com $\mathrm{KOH}$ e DABCO pode ser atribuída a hipótese da possível degradação causada pelo uso da base forte, ou seja, do $\mathrm{KOH}$ (base de Bronsted). Como citada anteriormente, essa hipótese baseia-se nos dados obtidos para a quitosana por Velazquez-Morales et al.1998. Estes autores observaram que a quantidade ótima do catalisador $\mathrm{KOH}$ foi de $2 \% \mathrm{w} / \mathrm{w}$, ocorrendo degradação da quitosana quando utilizou-se maiores concentrações e, como citado no procedimento experimental do presente trabalho, utilizou-se razão molar de $[\mathrm{KOH}] /\{\mathrm{OH}$ amido] igual a 0,1 , ou seja, $10 \%$ do total de grupos $\mathrm{OH}$. 


\section{VII - CONCLUSÕES}

Através das medidas de FTIR comprovou-se a obtenção do produto oxipropilado. A modificação química dos diferentes substratos de celulose e do amido de milho com óxido de propileno foi restrita apenas a superfície destas, para as reações com razão molar [OP]/OHcel] igual a 1, como pode ser observado através das microscopias e dos valores de índice de cristalinidade apresentadas.

As medidas de análise termogravimétrica (TGA) demonstraram inicialmente uma queda nessa propriedade para os substratos modificados com razão molar [OP]/OHcel] igual a 1 em relação ao não modificado e um aumento considerável para algumas amostras modificadas com razão molar [OP]/OHcel] igual a 5 em relação ao substrato com razão molar [OP]/OHcel] igual a 1.

As medidas de calorimetria exploratória diferencial (DSC) estão de acordo com os dados apresentados na literatura sobre a temperatura de transição vítrea $\left(T_{g}\right)$ para polissacarídeos oxipropilados.

Observou-se através das medidas de ângulo de contato que o material adquire caráter hidrofóbico considerável após ser modificado com razão molar de $[\mathrm{OP}] / \mathrm{OH}$ celulose] maior ou igual a 3 .

Em relação ao tipo de catalisador, o DABCO (base de Lewis) apresentou melhor desempenho, devido ao fato de ser uma base fraca em relação ao $\mathrm{KOH}$ (base de Bronsted) não contribuindo/promovendo degradação dos materiais. 
Os ensaios mecânicos apresentaram comportamentos diferentes para o substrato pré-tratado com $\mathrm{KOH}$ e $\mathrm{DABCO}$, apresentando melhores resultados quando utiliza-se DABCO como catalisador.

Os resultados obtidos através das técnicas utilizadas dão evidências claras de que é possível preparar compósito mono-componente (all-cellulose composite ou allstarch composite) via reação em uma única etapa sem a necessidade métodos laboriosos de purificação e utilização de vários solventes orgânicos. Os resultados obtidos demonstraram que a modificação através da reação de oxipropilação com razão molar $[\mathrm{OP}] / \mathrm{OH}]$ igual a 3 mostrou-se mais eficaz tanto para os diferentes substratos de celulose quanto para o amido. 


\section{VIII - REFERÊNCIAS BIBLIOGRÁFICAS}

AGNELLI, J. A. M. Introdução aos materiais poliméricos. São Carlos: Universidade Federal de São Carlos, 1994. 189 p. (Apostila de Engenharia de Materiais)

ASPINALL, G. O. The polysaccharides. London: Academic Press, 1988. 215 p.

ATHAWALE, V. D.; LELE, V. Synthese and characterization of graft copolymers of maize starch and methacrylonitrile. Cabohydrate Polymers, v. 41, n. 4, p. 407-416, 2000.

AZIZ, A.; DAIK, R.; GHANI, M. A.; DAUD, N. I. N.; YAMIN, B M. Hidroxypropylation and acetylation of sago starch. Malaysian Journal of Chemistry, v. 6, n. 1, p. 48-54, 2004.

BAGLEY, E. B.; FANTA, G. R.; BURR, R. C.; DOANE, W. R.; RUSSEI, C. R. Graft compolymersof polysaccharides with thermoplastic polymers: new type of filled plastic. Polymer Engineer Science, v. 17, n. 5, p. 311-316, 1977.

BOTARO, V. R. E.; GANDINI, A. Chemical modification of the surface of cellulosic fibres: 2. Introduction of alkenyl moieties via condensation reactions involving isocyanate functions. Cellulose, v. 5, n. 2, p. 65-78, 1998.

CANEVAROLO JUNIOR, S. V. Ciencia dos polímeros. São Paulo: Artliber, 2002. $183 \mathrm{p}$.

D’ALMEIDA, M. L. O. Celulose e papel: tecnologia de fabricação da pasta celulósica. São Paulo: IPT, 1988. 559 p.

DA ROZ, A. L.; CURVELO, A. A. S. Thermal characterization of benzylcellulose derivatives prepared from bleached pinus kraft pulp. Thermal Analysis and Calorimetry, v. 75, n. 2, p. 429-436, 2004.

DE OLIVEIRA, W.; GLASSER, W. G. Engineering plastics from Lignin: starlike macromers with propylene-oxide. Journal of Applied Polymer Science, v. 37, n. 11, p. 3119-3135, 1989. 
EICHHORN, S. J.; BAILLIE, C. A.; ZAFEIROPOULOS, N.; MWAIKAMBO, L. Y.; ANSELL, M. P.; DUFRESNE, A.; ENTWISTLE, K. M.; HERRERA-FRANCO, P. J.; ESCAMILLA, G. C.; GROON, L.; HUGHES, M.; HILL, C.; RIALS, T. G.; WILD, P. M. Review: current international research into cellulosic fibres and composites. Journal of Materials Science, v. 36, n. 9, p. 2107-2131, 2001.

ESAU, K. Anatomia de plantas com sementes. São Paulo: Edgard Blucher, 1974. $293 \mathrm{p.}$

EVTIOUGUINA, M.; BARROS, A. M.; CRUZ-PINTO, J. J.; PASCOAL NETO, C.; BELGACEM, N. M.; PAVIER, C.; GANDINI, A. The oxypropylation of cork residues: preliminary results. Bioresource Technology, v. 73, n. 2, p. 187-189, 2000.

EVTIOUGUINA, M.; GANDINI, A.; PASCOAL NETO, C.; BELGACEM, N. M. Urethanes and polyurethanes based on oxypropylated cork: 1. Appraisal and reactivity of products. Polymer International, v. 50, n. 10, p. 1150-1155, 2001.

EVTIOUGUINA, M.; BARROS-TIMMONS, A.; CRUZ-PINTO, J. J.; PASCOAL NETO, C.; BELGACEM, M. N.; GANDINI, A. Oxypropylation of cork and the use of the ensuing polyols in polyurethane formulations. Biomacromolecules, v. 3, n. 1, p. 57$62,2002$.

FABRI, P.; CHAMPON, G.; CASTELLANO, M.; BELGACEM, M. N.; GANDINI, A. Reactions of cellulose and wood superficial hydroxy groups with organometallic.

Polymer International, v. 53, n. 1, p. 7-11, 2004.

FELIX, J. M.; GATENHOLM, P. The nature of adhesion in composites of modified cellulose fibers and polypropylene. Journal of Applied Polymer Science, v. 42, n. 3, p. 609-620, 1991.

FENGEL, D.; WEGENER, G. Wood: chemistry, ultrastructure and reactions. Berlin: Walter de Gruyter, 1984, $613 \mathrm{p}$.

FERREIRA, F. C.; CURVELO, A. A. S.; MATTOSO, L. H. C. Preparation and caracterization of benzylated sisal fibers. Journal of Applied Polymer Science, v. 89, n. 11 , p. 2957-2965, 2003.

GANDINI, A.; BELGACEM, N. M. Recent advances in the elaboration of polymeric materials derived from biomass components. Polymer International, v. 47, n. 3, p. 267-276, 1998. 
GANDINI, A.; BELGACEM, N. M.; ZHAO-XIA, G.; MONTANARI, S. Lignins as macromonomers for polyesters and polyurethanes. In: HU, T. Q. Chemical modification, properties and usage of lignin, New York: Kluwer Academic Plenum, 2002 , p. 57.

GANDINI, A.; BOTARO, V.; ZENO, E.; BACH, S. Activation of solid polymer surfaces with bifunctional reagents. Polymer International, v. 50, n. 1, p. 7-9, 2001.

GANDINI, A.; BELGACEM, M. N. Polymers from the vegetal biomass. In: CONCISE polymeric materials encyclopedia. New York: CRC Press, 1998, p. 1601.

GANDINI, A.; BELGACEM, M. N. Recent contributions to the preparation of polymers derived from renewable resources. Journal of Polymers and the Environment, v. 10, n. 3, p. 105-114, 2002.

GINDL, W.; KECKES, J. All-cellulose nanocomposite. Polymer, v. 46, n. 23, p. 10221-10225, 2005.

GLASSER, W. G.; TAIB, R.; JAIN, R. K.; KANDER, R. Fiber-reinforced cellulose thermoplastic composites. Journal of Applied Polymer Science, v. 73, n. 7, p. 1329-1340, 1999.

GRAY, J. A.; BEMILLER, J. N. Influence of reaction conditions on the location of reactions in waxy maize starch granules reacted with a propylene oxide analog at low substitution levels. Carbohydrate Polymers, v. 60, n. 2, p.147-162, 2005.

GUINESI, L. S.; DA RÓZ, A. L.; CORRADINI, L.; MATTOSO, L. H. C.; TEIXEIRA, E. M.; CURVELO, A. A. S. Kinetics of thermal degradation applied to starchs from different botanical origins by non-isothermal procedures. Thermochimica Acta, v. 447, n. 2, p. 190-196, 2006.

HAN, J. H.; BEMILLER, J. N. Rate of hydroxypropylation of starches as a function of reaction time. Starch-Starke, v. 57, n. 9, p. 395-404, 2005.

HAN, J. H.; BEMILLER, J. N. Influence of reaction conditions on MS values and physical properties of waxy maize starch derivatized by reaction with propylene oxide. Carbohydrate Polymers, v. 64, n. 2, p. 158-162, 2006. 
HATAKEYAMA, T.; QUINN, F.X. Thermal analysis: fundamentals and applications to polymer science. New York: Wiley, 1994, 158 p.

HERMANS, P. H.; WEINDINGER, A. Quantitative X-ray investigations on the crystallinity of cellulose fibers: a background analysis. Journal of Applied Physics, v. 19 , p. $491-506,1948$.

HERMANS, P. H.; WEINDINGER, A. X-ray studies on the crystallinity of cellulose. Journal of Polymer Science, v. 4, p. 135-144, 1949.

HERMANS, P. H.; WEINDINGER, A. Crystallinity of cellulose after treatment with sodium hydroxide. Journal of Polymer Science, v. 6, n. 5, p. 533-538, 1951.

HOFMANN, K.; GLASSER, W. G. Engineering Plastics from Lignin: synthesis and properties of epoxidized lignin-poly (propylene oxide) copolymers. Journal of Wood Chemistry and Technology, v. 13, n. 1, p. 73-95, 1993.

HULLEMAN, S. H. D.; KABISVAART, M. G.; JABSSEN, F. H. P.; FEIL, H.; VLIEGENTHART, J. F.G. Origins of B-type crystallinity in glycerol-plasticized, compression-moulded potato starches. Carbohydrate Polymers, v. 39, n. 4, p. 351360, 1999.

JAIN, R. K.; GLASSER, W. G. Lignin Derivatives. 2. Functional Ethers.

Holzforschung, v. 47, n. 4, p. 325-332, 1993.

JAIN, R. K.; SJOSTEDT, M.; GLASSER, W. G. Thermoplastic xylan derivatives with propylene oxide. Celulose, v. 7, n. 4, p. 319-336, 2001.

JANDURA, P.; KOKTA, B. V.; RIEDL, B. Cellulose fibers/polyethylene hybrid composites: effect of long chain organic acid cellulose esters and organic peroxide on rheology na tensile properties. Journal of Reinforced Plastics and Composites, v. 20, n. 8, p. 697-717, 2001.

JI, Y.; AO, Z.; HAN, J. A.; JANE, J. L.; BEMILLER, J. N. Waxy maize starch subpopulations with different gelatinization temperatures. Carbohydrate Polymers, v. 57, n. 2, p. 177-190, 2004. 
KAVITHA, R.; BEMILLER, J. N. Characterization of hydroxypropylated potato starch. Carbohydrate Polymers, v. 37, n. 2, p. 115-121, 1998.

LEE, D. S.; PERLIN, A. S. C-13-NMR-Spectral and related studies on the distribution of substituents in O-(2-Hydroxypropyl) Cellulose. Carbohydrate Research, v.106, n. 1, p. 1-19, 1982.

LOPES, L. S.; MACHADO, G. O.; PAWLICKA, A.; DONOSO, J. P. Nuclear magnetic resonance and conductivity study of hydroxyethylcellulose based polymer gel electrolytes. Electrochimica Acta, v. 50, n. 19, p. 3978-3984, 2005.

LU, X.; ZHANG, M. Q.; RONG, M. Z.; SHI, Z.; YANG, G. C. Self-reinforced melt processable composites of sisal. Composite Science and Technology, v. 63, n. 2, p. 177-186, 2003.

LU, X.; ZHANG, M. Q.; RONG, M. Z.; YUE, D. L.; YANG, G. C. Environmental degradability of self-reinforced composites made from sisal. Composite Science and Technology, v. 64, n. 9, p. 1301-1310, 2004.

MACHADO, G. O.; PAWLICKA, A.; YONASHIRO, M. Solid polymeric electrolytes networks of hydroxypropyl cellulose with jeffamine. Nonlinear Optics, Quantum Optics, v. 32, p. 141-148, 2004.

MACHADO, G. O.; FERREIRA, H. C. A.; PAWLICKA, A. Influence of plasticizer contents on the properties of HEC-based solid polymeric electrolytes.

Electrochimica Acta, v. 50, n. 19, p. 3827-3831, 2005.

MANI, R.; TANG, M. B. Synthesis and characterization of starch-graftpolycaprolactones as compatiblizer of starch/polycaprolactone blends.

Macromolecular Rapid Communications, v. 19, n. 6, p. 283-286, 1998.

MATSUMURA, H.; SUGIYAMA, J.; GLASSER, W. G. Cellulosic nanocomposites : I. Thermally deformable cellulose hexanoates from heterogeneous reaction. Journal of Applied Polymer Science, v. 78, n. 13, p. 2242-2253, 2000.

MATSUMURA, H.; GLASSER, W. G. Cellulosic nanocomposites. II. Studies by atomic force microscopy . Journal of Applied Polymer Science, v. 78, n. 13, p. 2254-2261, 2000. 
MOHANTY, A. K.; MISRA, M.; HINRICHSEN, G. Biofibres, biodegradable polymers and biocomposites: an overview. Macromolecular Materials and Engineering, $v$. 276, n. 3-4, p. 1-24, 2000.

MORRISON, R.; BOYD, R. Química Orgânica. Lisboa: Fundação Calouste Gulbenkian, 1996. 1510 p.

NISHINO, T.; MATSUDA, I.; HIRAO K. All-cellulose composite. Macromolecules, v. 37, n. 20, p. 7683-7687, 2004.

OWENS, D. K.; WENDT, R. C. Estimation of the surface free energy of polymers. Journal of Applied Polymer Science, v. 13, n. 8, p. 1741-1747, 1969.

PATIL, D. R.; FANTA, G. R. Synthesis and processing of graft-compolymers forn corn starch and methyl acrylate - physical and mechanical - properties. Starch-Stark, v. 46, n. 4, p. 142-146, 1994.

PAVIER, C,; GANDINI, A. Oxypropylation of sugar beet pulp. 1. Optimisation of the reaction. Industrial Crops And Products, v. 12, n. 1, p. 1-8, 2000.

PAVIER, C.; GANDINI, A. Oxypropylation of sugar beet pulp. 2. Separation of the grafted pulp from the propylene oxide homopolymer. Carbohydrate Polymers, v. 42, n. 1, p. 13-17, 2000.

PAVIER, C,; GANDINI, A. Urethanes and polyurethanes from oxypropylated sugar beet pulp - I. Kinetic study in solution. European Polymer Journal, v. 36, n. 8, p. 1653-1658, 2000.

PAVIER, Claire. Oxypropylation de la pulpe de betterave à sucre et utilisation des polyols obtenus pour la préparation de nouveaux matériaux polyuréthenes. 1998. 291 f. Tese (Doutorado em Ciências e Engenharia de Materiais) - Ecole Française de Papeterie et des Industries Graphiques, Institut National Polytechnique de Grenoble, Grenoble, 1998.

ST PIERRE, L. E.; PRICE, C. C. The room temperature polymerization of propylene oxide. Journal of the Americam Chemical Society, v. 78, n. 14, p. 3432-3436, 1956. 
SAO, K. P.; SAMANTARAY, B. K.; BHATTACHERJEE, S. X-Ray study of crystallinity and disorder in Ramie fiber. Journal of Applied Polymer Science, v. 52, n. 12, p. 1687-1694, 1994.

SCHOENENBERGER, C.; LE NEST, J. F.; GANDINI, A. Polymer electrolytes based on based modified polysaccharides. 2. Polyether-modified cellulosics.

Electrochimica Acta, v. 40, n. 13-14, p. 2281-2284, 1995.

SEAVEY, K. C.; GHOSH, I.; DAVIS, R. M.; GLASSER, W. G. Continuous cellulose fiber-reinforced cellulose ester composites. I. Manufacturing options. Cellulose, v. 8, n. 2, p. 149-159, 2001.

SEAVEY, K. C.; GLASSER, W. G. Continuous cellulose fiber-reinforced cellulose ester composites. II. Fiber surface modification and consolidations. Cellulose, v. 8, n. 2, p. 161-169, 2001.

SEOW, C. C.; THEVAMALAR, K. Internal plasticization of granular rice starch by hydroxypropylation: effects on phase-transitions associated with gelatinization.

Starch-Starke, v. 45, n. 3, p. 85-88, 1993.

SHI, X.; BEMILLER, J. N. Effect of sulfate and citrate salts on derivatization of amylose and amylopectin during hydroxypropylation of corn starch. Carbohydrate Polymers, v. 43, n. 4, p. 333-336, 2000.

SHI, X.; BEMILLER, J. N. Aqueous leaching of derivatized amylose from hydroxypropylated common corn starch granules. Starch-Starke, v. 54, n. 1, p. 1619, 2002.

SMOLE, M. S.; PERSIN, Z.; KREZE, T.; KLEINSCHEK, K. S.; RIBITSCH, V.; NEUMAYER, S. X-Ray study of pre-treated regenerated cellulose fibres. Materials Research Innovations, v. 7, n. 5, p. 275-282, 2003.

SOLOMONS, T. W.; CRAIG, B. F. Organic chemistry. New York: John Wiley, 2000. $1258 \mathrm{p}$.

SPERLING, L. H. Introduction to physical polymer science. New York: John Wiley, 1992. 594 p. 
STAPLEV, J. A.; BEMILLER, J. N. Hydroxypropylated starch: granule subpopulation reactivity. Cereal Chemistry, v. 80, n. 5, p. 550-552, 2003.

STEINER, E. C.; PELLETIER, R. R.; TRUCKS, R. O. A study of the polymerization of propylene oxide catalyzed by anhydrous potassium hydroxide. Journal of the Americam Chemical Society, v. 86, n. 21, p. 4678-4686, 1964.

TASKER, S.; BADYAL, J. P. S.; BACKSON, S. C. E.; RICHARDS, R. W. Hydroxil accessibility in celluloses. Polymer, v. 35, n. 22, p. 4717-4721, 1994.

THYGENSEN, A.; ODDERSHEDE, J.; LILHOLT, H.; THOMSEN, B. A.; STAHL, K. On the determination of crystallinity and cellulose content in plant fibres. Cellulose, v. 12, n. 6, p. 563-576, 2005.

TREJO-O'REILLY, J. A.; CAVAILLE, J. Y.; BELGACEM, N. M.; GANDINI, A. Surface energy and wettability of modified cellulosic fibres for use in composite materials.

Journal of Adhesion, v. 67, n. 1-4, p. 359-374, 1998.

VALADEZ-GONZALEZ, A.; CERVANTES-UC, J. M.; OLAYO, R.; HERRERAFRANCO, P. J. Effect of fiber surface treatment on the fiber-matrix bond strength of natural fiber reinforced composites. Composites Part B: Engineering, v. 30, n. 3, p. 309-321, 1999.

VAN HUNG, P.; MORITA, N. Physicochemical properties of hydroxypropylated and cross-linked starches from A-type and B-type wheat starch granules. Carbohydrate Polymers, v. 59, n. 2, p. 239-246, 2005.

VAN SOEST, J. J. G.; VLIEGENTHART, F. G. J. Crystallinity in starch plastics: consequences for material properties. Trends in Biotechnology, v. 15, p. 208-213, 1997.

VELÁSQUEZ-MORALES, P.; LE NEST, J. F.; GANDINI, A. Polymer electrolytes derived fromchitosan/polyether networks. Electrochimica Acta, v. 43, n. 10-11, p. 1275-1279, 1998.

VILLWOCK, V. K.; BEMILLER, J. N. Effects of salts on the reaction of normal corn starch with propylene oxide. Starch-Starke, v. 57, n. 7, p. 281-290, 2005. 
YADAV, M. P.; BEMILLER, J. N.; WU, Y. S. O-(hydroxypropyl) sucrose. Journal of Carbohydrate Chemistry, v. 13, n. 7, p. 991-1001, 1994.

WU, L. C. F.; GLASSER, W. G. Engineering plastics from lignin: synthesis of hydroxypropyl lignin. Journal of Applied Polymer Science, v. 29, n. 4, p. 11111123, 1984. 